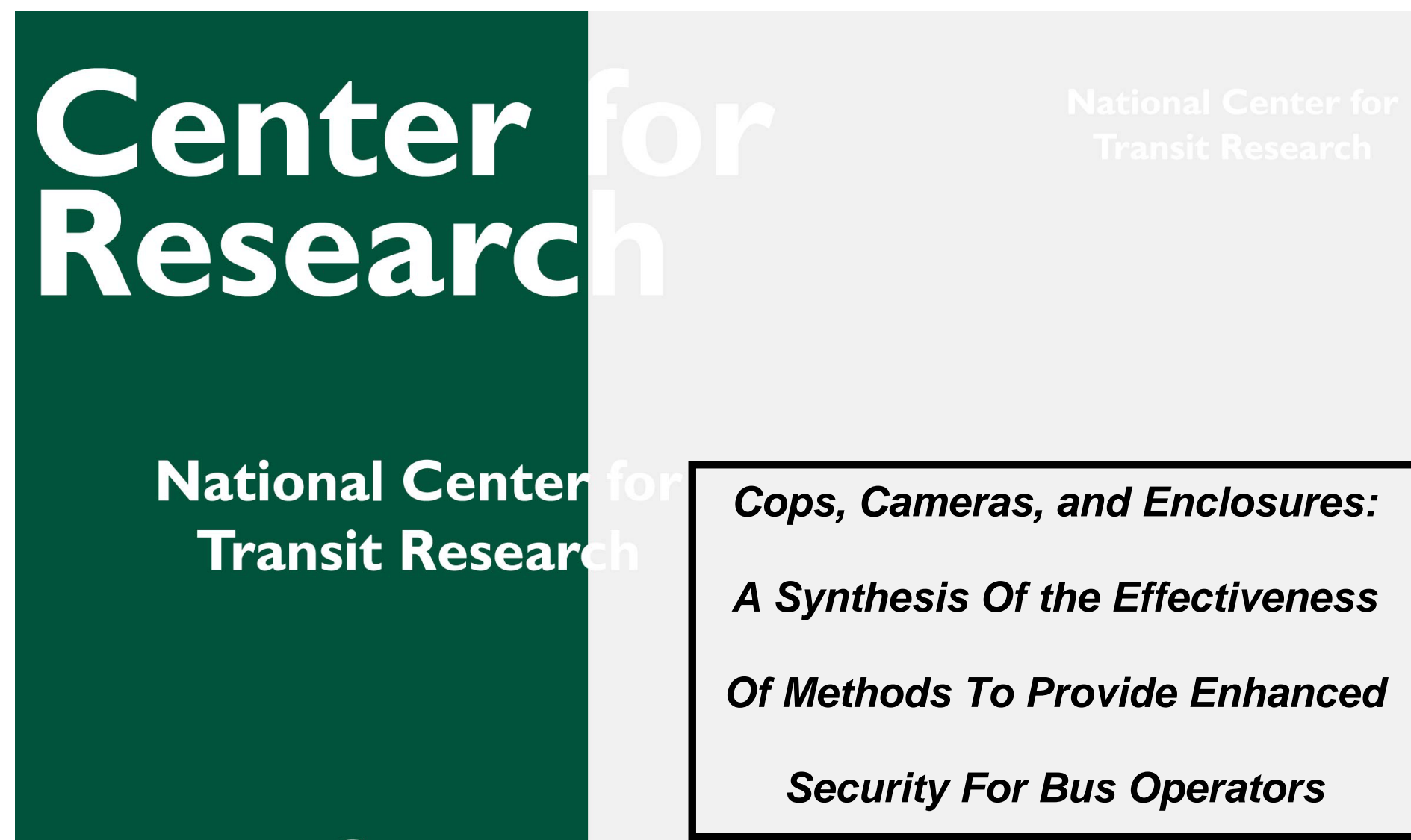

nter for search

National Center for Transit Research

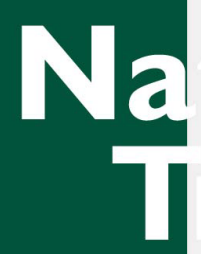

National Center for Transit Research Center for Urban Transportation Research University of South Florida

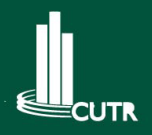




\title{
Cops, Cameras, and Enclosures: \\ A Synthesis Of the Effectiveness Of Methods \\ To Provide Enhanced Security For Bus Operators
}

\author{
Principal Investigators: \\ Darin Allan \\ Joel Volinski
}
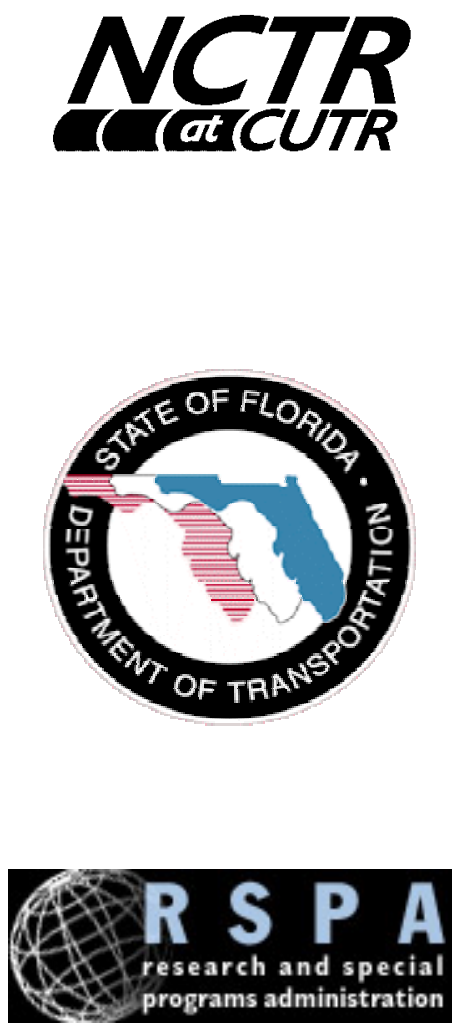

\author{
National Center for Transit Research \\ Center for Urban Transportation Research \\ College of Engineering / CUT 100 \\ University of South Florida \\ 4202 E Fowler Ave \\ Tampa, FL 33620-5375 \\ Tel (813) 974-3120 \\ http://www.nctr.usf.edu/ \\ Project Manager: \\ James Mike Johnson \\ Florida Department of Transportation \\ 605 Suwannee St \\ Tallahassee, FL 32399-0450 \\ Tel (904) 488-7774 \\ http://www.dot.state.fl.us/
}

\author{
Research \& Special Programs Administration \\ US Department of Transportation \\ RSPA/DIR-1, Room 8417 \\ $4007^{\text {th }}$ St SW \\ Washington, DC 20590 \\ http://www.rspa.dot.gov/
}

This document is disseminated under the sponsorship of the U.S. Department of Transportation, University Transportation Centers Program, in the interest of information exchange.

The opinions, findings and conclusions expressed in this publication are those of the authors and not necessarily those of the Florida Department of Transportation or the U.S. Department of Transportation. 


\begin{tabular}{|c|c|c|c|}
\hline $\begin{array}{l}\text { 1. Report No. } \\
392-12\end{array}$ & 2. Government Accession No. & \multicolumn{2}{|c|}{ 3. Recipient's Catalog No. } \\
\hline \multirow{2}{*}{\multicolumn{2}{|c|}{$\begin{array}{l}\text { 4. Title and Subtitle } \\
\text { Cops, Cameras, and Enclosures: A Synthesis Of the Effectiveness Of Methods To Provide } \\
\text { Enhanced Security For Bus Operators }\end{array}$}} & \multicolumn{2}{|c|}{$\begin{array}{l}\text { 5. Report Date } \\
31 \text { May } 2001\end{array}$} \\
\hline & & \multicolumn{2}{|c|}{ 6. Performing Organization Code } \\
\hline \multicolumn{2}{|l|}{$\begin{array}{l}\text { 7. Author(s) } \\
\text { Darin Allan \& Joel Volinski }\end{array}$} & \multicolumn{2}{|c|}{ 8. Performing Organization Report No. } \\
\hline \multirow{2}{*}{\multicolumn{2}{|c|}{$\begin{array}{l}\text { 9. Performing Organization Name and Address } \\
\text { National Center for Transit Research } \\
\text { Center for Urban Transportation Research } \\
\text { College of Engineering / CUT } 100 \\
\text { University of South Florida } \\
\text { 4202 E Fowler Ave } \\
\text { Tampa, FL 33620-5375 }\end{array}$}} & \multicolumn{2}{|l|}{ 10. Work Unit No. } \\
\hline & & \multicolumn{2}{|c|}{$\begin{array}{l}\text { 11. Contract or Grant No. } \\
\text { DTRS98-G-0032 }\end{array}$} \\
\hline \multirow{2}{*}{\multicolumn{2}{|c|}{$\begin{array}{l}\text { 12. Sponsoring Agency Name and Address } \\
\text { Research \& Special Programs Administration } \\
\text { US Department of Transportation } \\
\text { RSPA/DIR-1, Room } 8417 \\
4007^{\text {th }} \text { St SW } \\
\text { Washington, DC } 20590\end{array}$}} & \multicolumn{2}{|c|}{ 13. Type of Report and Period Covered } \\
\hline & & \multicolumn{2}{|c|}{ 14. Sponsoring Agency Code } \\
\hline \multicolumn{4}{|c|}{$\begin{array}{l}\text { 15. Supplementary Notes } \\
\text { Supported by a grant from the Florida Department of Transportation and the U.S. Department of Transportation. }\end{array}$} \\
\hline \multicolumn{4}{|c|}{$\begin{array}{l}\text { 16. Abstract } \\
\text { The safety of operators and passengers is a primary concern of transit systems and has become an increasingly important issue to } \\
\text { transit bus operators themselves. Many transit agencies have experienced incidents of assaults against their bus operators that have } \\
\text { resulted in serious injuries or deaths. These incidents can also expose passengers to assault and injury. Even when there are less } \\
\text { serious consequences, assaults on operators can lower their morale, increase absenteeism, and strain labor-management relations } \\
\text { over whether or not the agencies are doing enough to protect their employees. } \\
\text { There is also substantial cost to transit agencies in terms of lost availability of operators who rightfully go on workers' } \\
\text { compensation status. A number of transit agencies use different techniques to minimize the possibilities of assaults against their } \\
\text { bus operators and passengers. Many use either uniformed or plainclothes police officers or security guards on particularly } \\
\text { troubling routes. Digital cameras strategically placed inside buses are also being used to help discourage criminal assaults as well } \\
\text { as other unwanted behavior such as graffiti and unwarranted claims of injuries from passengers (or alleged passengers). Perhaps } \\
\text { the most visible effort to discourage assaults on operators is the provision of bus operator enclosures that separate the operators } \\
\text { from anyone else on the bus and protect them from attacks. However, while this method can provide enhanced protection to bus } \\
\text { operators, it might negatively affect passenger relations and increase the image of a bus as a place where crime might be } \\
\text { committed. }\end{array}$} \\
\hline \multicolumn{4}{|c|}{$\begin{array}{l}\text { This project surveyed transit agencies that have employed these techniques to determine their level of success, cost effectiveness, } \\
\text { and acceptance by both bus operators and passengers. The project also identifies other techniques transit systems are using to } \\
\text { increase the chances of their bus operators avoiding dangerous situations, such as passenger relations training to avoid conflict. } \\
\text { The effect "full wrap advertising" has on onboard activity and safety of passengers is also explored. This project is presented in } \\
\text { synthesis form. }\end{array}$} \\
\hline $\begin{array}{l}\text { 17. Key Words } \\
\text { Transit, security, bus operator, assault, } \\
\text { crime, police, video, surveillance, } \\
\text { enclosure, CAD/AVL, training, law. }\end{array}$ & $\begin{array}{l}\text { 18. Distribution Statement } \\
\text { This document is available to the public throug } \\
\text { Service (NTIS), http://www.ntis.gov/. } \\
\text { An electronic version in the .pdf file format is } \\
\text { NCTR web site at http://www.nctr.usf.edu/. }\end{array}$ & the National & $\begin{array}{l}\text { hnical Information } \\
\text { e public via the }\end{array}$ \\
\hline $\begin{array}{l}\text { 19. Security Classif. (of this report) } \\
\text { Unclassified }\end{array}$ & $\begin{array}{l}\text { 20. Security Classif. (of this page) } \\
\text { Unclassified }\end{array}$ & $\begin{array}{l}\text { 21. No. of pages } \\
83\end{array}$ & 22. Price \\
\hline
\end{tabular}

Form DOT F 1700.7 (8-69) 


\section{ACKNOWLEDGMENTS}

Special thanks goes to those who provided exceptional assistance towards the production of this report, including...

Broward County Transit: William Sorrells, Manager of Safety \& Training.

Denver RTD: Keith Hopkins, Security Systems Administrator.

Detroit DOT: Jerry Jones, Chief of Security.

Miami-Dade Transit: Derrick Gordon, Chief of Northeast Bus Operations; Aaron Lee, Union Shop Steward; and the Bus Operators of the Northeast Division, including Edward Vargas and Vonna Richardson.

Phoenix Transit System: Dave Martin, Chief of Transit Public Safety.

San Francisco Muni: Paul Peterson, Superintendent of Training and Lt. Michael Slade, San Francisco Police Department.

Washington Metro: Lt. Timothy Mallory, Metrobus Enforcement Commander.

Kalatel: Rick Gougeon, MobilView Manager.

North American Bus Industries: Rich Himes, Sales.

Orbital Transportation Management Systems: Franny Yuhas and Marisa Greshko, Sales.

Center for Urban Transportation Research: Francis Cleland, Senior Research Associate; Jennifer Perone, Graduate Student Research Assistant in Psychology; Jose Fernandez, Graduate Student Research Assistant in Economics; and Anthony Chaumont, Student Research Assistant in Mechanical Engineering.

\section{Peer Review Committee Members}

- Derrick Gordon, Chief of Northeast Bus Operations, Miami-Dade Transit.

- William Schneeman, Director of Operations, Central Florida Regional Transportation Authority ("Lynx").

- James Mike Johnson, Administrator of Transit Operations, Florida Department of Transportation.

- Dennis Hinebaugh, Transit Program Director, Center for Urban Transportation Research. 


\section{FOREWORD}

The safety of passengers and employees is a primary concern of transit systems and has become an increasingly important issue to transit bus drivers themselves, hereafter referred to as "operators." Many transit agencies have experienced incidents of assaults against their bus operators that have resulted in serious injuries or deaths. These incidents can also expose passengers to assault and injury. Even when there are less serious consequences, assaults on operators can lower their morale, increase absenteeism, and strain labor-management relations over whether or not the agencies are doing enough to protect their employees.

There is also substantial cost to transit agencies in terms of lost availability of operators who rightfully go on workers' compensation status. A number of transit agencies use different techniques to minimize the possibilities of assaults against their bus operators and passengers. Many use either uniformed or plainclothes police officers or security guards on particularly troubling routes. Digital video cameras strategically placed inside buses are also being used to help discourage criminal assaults as well as other unwanted behavior such as graffiti and unwarranted claims of injuries from passengers (or alleged passengers). Perhaps the most visible effort to discourage assaults on operators is the provision of enclosures that separate the operators from anyone else on the bus and protect them from attacks. However, while this method can provide enhanced protection to bus operators, it might negatively affect passenger relations and increase the image of a bus as a place where crime might be committed.

This project surveyed transit agencies that have employed these techniques to determine their level of success, cost effectiveness, and acceptance by both bus operators and passengers. The project also identifies other techniques transit systems are using to increase the chances of their bus operators avoiding dangerous situations, such as passenger relations training to avoid conflict. The effect "full wrap" bus exterior advertising has on onboard activity and safety of passengers is also explored. This project is presented in synthesis form. 


\section{SUMMARY}

Data from the National Transit Database reveal that bus operators are relatively secure from violent crime, despite well-publicized exceptional incidents like what happened in Seattle. By far, the most common violent offense against bus operators is aggravated assault. The second most common violent offense against bus operators is robbery. Rape is rare and homicide is virtually unheard of, except for the killing of operator Mark McLaughlin in Seattle in 1998.

Still, no one wishes to become a crime victim, and it only takes a few well-publicized incidents to raise valid concerns of what can be done to improve personal security. Ignoring such concerns in the long run may make it difficult for transit agencies to hire and retain good bus operator employees. Additionally, though incidents may be rare, their impact can be fiscally significant in workers' compensation payouts.

Because of the unique characteristics of bus service provision, the security of bus operators may be seen as less than that of workers in other transit modes, e.g. train operators. These unique characteristics derive primarily from the methods of fare collection that have remained virtually unchanged over decades of transit service. Even with the switch to exact change and the introduction of prepaid fares, many systems still offer transfers. The operator's presence serves to enforce the transit system's fare policy onboard buses. If the transfer receipt does not clearly indicate the necessary information for the receiving bus operator to validate, and/or if the transit system's transfer policies are vague or too complex for customers to understand, disputes between customers and bus operators may result.

Because of the varied responsibilities placed on bus operators, the designs of their workstations on American transit buses logically submit to function. In most cases, the bus operator is nearly fully exposed to bus passengers. A modesty panel behind the operator's seat does minimize distractions from passengers as well as the glare from onboard lighting, but few other barriers provide physical separation and protection for the bus operator.

In general, transit agencies typically employ more than one technique to provide onboard security, "packaging" various methods to get the most bangs for their limited bucks. With few exceptions (e.g. cab enclosures and training) most methods are employed to protect both employees and customers. Furthermore, most methods employed yield additional benefits that address concerns other than, and in addition to, security matters. For example, though Computer Aided Dispatch/Automatic Vehicle Location (CAD/AVL) systems are typically procured for their efficiencies in real-time fleet management, their bus tracking features-integrated with advanced communication systems and video surveillance-provide significant advantages in responding to transit crime. Onboard video surveillance systems provide records of onboard passenger activity including vandalism. The video can be used as powerful evidence in prosecuting property damage crimes. Visible onboard systems, security staff, and interior designs that mitigate crime may facilitate positive marketing efforts to discretionary customers, instilling greater confidence in the security of the transit system.

Security methods may be classified differently for analyses with different purposes. One classification may differentiate technology or automated methods versus manual methods using manpower. Technology methods include communications systems, covert alarms, video surveillance, and CAD/AVL. Manpower methods primarily involve security staff and/or police patrols.

The security methods for transit buses discussed in this report may also be categorized as proactive, reactive, or punitive. Crime prevention (proactive) methods include video surveillance, "code of 
conduct" postings, Crime Prevention Through Environmental Design (CPTED) principles, operator cab enclosures, security staff, police officers, and violence prevention/anger management training. Incident management (reactive) methods include CAD/AVL systems, video/audio surveillance, security staff, police officers, and self defense training. Punishment-based (punitive) methods include state laws and local ordinances to protect public transit employees and customers by providing special punishments and laws that codify greater charges for transit crimes.

According to the results of the survey, the four highest rated methods in terms of effectiveness were in-house security, an enclosure to protect operators in new bus specifications, plainclothes sworn police, and an enclosure to protect bus operators retrofitted into existing buses. The three least expensive rated methods were violence prevention training, a panic button that changes the message of the headsign, and plainclothes security. The three highest effectiveness-to-cost ratios belong to violence prevention training, in-house security, and plainclothes security.

Further analysis shows that sworn police consistently rate high in terms of effectiveness; their cost, however, also rates relatively higher than most other methods. This could support the belief that "you get what you pay for." Furthermore, manpower is almost always more expensive than technology due to annualized salaries and fringe benefits.

Keeping in mind the survey's narrow focus of each method's role in keeping bus operators secure from crime, lower rated methods may actually warrant consideration. For example, CAD/AVL rated a solid "good" in effectiveness, but its cost was also rated "expensive" which resulted in the lowest effectiveness-to-cost ratio among all surveyed methods. However, the benefits of CAD/AVL are primarily concerned with effective fleet management and dispatch, which has a large impact on a transit agency's sensitive operating budget. The security features of CAD/AVL may be viewed as added benefits. Similarly, the benefits of onboard video surveillance are shared among security, risk management, maintenance, and marketing. The survey for this project only asked respondents' perceptions of the methods in addressing security of bus operators.

Interestingly, violence prevention training was rated the technique with the highest effectiveness-to-cost ratio. This may reflect the transit industry's conservative nature in that violence prevention training has been the standard reinforcing response to keeping bus operators safe from crime. Changing times and attitudes are apparent, however, in the application of more aggressive strategies.

The average scores and effectiveness-to-cost ratios for each surveyed method are indicated in the following table. The reader is cautioned, however, not to blindly seize the scores. The limited sample size of the survey-31 transit agencies-may not represent the unique conditions or circumstances of each and every U.S. transit system. They may provide guidance, but should not be used as the sole basis in decision-making.

The full report provides further insights into the advantages and disadvantages of each security technique to protect bus operators. It also includes examples from transit systems that employ the techniques, discovered through research and agency contacts to support this report.

(Table on following page.) 


\section{Bus Operator Security Survey Average Response Ratings}

\begin{tabular}{|c|c|c|c|c|}
\hline \hline \multicolumn{2}{|c|}{ METHODS $\boldsymbol{}$} & $\begin{array}{c}\text { Effectiveness } \\
\text { (1 to 4) }\end{array}$ & Cost (1 to 3) & $\begin{array}{c}\text { Effectiveness : } \\
\text { Cost Ratio }\end{array}$ \\
\hline \multicolumn{2}{|c|}{ 2-Way Radio } & 3.1 & 2.2 & 1.4 \\
\hline \multirow{2}{*}{ Panic Button } & dispatch & 3.0 & 2.3 & 1.3 \\
\cline { 2 - 5 } & headsign & 2.7 & 1.7 & 1.6 \\
\hline CAD / AVL & 3.0 & 3.0 & 1.0 \\
\hline Video Cameras Onboard & 3.2 & 2.5 & 1.3 \\
\hline \multirow{4}{*}{$\begin{array}{c}\text { Security } \\
\text { (Onboard) }\end{array}$} & contracted & 2.7 & 2.3 & 1.2 \\
\cline { 2 - 5 } & in-house & 3.8 & 2.0 & 1.9 \\
\cline { 2 - 5 } & uniformed & 3.0 & 2.1 & 1.4 \\
\cline { 2 - 5 } & plainclothes & 3.0 & 1.7 & 1.8 \\
\hline \multirow{3}{*}{$\begin{array}{c}\text { Sworn Police } \\
\text { (Onboard) }\end{array}$} & contracted & 3.3 & 2.3 & 1.4 \\
\cline { 2 - 5 } & in-house & 3.4 & 2.2 & 1.5 \\
\cline { 2 - 5 } & uniformed & 3.3 & 2.2 & 1.5 \\
\cline { 2 - 5 } & plainclothes & 3.6 & 2.2 & 1.6 \\
\hline \multirow{2}{*}{$\begin{array}{c}\text { Specialized } \\
\text { Operator Training }\end{array}$} & self-defense & 2.8 & 2.0 & 1.4 \\
\cline { 2 - 5 } & prevention & 2.9 & 1.4 & 2.1 \\
\hline $\begin{array}{c}\text { Structure to } \\
\text { Protect Operator }\end{array}$ & retrofit & 3.5 & 2.5 & 1.4 \\
\cline { 2 - 5 } & new specs & 3.7 & 2.5 & 1.5 \\
\hline
\end{tabular}




\section{TABLE OF CONTENTS}

\section{ACKNOWLEDGMENTS}

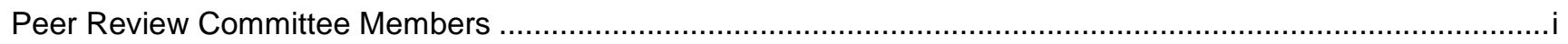

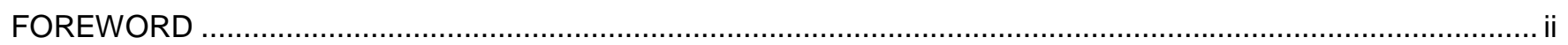

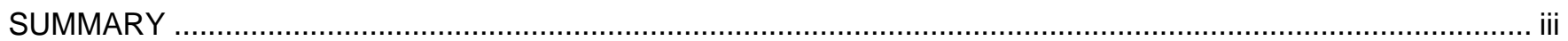

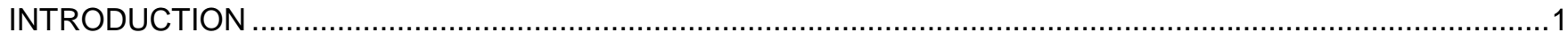

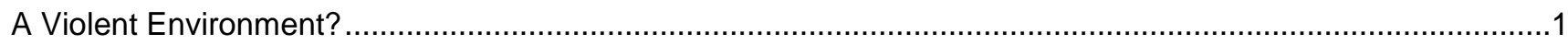

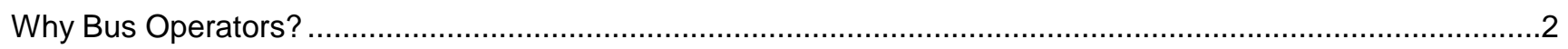

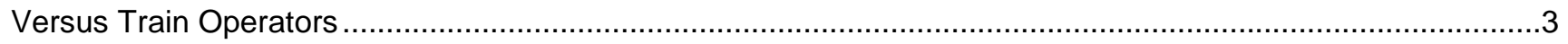

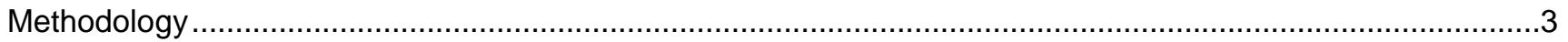

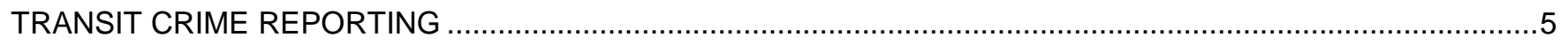

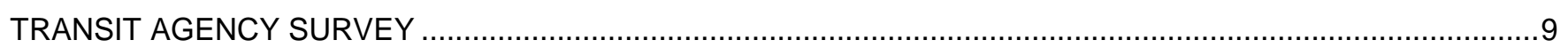

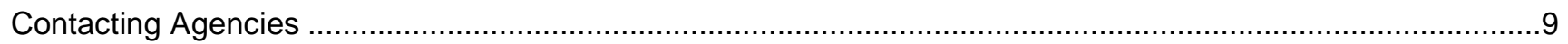

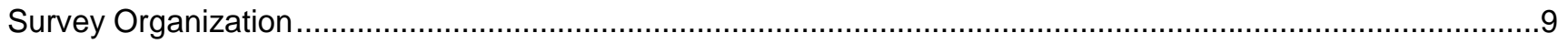

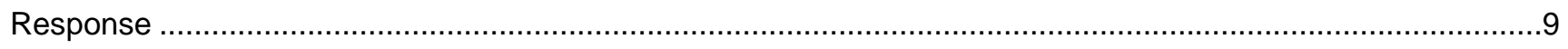

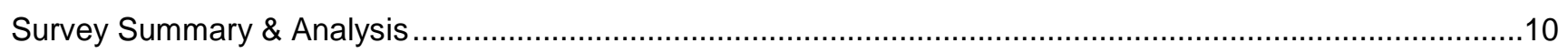

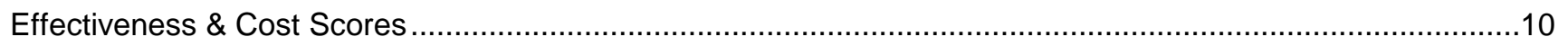

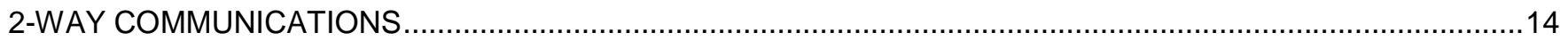

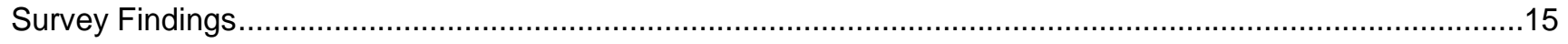

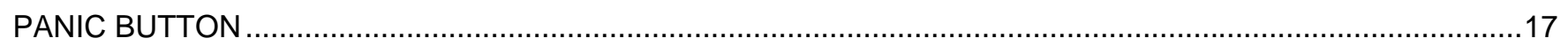

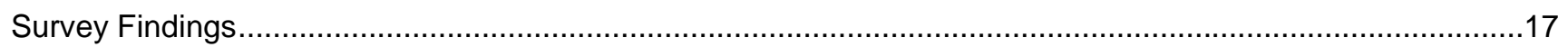

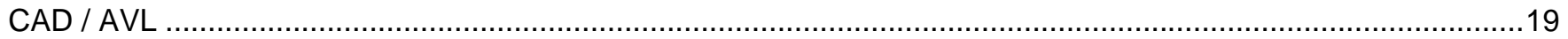

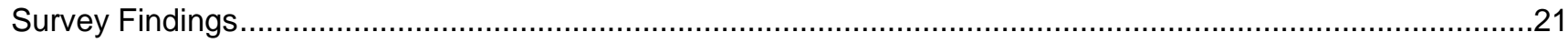

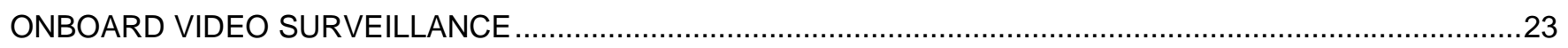

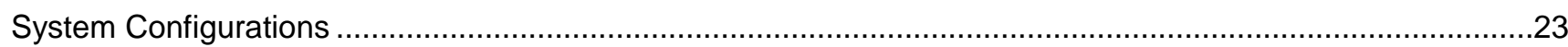

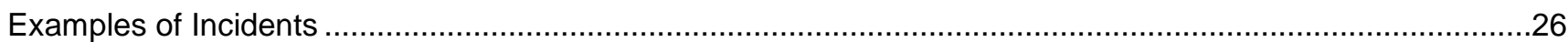

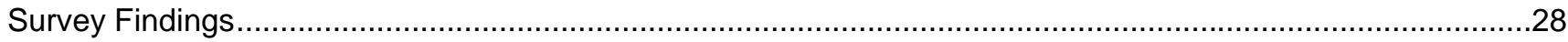

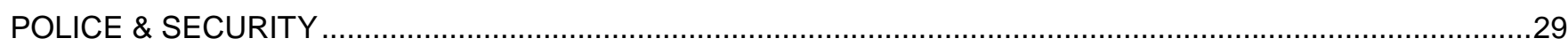

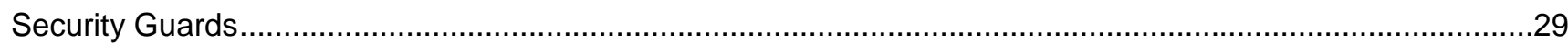

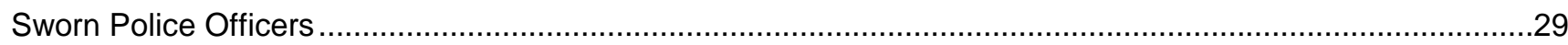

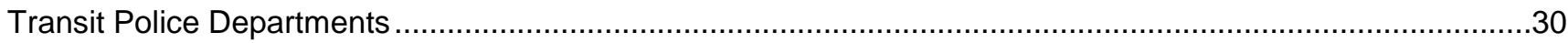

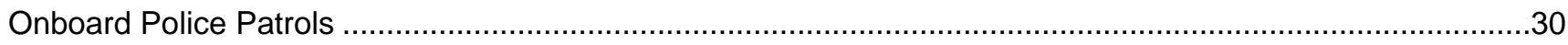

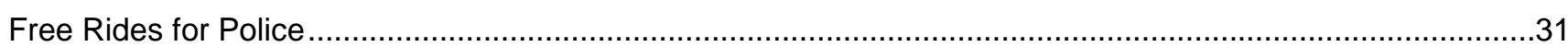

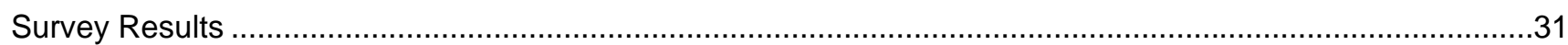

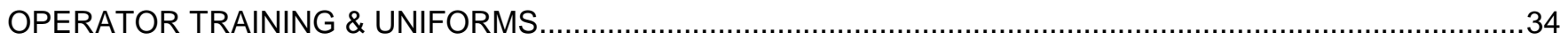

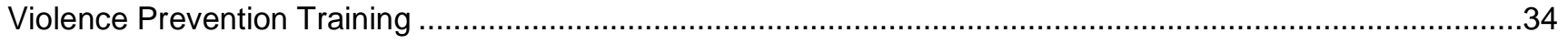

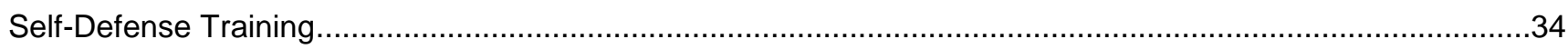

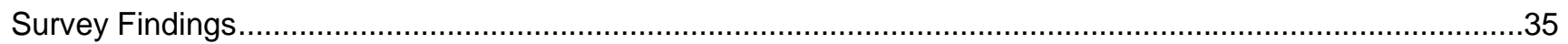

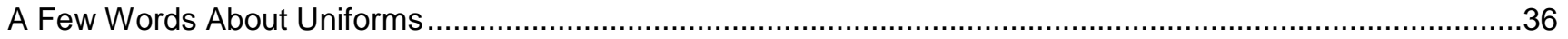


CAB ENCLOSURES.

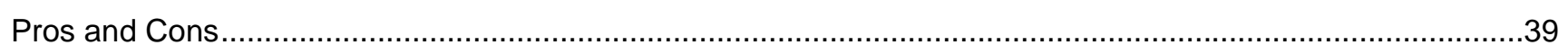

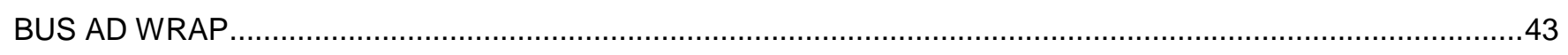

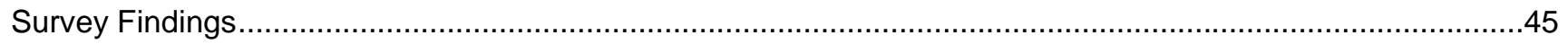

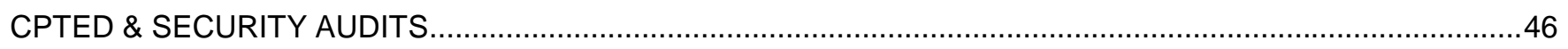

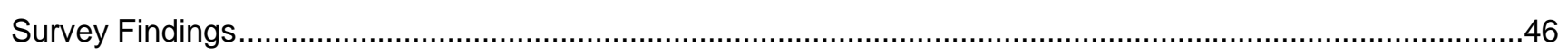

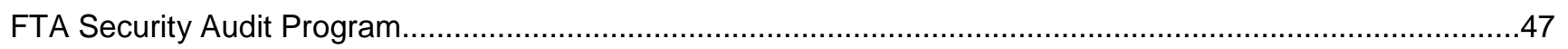

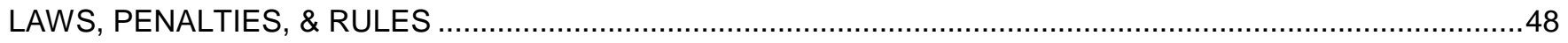

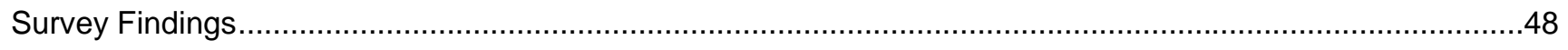

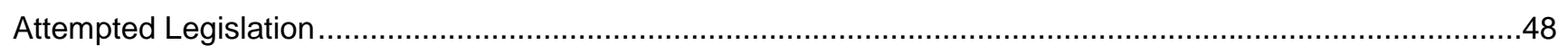

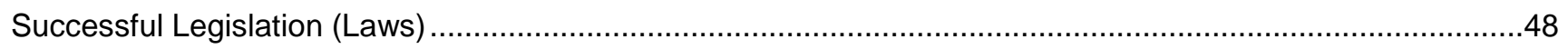

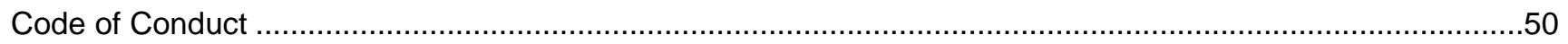

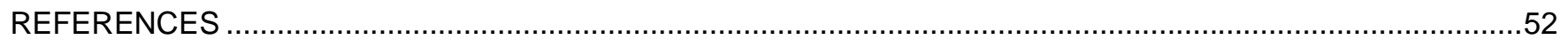

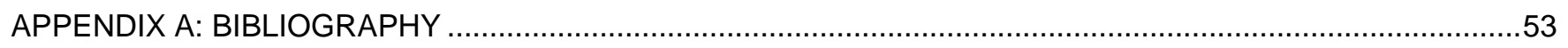

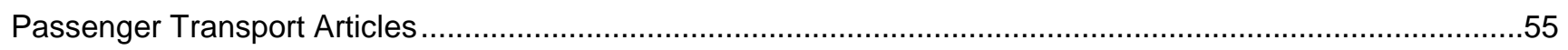

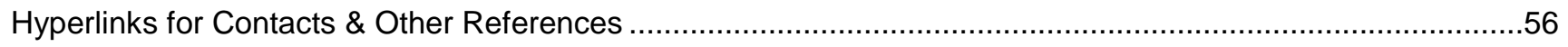

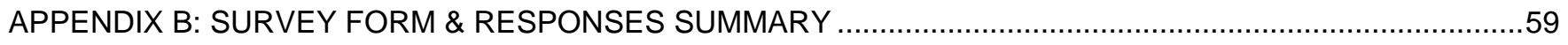

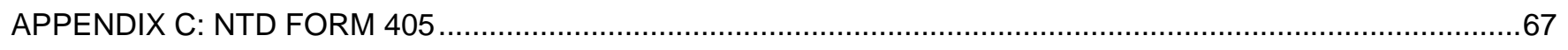

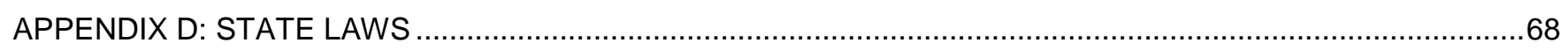

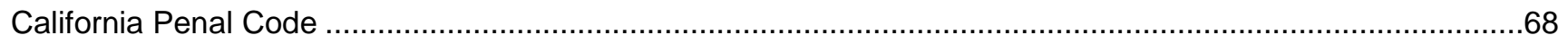

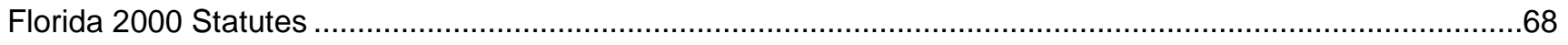

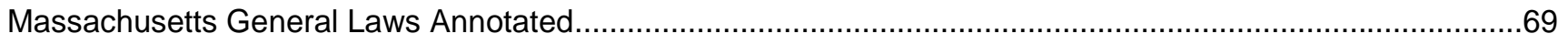

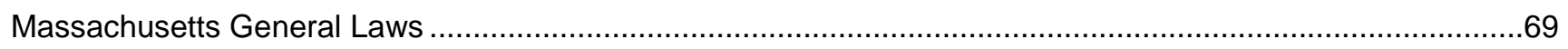

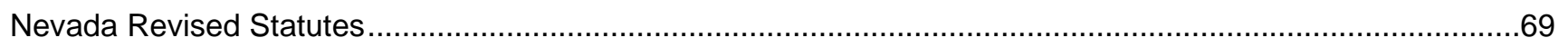

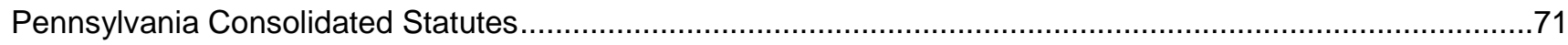

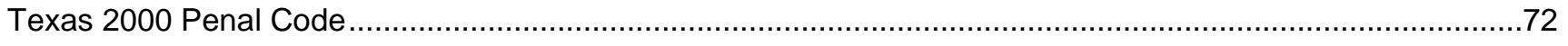

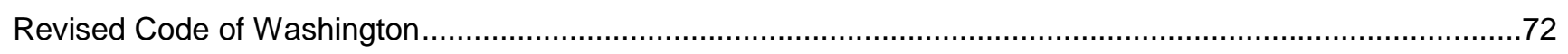

TABLES \& FIGURES

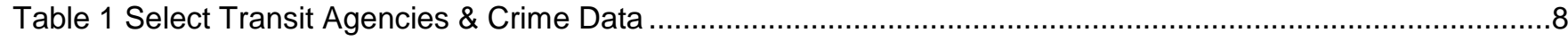

Table 2 Bus Operator Security Survey Average Response Ratings ............................................................12

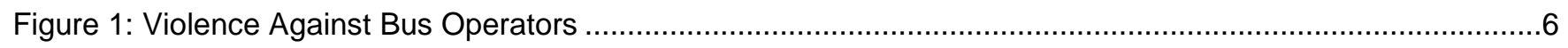

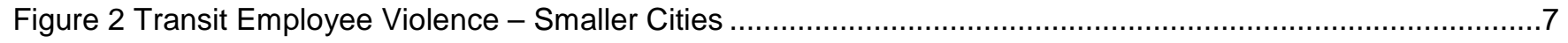

Figure 3 Transit Employee Violence - Larger Cities .................................................................................

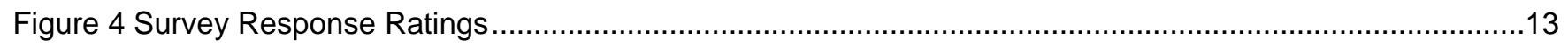




\section{INTRODUCTION}

\section{A Violent Environment?}

In July 1989 an irate passenger was kicked off a public transit bus at Fort Lauderdale's main airport. Seeking revenge, the passenger boarded the next bus in pursuit of the bus operator who expelled him from his bus. When he caught up to the first bus, he shot and killed the operator and another passenger. Then, while hijacking a car for his escape, the killer shot and paralyzed a motorist who also died months later. ${ }^{1}$

On Friday afternoon, 27 November 1998, a southbound Metro bus with about 35 passengers was at the north end of the Aurora Bridge in the Fremont neighborhood, approaching downtown Seattle. Unexpectedly, a passenger sitting in the front section of the 60-foot articulated bus, fired multiple shots at operator Mark McLaughlin, and then shot himself in the head. The bus crashed through a bridge railing and plunged about 50 feet below, hitting the edge of an apartment building, before landing upright on the ground. The driver and killer were dead and a third passenger died from his injuries the next day. Nineteen passengers were hospitalized. There was no apparent motive for the killing, and witnessing passengers confirmed there had been no argument between the driver and killer immediately preceding the shooting. The killer had been unemployed and in and out of a homeless shelter. ${ }^{2}$

In August 2000, a female public transit bus operator in Daytona Beach successfully obtained an injunction against a male passenger that forbade him from riding her bus. The unemployed man had no driver's license and rode buses daily to get around. The bus operator felt harassed by and scared of him after he talked about stalking other women, revealed he knew her home address, and even went to her house once. Other transit employees also reported being harassed by him. The bus operator felt safer in her workplace with the injunction. ${ }^{3}$
Late Wednesday night, 10 January 2001, a young male assaulted a Port Authority " $T$ " (light rail) operator in Pittsburgh. The assailant had attempted robbery, armed with a razor knife. The "T" operator suffered a serious facial cut. The criminal was not caught. ${ }^{4}$

Most recently, on Wednesday, 2 May 2001, a bus was hijacked in Los Angeles following a suspected drug-related shooting in a mostly-vacant apartment building. The incident began with police officers pursuing the suspect when his fleeing victim collapsed outside the police union headquarters. Running from police, the suspect-armed with a semi-automatic handgun-boarded an MTA bus, held his gun to the head of the operator, and ordered her to drive. Witnesses said the suspect locked his arm around the operator's neck as she drove through more than a dozen blocks in downtown Los Angeles. The bus crashed into a minivan, killing the driver, before crashing into other cars parked in a lot. The assailant was apprehended a short distance away while attempting to hijack a car. The bus operator, Ema Gutierrez, suffered a broken nose and collarbone, a potential broken knee, and cuts on her neck and face. Five passengers also sustained injuries. In a city that is home to the American film industry, the sensational incident provoked comparisons to the 1994 action movie, "Speed" in which a transit bus speeds through Los Angeles, its passengers hostage to an onboard bomb. ${ }^{5}$

Is the onboard environment of public transit vehicles increasingly violent? Are bus operators more subject to assaults, robberies, rapes, and homicides than employees in other workplaces? Certainly the events of violent crimes are more often publicized today than in prior times. The shock of the shooting tragedy in Seattle resonated throughout the American transit industry, particularly within the minds of front line operations staff. A recent report by one of this report's coauthors discussed bus operators' concerns for their personal security as one factor in excessive employee absenteeism, 
particularly on routes serving schools or high crime areas. $^{6}$

\section{Why Bus Operators?}

Why does this report focus specifically on the security of bus operators? Because of the unique characteristics of bus service provision, the security of bus operators may be seen as less than that of workers in other transit modes, e.g. train operators. These unique characteristics derive primarily from the methods of fare collection that have remained virtually unchanged over decades of transit service. On a bus, the typical customer pays his fare with cash by himself inserting coins or bills in the farebox located onboard at the front door entrance and next to the operator. In earlier years, the bus operator maintained a coin purse so that change could be made for passengers paying with bills. Today most every bus system requires boarding customers to either have exact change or use prepaid fare media (e.g. tickets, tokens, or passes) for payment. In talking with veteran transit personnel, they are unanimous in their views that the switch to "exact change" fare policies sharply reduced incidents of crime against bus operators. As bus operators no longer carry cash, they are less attractive as targets for robbery and other crimes.

However, even with the switch to exact change and the introduction of prepaid fares, many systems still offer transfers. A transfer is usually a slip of paper, like a receipt, which indicates a customer has already paid the fare on one bus route and allows transfer to another route to complete his trip. Some, but not all, systems impose a transfer fee, less than a full fare charge. The bus operator receiving a customer from another route must visually inspect the transfer receipt to determine its validity. Transfer policies typically require that a customer use the transfer within a specified time limit and only on specified routes.

Thus, the operator's presence serves to enforce the transit system's fare policy onboard buses. If the transfer receipt does not clearly indicate the necessary information for the receiving bus operator to validate, and/or if the transit system's transfer policies are vague or too complex for customers to understand, disputes between customers and bus operators may result. Some transit systems have eliminated the use of transfers, citing the actual costs of customer disputes as well as the negative image resulting from such disputes for the transit agency. Other systems continue this traditional practice that can also provide service planners additional data on how customers use the system.

Bus operators are also expected to provide information to assist customers in making their trips on the transit system. New or infrequent customers may be unfamiliar with routes, schedules, fare policies, streets or other landmarks and usually require help from the bus operator. Providing printed schedules and system maps onboard can help minimize customers' distracting the bus operator from operating the vehicle, but customers prefer to get information more quickly from the operator than they can glean from complex printed timetables.

Finally, the bus operator is also expected to monitor the comfort and security of riding customers. Because most systems provide their bus operators with onboard radios to communicate directly with dispatchers, the bus operator is expected to confer with dispatch whenever an onboard incident requires immediate response from other transit personnel, e.g. faulty air conditioning, a mess needing cleanup, a fight between passengers, or a medical emergency. The operator regularly monitors potential threats from the onboard environment by checking his rearview mirror. Since passenger capacity on standard 40-foot transit buses is significantly less than on multiple car trains, it is viewed as cost effective to utilize a single bus operator, rather than additional onboard staff or technologies, to address customers' needs. 
Because of the varied responsibilities placed on bus operators, the designs of their workstations on American transit buses logically submit to function. In most cases, the bus operator is nearly fully exposed to bus passengers. A modesty panel behind the operator's seat does minimize distractions from passengers as well as the glare from onboard lighting, but few other barriers provide physical separation and protection for the bus operator.

\section{Versus Train Operators}

In contrast, train operators on light rail transit (LRT), heavy rail, and intercity commuter trains typically have little interaction with customers. Customers usually pay their fares prior to boarding the train, either via ticket vending machines or ticket sales personnel at the station. Most heavy rail systems employ turnstiles to permit only those customers who have paid their fares to have access to the train's boarding platform. Some long haul commuter trains still utilize an onboard conductor who passes through the train to collect fares.

Train operators usually sit in an enclosed cab, isolated from the riding customers. If a customer needs to speak with the train operator, he must use an intercom, which is primarily limited for emergencies only. This greatly discourages any potential interaction between riding customers and the train operator. Kiosks displaying information about the transit system, routes, schedules, fare policies, etc., are provided to a greater extent at train stations than at bus stops. Onboard security is typically provided by roving security guards or police officers who randomly board trains during their routine patrols or respond to specific incidents.

Thus, there is necessarily greater interaction with customers for bus operators than for train operators. This situation may change in the future with the potential evolution of fare payment policies and systems-e.g. the elimination of transfers, prepayment and "proof of payment" typical on new LRT and the emerging "rail on rubber wheels," i.e. bus rapid transit (BRT) modes. In the meantime, however, the need exists to continually address the security of bus operators.

This report, therefore, focuses on current developments in keeping bus operators secure from crime. With few exceptions, most security methods transit agencies employ address both employee and patron. A secure environment benefits all onboard. To the extent possible, this report highlights the unique features of each security method that may contribute to the security of the bus operator.

\section{Methodology}

Initially, a review of sources of information that may exist on the subject of providing protection for bus operators and passengers was conducted. This included, but was not limited to, a review of the Transportation Research Information Services database, proceedings from conferences of the American Public Transportation Association (APTA), issues of APTA's Passenger Transport over the past four years, and an Internet search for newspaper articles or reports that might be available. The reviewed materials are listed in Appendix A.

A survey was developed in both electronic and hard copy formats and distributed to selected transit agencies of various sizes across the U.S. The chief purposes of the survey were to discover what techniques transit agencies employ to keep their bus operators secure from crime and how they perceive each method's effectiveness and cost, relative to the others. Project staff made follow up telephone calls to clarify answers and obtain additional and more detailed information.

The project manager visited two (2) transit agencies in Florida-Broward County Transit and MiamiDade Transit - that employ particularly interesting and effective onboard security techniques. Input was obtained from security and operations staff as well as bus operators. 
Draft versions of the report were shared with members of a peer review committee composed of transit professional staff involved in and knowledgeable of security matters. Other reviewers included researchers from the NCTR at the Center for Urban Transportation Research (CUTR), located at the University of South Florida in Tampa. Their review and comment were invaluable in developing the final report. 


\section{TRANSIT CRIME REPORTING}

Since 1996, crime data on federally funded public transit systems are collected in and reported from the Federal Transit Administration (FTA)'s National Transit Database (NTD), particularly Form 405, Transit Safety and Security. According to the NTD reporting manual, "All transit agencies in or serving an urbanized area (UZA) of 200,000 or more population must complete this form."7 A separate form must be completed for each mode of service a transit agency either directly operates or purchases. Page 2 of the form is concerned with Security Items (versus Safety Items on Page 1) and includes serious offenses which are reported in Part I and less serious offenses which result in arrests in Part II (a copy is presented in Appendix C). The serious offenses include both Violent Crime and Property Crime incidents. The incidents are detailed by victim (patrons, employees, or others) and by location (in vehicle, in station, or other transit property).

Unfortunately, the less serious offenses in Part II including "other assaults" and "disorderly conduct" are only broken down by location and do not contain details regarding who the victims are. Since this report focuses on the security of bus operators, i.e. "in vehicle employees," the NTD data may be viewed as incomplete and do not fully or accurately reflect the reality of criminal activities to which bus operators are subject. This sentiment was expressed by at least one respondent to the questionnaire, who felt that onboard criminal activity is underreported in the NTD. Of course, a database is only as good as the data it contains. The burden still lies on transit agencies to report accurate and complete data. It is crucial that systematic methods are in place for compiling, maintaining, and reporting data, not only to fulfill the federal government requirements of NTD reporting, but also for the management and evaluation needs of the local transit agency and its funding partners.
Despite its shortcomings, the NTD is the only comprehensive source of transit agency data. It includes data that agencies potentially would not collect on their own and thus would be otherwise unavailable for analysis. The crime data reported for years 1996-99 were analyzed for this section.

The reporting format for NTD security data follows the standards set by the FBI Uniform Crime Reporting (UCR) Program. Notably, the definitions for crimes are taken directly from the FBI Uniform Crime Reporting Handbook (1984). Thus, Part I Violent Crime includes crimes against individuals and is classified as homicide, forcible rape, robbery, and aggravated assault.

\section{Violent Crimes Definitions}

Homicide: The killing of one or more human beings by another. This includes murder, non-negligent manslaughter and manslaughter by negligence.

Forcible Rape: The carnal knowledge of a female forcibly and against her will. This includes assault to rape or attempt to rape.

Robbery: The taking or attempting to take anything of value from the care, custody, or control of a person or persons by force or threat of force or violence and/or by putting the victim in fear. The use or threat of force includes firearms, knives or cutting instruments, other dangerous weapons (clubs, acid, explosives), and strong-arm techniques (hands, fists, feet).

Aggravated Assault: An unlawful attack by one person upon another for the purpose of inflicting severe or aggravated bodily injury. This type of assault usually is accompanied by the use of a weapon or by means likely to produce death or great bodily harm.

SOURCE: NTD Reporting Manual, (1999).

The NTD data reveal that bus operators are relatively secure from violent crime, despite wellpublicized exceptional incidents like what happened in Seattle. By far, the most common violent offense against bus operators is aggravated assault. In the first reporting year in which the NTD was expanded to include crime statistics, there were reported 617 
aggravated assaults nationwide against bus operators. Three years later, in 1999, there were 377 - a decrease of $39 \%$. The second most common offense against bus operators is robbery, with 86 reported incidents in 1996 down to 65 in 1999-a $24 \%$ decrease. In the first two years, there were no rapes committed onboard against women bus operators; there were two incidents in 1998 and four in 1999. Onboard homicide is virtually unheard of, except for the killing of operator Mark McLaughlin in Seattle in 1998. There were no reported homicides in years 1996, 1997, and 1999. The fouryear trends for the four violent crime categories are represented graphically in Figure 1.

Figure 1: Violence Against Bus Operators

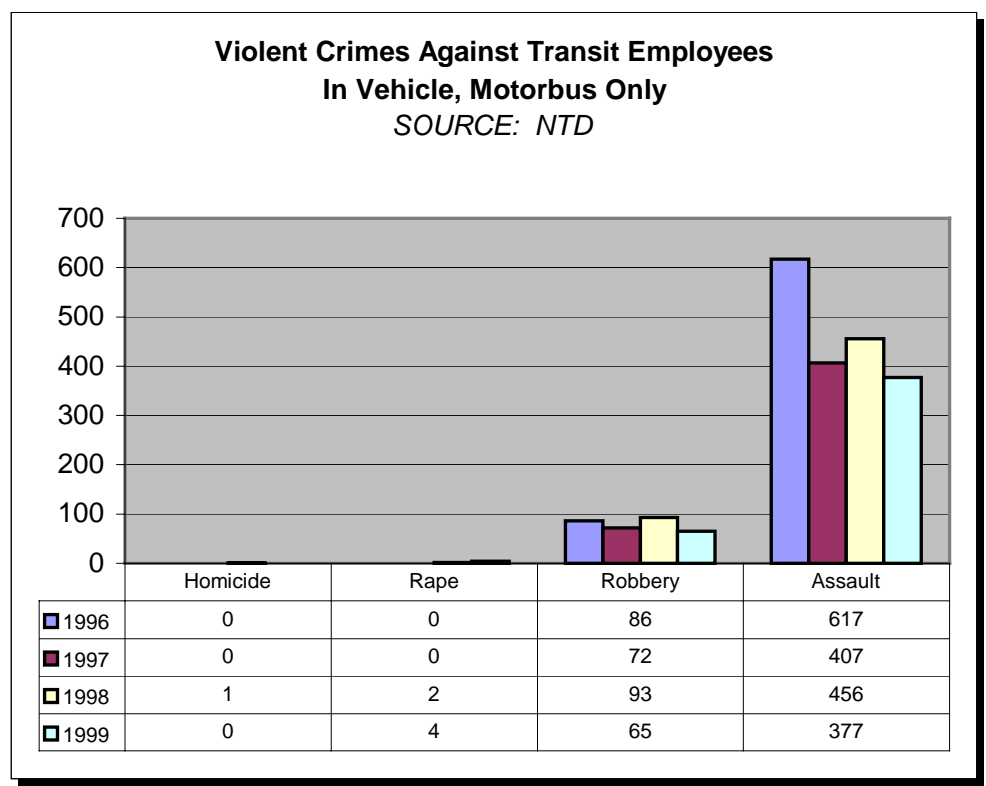

It is precarious to perceive actual trends in transit crime with only four years of data; however, the accumulated data to date indicate that violent crimes against bus operators are decreasing. The declines in transit crime parallel recent trends in most reported crimes witnessed in cities throughout the U.S. This makes sense. The bulk of public transit service is found in urban areas; it is intuitive that public transit service is subject to its environment, and most violent crime occurs in urbanized settings.
The NTD summarizes in-vehicle violent crime against transit employees for all agencies serving areas both greater and lesser than 1 million in population; however, the mode detail is lost in this summary. Still, knowing that the bulk of transit service is supplied and consumed on motorbuses the reader can confidently compare and contrast Figures 2 and 3. Note that, although the hierarchies of which crimes are more frequent within each figure are the same (i.e. assaults outnumber robberies, which outnumber rapes and homicides), the y-axis and data in Figure 3 indicate substantially greater incidents of crime in larger cities than smaller ones.

Finally, for the reader's information, Table 1 indicates the latest available (i.e. reporting year 1999) NTD violent crime data for the 55 transit agencies solicited to provide information regarding their security practices for this report. As expected, the larger crime incident numbers almost exclusively belong to the larger bus systems, i.e. systems with the greatest amounts of both service supplied and consumed, serving the larger metro areas. Systems with the most assaults reported include those serving Minneapolis (49), Miami (34), Boston (32), Chicago (25), Fort Lauderdale (24), Detroit (21) and Milwaukee (20). Robberies mostly occurred on systems serving Los Angeles (11), New Jersey (8), and Oakland (6). The only reported rapes occurred in Los Angeles (2) and San Diego (1). There were no homicides of bus operators in 1999. 
Figure 2 Transit Employee Violence - Smaller Cities

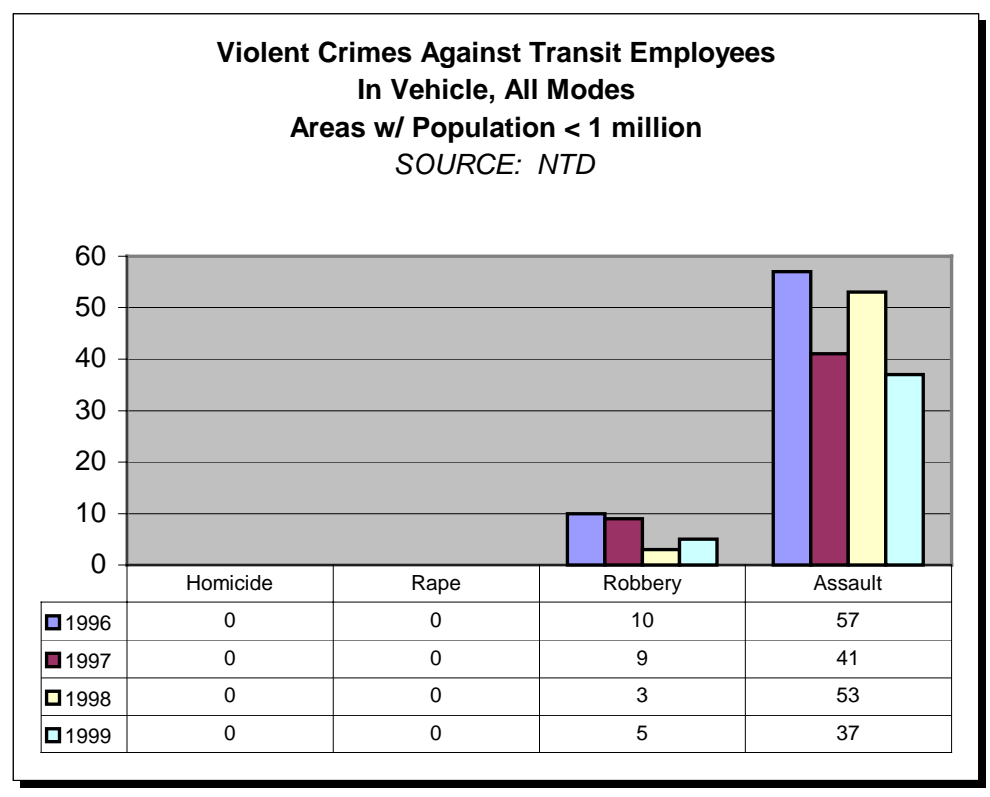

to more than 3.5 billion passengers along more than 1 billion miles of routes on nearly 28,000 buses, these 55 transit systems reported only 321 aggravated assaults, 54 robberies, 3 forcible rapes, and no homicides; their combined experience signifies that bus operators are relatively secure from violent crime.

Still, no one wishes to become a crime victim, and it only takes a few well-publicized incidents to raise valid concerns of what can be done to improve personal security. Ignoring such concerns in the long run may make it difficult for transit agencies to hire and retain good bus operator employees.

One might expect that transit in America's largest metropolis-New York City-would report higher incidences of crime. However, in 1999 New York City Transit reported no violent crimes committed against its bus operators while on duty. The reader should be cautioned in making too many assumptions with the NTD data presented here. Internal data collection and reporting procedures vary among transit agencies. It is possible, but unproven, that some transit agencies may actively suppress crime statistics that may cause irreparable damage to system patronage. Knowledge of crime typically results in fear; a high variance between perception and reality of crime incidence certainly makes a difference in a customer's decision to ride transit. More in-depth analysis is needed to attempt to explain the perceived inconsistencies in NTD crime data among transit agencies.

The point in presenting Table 1 is perspective. Due to the nature of public transit service, bus operators necessarily interact greatly with the public they serve. In providing transportation
Additionally, though incidents may be rare, their impact can be fiscally significant in workers' compensation payouts. The following sections of this report highlight the security methods transit agencies employ to keep their operators secure from crime.

Figure 3 Transit Employee Violence - Larger Cities

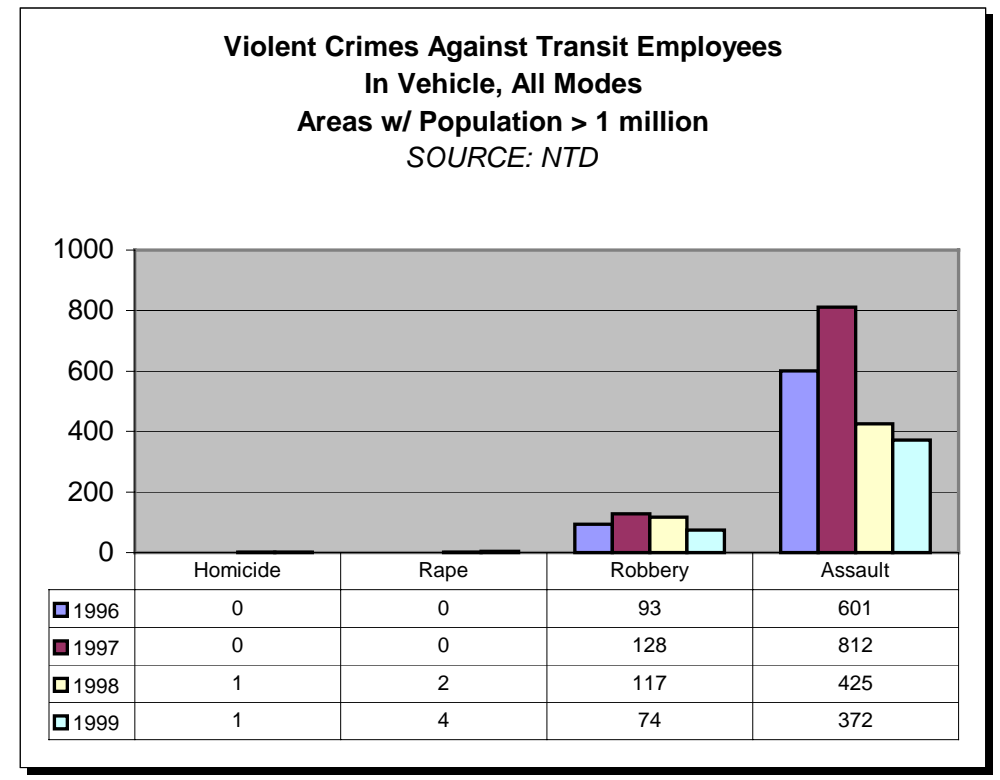




\section{Table 1 Select Transit Agencies \& Crime Data}

1999 National Transit Database

Violent Offenses Against Bus Operators

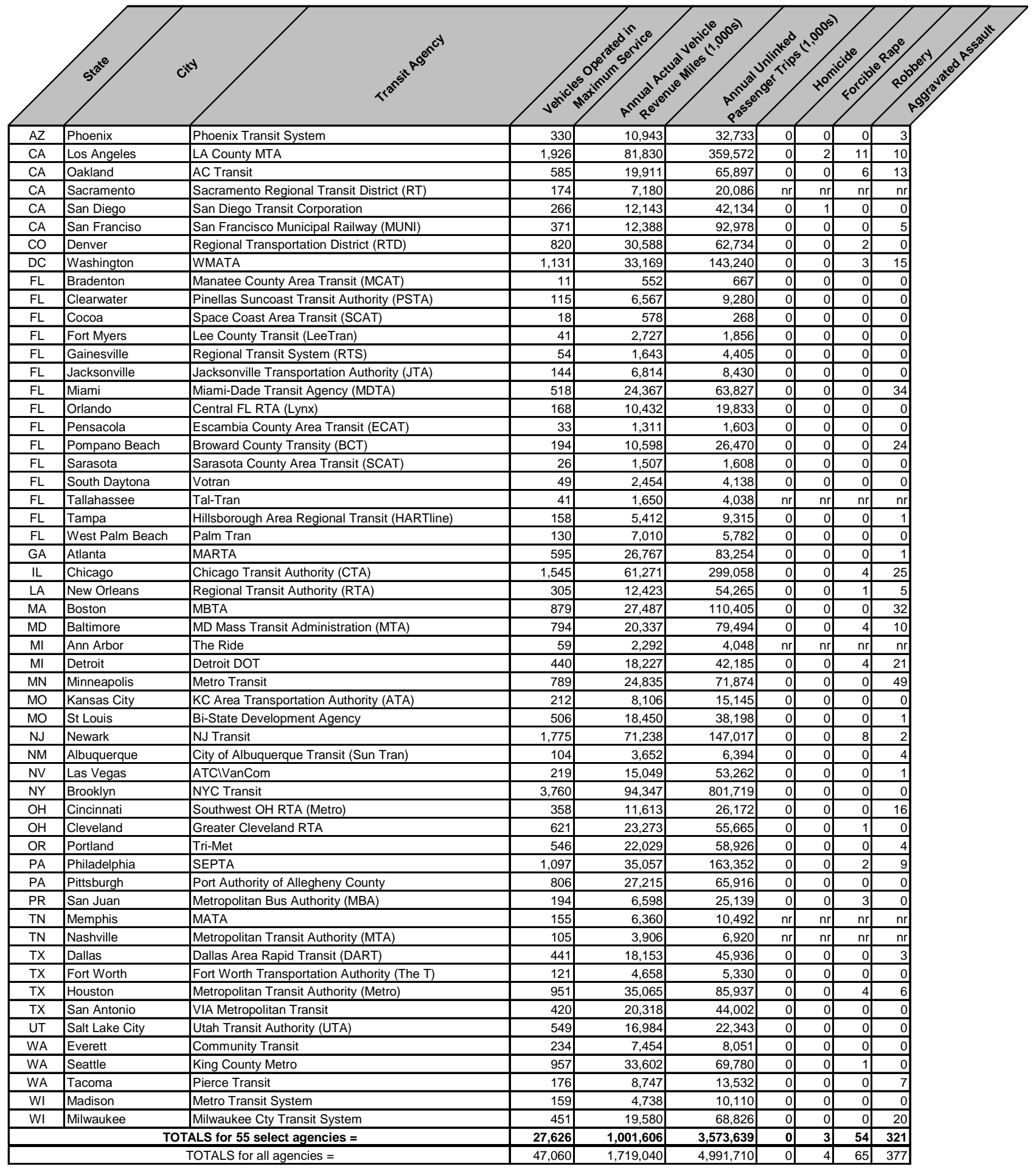

$\mathrm{nr}=$ not reported 


\section{TRANSIT AGENCY SURVEY}

\section{Contacting Agencies}

Fifty-five (55) transit agencies were identified to obtain information on what techniques they are using to help protect their bus operators and passengers, as well as how these methods are perceived regarding their relative effectiveness and cost. The list of agencies included most large, many medium, and some small transit agencies from across the U.S., including all transit properties in Florida. A survey was developed as an HTML (hypertext markup language) form and posted for public access on the web server for the National Center for Transit Research (NCTR). The HTMLformatted survey was developed so that a transit staff person could access it online at his/her leisure and complete it in about 10 minutes. The transit agency staff person targeted to complete the survey was the one most responsible for security onboard buses. Because of variations in transit agency organizational structures, actual respondents included police officers, security directors, general managers, planners, research staff and/or their subordinates. Where possible, a specific contact name was first identified via the American Public Transportation Association (APTA)'s Directory, agency web sites, phone and email queries, and personal contacts of project staff.

In October 2000, the identified individuals at the 55 agencies were contacted via email, telephone, and snail mail as necessary to request their participation and completion of the survey in either electronic or hard copy format. In the Spring of 2001, project staff followed up with these transit agencies to encourage completion of the survey. In the meantime, project staff made follow up telephone calls to the contacts identified on the returned surveys to clarify their answers, as necessary, and to collect more in-depth information.

\section{Survey Organization}

The survey form was arranged in four sections. Under "Contact Information," the respondent was asked to provide the agency's name as well as his/her name, title, phone, and email address. A second section asked for "National Transit Database (NTD) Information," specifically crime data, for the agency's most recent reporting year (1999). However, this section was later deleted in midproject when the requested data became available online via the NTD web site.

Based upon the literature review, eight specific security methodologies were listed in the third section of the survey form, "Security Methods/Techniques." If the transit agency utilized any of the suggested methodologies, the respondent was asked to rate each on its perceived effectiveness (poor, fair, good, or excellent) and cost (inexpensive, reasonable, or expensive) as a security method, relative to the other methods the agency employs. In the online form of the survey, the respondent rated the security methods by simply clicking on check boxes. Radio buttons would have made computer analysis of the responses easier, but it was decided to use check boxes because they can be unchecked if the respondent makes an error. If the responding agency does not currently employ a particular method but has budgeted for its future implementation, the respondent was asked to check a single box indicating the same. The fourth section suggested additional factors that may influence onboard crime and encouraged the respondents' comments in text boxes.

\section{Response}

As this report was written, 31 of the 55 agencies solicited had responded, including 13 large (i.e. identified in the 1999 National Transit Database among the "Top 30 Agencies"), 11 medium, and 7 small (i.e. less than 100 buses). Most responded via the electronic web form, but some mailed or faxed their completed surveys. 
Although a response rate of $56 \%$ may be considered respectable, the reader should be aware that the respondents did not address or answer every question. The actual number of responses to the effectiveness and cost evaluations for some of the listed security methods in the third section are, therefore, low. Furthermore, some respondents did not follow survey instructions and evaluated the perceived effectiveness and/or costs of security methods their agency did not actually employ; follow up phone calls discovered the inconsistencies and their tabulated responses were changed to reflect truth. Thus, the survey results should not be viewed as scientific; rather, the responses are suggestive.

The survey form, a listing of the 31 responding transit agencies, and a summary of the security methods they employ are presented in Appendix B.

\section{Survey Summary \& Analysis}

In general, transit agencies typically employ more than one technique to provide onboard security, "packaging" various methods to get the most bangs for their limited bucks. With few exceptions (e.g. cab enclosures and training) most methods are employed to protect both employees and customers. Furthermore, most methods employed yield additional benefits that address concerns other than, and in addition to, security matters. For example, though CAD/AVL systems are typically procured for their efficiencies in real-time fleet management, their bus tracking features, integrated with advanced communication systems and video surveillance, provide significant advantages in responding to transit crime. Onboard video surveillance systems provide records of onboard passenger activity including vandalism. The video can be used as powerful evidence in prosecuting property damage crimes. Visible onboard systems, security staff, and interior designs that mitigate crime may facilitate positive marketing efforts to discretionary customers, instilling greater confidence in the security of the transit system.
Security methods may be classified differently for analyses with different purposes. One classification may differentiate technology or automated methods versus manual methods using manpower. Technology methods include communications systems, covert alarms, video surveillance, and CAD/AVL. Manpower methods primarily involve security staff and/or police patrols.

The security methods for transit buses discussed in this report may also be categorized as proactive, reactive, or punitive. Crime prevention (proactive) methods include video surveillance, "code of conduct" postings, CPTED principles, operator cab enclosures, security staff, police officers, and violence prevention/anger management training. Incident management (reactive) methods include $\mathrm{CAD} / \mathrm{AVL}$ systems, video/audio surveillance, security staff, police officers, and self defense training. Punishment-based (punitive) methods include state laws and local ordinances to protect public transit employees and customers by providing special punishments and laws that codify greater charges for transit crimes.

The results and analyses of survey responses for specific security methods are presented in subsequent sections of this report under the subheading, "Survey Findings."

\section{Effectiveness \& Cost Scores}

For each surveyed method, a numerical score was assigned, based upon the average scores of respondents' qualitative perception ratings. Responses for "effectiveness" were assigned scores as follows: poor $=1$, fair $=2$, good $=3$, and excellent $=4$. Similarly, responses for "cost" were assigned the following scores: inexpensive $=1$, reasonable $=2$, and expensive $=3$. Finally, an "effectiveness to cost" ratio was calculated for each method based on the average effectiveness and cost scores of all respondents. As discussed earlier, transit agencies employ multiple strategies and, with limited resources, must choose which to employ. The ratios 
may provide guidance to those transit agencies in comparing proposed strategies. The average scores and effectiveness-to-cost ratios for each surveyed method are indicated in both Table 2 and Figure 4. The reader is cautioned, however, not to blindly seize the scores. The limited sample size of the survey-31 transit agencies-may not represent the unique conditions or circumstances of each and every U.S. transit system. They may provide guidance, but should not be used as the sole basis in decision-making.

The four highest rated methods in terms of effectiveness were in-house security (average score of 3.8), an enclosure to protect operators in new bus specifications (average score of 3.7), plainclothes sworn police (average score of 3.6), and an enclosure to protect bus operators retrofitted into existing buses (average score of 3.5). The three least expensive rated methods were violence prevention training (average score of 1.4), a panic button that changes the message of the headsign and plainclothes security (average score of 1.7 for both methods). The three highest effectiveness-to-cost ratios belong to violence prevention training (2.1), in-house security (1.9), and plainclothes security (1.8).

Further analysis shows that sworn police consistently rate high in terms of effectiveness; their cost, however, also rates relatively higher than most other methods. This could support the belief that "you get what you pay for." Furthermore, manpower is almost always more expensive than technology due to annualized salaries and fringe benefits.

Keeping in mind the survey's narrow focus of each method's role in keeping bus operators secure from crime, lower rated methods may actually warrant consideration. For example, CAD/AVL rated a solid "good" in effectiveness, but its cost was also rated "expensive" which resulted in the lowest effectiveness-to-cost ratio among all surveyed methods. However, the benefits of CAD/AVL are primarily concerned with effective fleet management and dispatch, which has a large impact on a transit agency's sensitive operating budget. The security features of CAD/AVL may be viewed as added benefits. Similarly, the benefits of onboard video surveillance are shared among security, risk management, maintenance, and marketing. The survey for this project only asked respondents' perceptions of the methods in addressing security of bus operators.

Interestingly, violence prevention training was rated the technique with the highest effectiveness-to-cost ratio. As discussed later, this may reflect the transit industry's conservative nature in that violence prevention training has been the standard reinforcing response to keeping bus operators safe from crime. Changing times and attitudes are apparent, however, in the application of more aggressive strategies. 
Table 2

Bus Operator Security Survey

Average Response Ratings

\begin{tabular}{|c|c|c|c|c|}
\hline \multicolumn{2}{|c|}{ METHODS $\boldsymbol{V}$} & $\begin{array}{c}\text { Effectiveness } \\
\text { (1 to 4) }\end{array}$ & Cost (1 to 3) & $\begin{array}{c}\text { Effectiveness } \\
\text { Cost Ratio }\end{array}$ \\
\hline \multicolumn{2}{|c|}{ 2-Way Radio } & 3.1 & 2.2 & 1.4 \\
\hline \multirow{2}{*}{ Panic Button } & dispatch & 3.0 & 2.3 & 1.3 \\
\cline { 2 - 5 } & headsign & 2.7 & 1.7 & 1.6 \\
\hline CAD / AVL & 3.0 & 3.0 & 1.0 \\
\hline Video Cameras Onboard & 3.2 & 2.5 & 1.3 \\
\hline \multirow{4}{*}{$\begin{array}{c}\text { Security } \\
\text { (Onboard) }\end{array}$} & contracted & 2.7 & 2.3 & 1.2 \\
\cline { 2 - 5 } & in-house & 3.8 & 2.0 & 1.9 \\
\cline { 2 - 5 } & uniformed & 3.0 & 2.1 & 1.4 \\
\cline { 2 - 5 } & plainclothes & 3.0 & 1.7 & 1.8 \\
\hline \multirow{3}{*}{$\begin{array}{c}\text { Sworn Police } \\
\text { (Onboard) }\end{array}$} & contracted & 3.3 & 2.3 & 1.4 \\
\cline { 2 - 5 } & in-house & 3.4 & 2.2 & 1.5 \\
\cline { 2 - 5 } & uniformed & 3.3 & 2.2 & 1.5 \\
\cline { 2 - 5 } & plainclothes & 3.6 & 2.2 & 1.6 \\
\hline \multirow{2}{*}{$\begin{array}{c}\text { Specialized } \\
\text { Operator Training }\end{array}$} & self-defense & 2.8 & 2.0 & 1.4 \\
\cline { 2 - 5 } & prevention & 2.9 & 1.4 & 2.1 \\
\hline \multirow{2}{*}{\begin{tabular}{c} 
Protect Operator \\
\cline { 2 - 5 }
\end{tabular}} & netrofit & 3.5 & 2.5 & 1.4 \\
\cline { 2 - 5 } & new specs & 3.7 & 2.5 & 1.5 \\
\hline
\end{tabular}


Figure 4 Survey Response Ratings

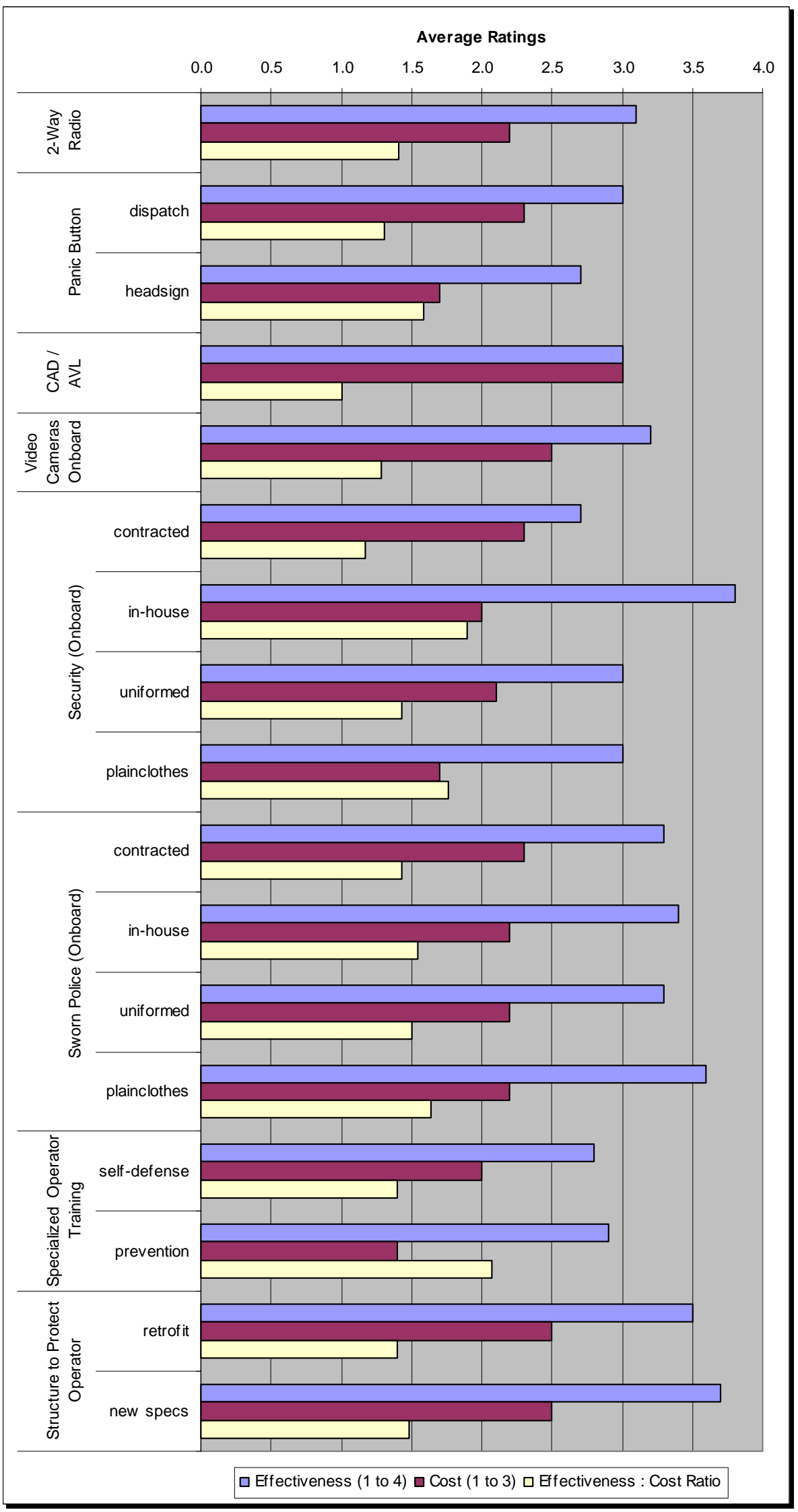

Cops, Cameras, and Enclosures

p. 13 


\section{2-WAY COMMUNICATIONS}

Although fixed route transit service implies both a static schedule and route a bus driver must follow, the environment in which the service operates is dynamic. Because of unexpected occurrences, the link between bus operators in the field and dispatch personnel in a central control office is a vital one. Central dispatch staffs with their broader viewpoints are ideally suited for allocating limited system resources. Thus, bus operators depend upon dispatchers and road supervisors for direction in an unplanned event.

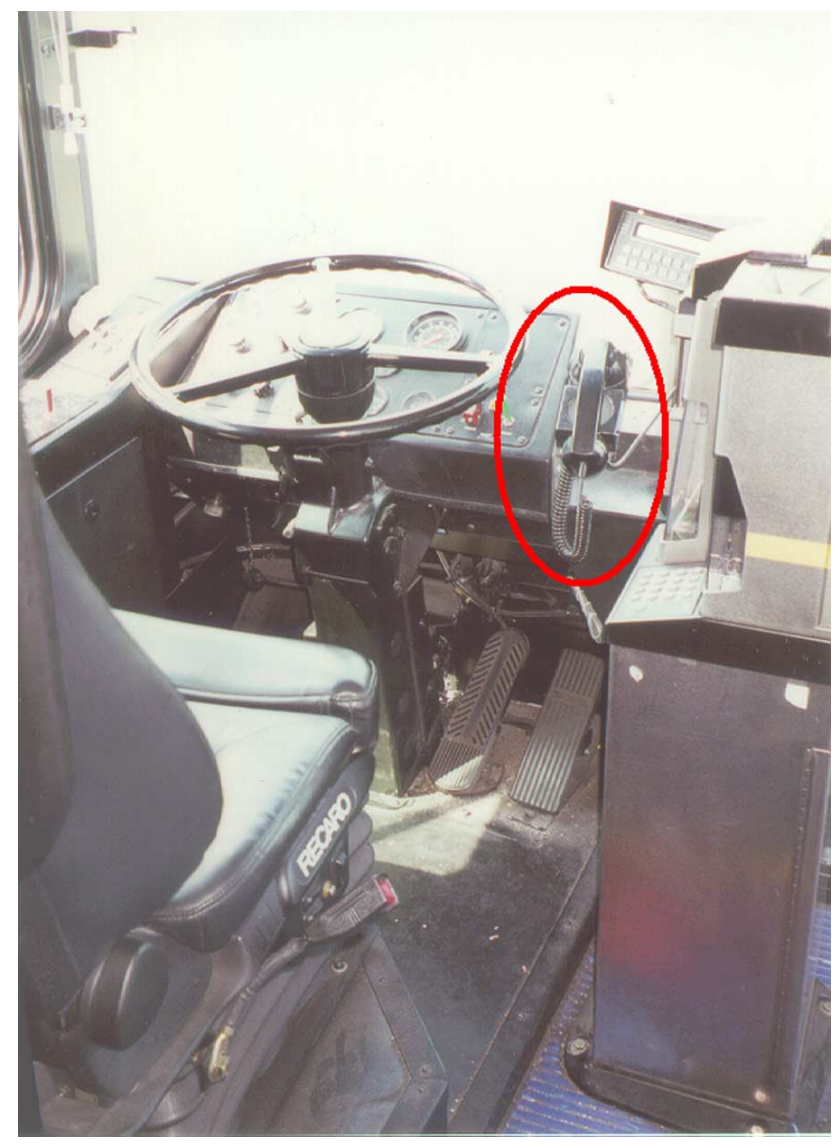

Picture 1 A typical bus operator's workstation includes a 2-way radio for voice communications with dispatch. Note the farebox on the right.

Most transit systems employ some form of electronic system for voice communications. Although some systems are upgrading their communications systems to accommodate the additional demands of digital data transfer between onboard advanced technology "probes" (e.g. automatic vehicle location, video surveillance, mechanical systems sensors, et. al.) and their associated off-board automated central processing units, the ability of a bus operator to speak with a live human dispatcher, when possible, still has its advantages. For example, an activated panic button may signal the dispatcher that an emergency situation may exist onboard a bus; however, voice communication between dispatcher and bus operator may confirm the panic button's activation was accidental, no emergency situation exists and, therefore, no further response is necessary.

Similarly, 2-way voice communication allows more descriptive and accurate information during real or potential security threats. For smaller or poorer transit systems unable to upgrade onboard systems, 2-way radio communication is essential. Even for systems employing advanced technologies, voice communication is still a mainstay application.

There are a variety of technologies and methods to convey communication signals; each has its own strengths and weaknesses. A number of factors may impact the viability and/or effectiveness of a particular communication technology. Regional terrain, building densities and heights, available service providers, available radio frequencies, system service area-alone or in combination, these and other factors must be considered when choosing a communication system or systems. (For a more detailed discussion of communication technologies for transit, the reader may refer to the U.S. Department of Transportation's publication, Advanced Public Transportation Systems: The State of the Art, including updates.)

The City of Detroit's D-DOT public bus system is testing cellular phones as a supplemental communication system between bus operators and support staff. D-DOT operations staffs have found their existing 2-way radio system unable to handle 
increasing voice traffic and interference from various sources. Now, some operators are issued cellular phones when reporting for their runs. The phones are preprogrammed with unique telephone numbers for specific situations. For example, the operator may connect directly with officers from the City of Detroit Police Department who are assigned to patrol transit. Other numbers will connect the bus operator with dispatch, road supervisors, and maintenance staff.

An advantage, in the case of emergencies, is that response time may be shortened since the call for help is made directly to police, rather than through the dispatcher. Police may more accurately assess an onboard emergency situation by speaking directly with the bus operator instead of having reports relayed by a dispatcher. In effect, the "middle man," i.e. dispatch staff, is eliminated when time is critical. D-DOT may find, however, as did Lynx in Orlando, that regular cellular communications can be expensive.

Lynx tested an automatic vehicle location (AVL) system provided by $3 \mathrm{M}$. The system was outfitted on six express buses. For the limited trial, the chosen communication method was cellular. Initially, the system was set so that the onboard systems would automatically communicate with the central computer in dispatch, reporting the buses' locations at frequent intervals. Additionally, the onboard computers were loaded with the route manifests and also reported early and late arrivals at designated time points. Orlando's Interstate 4 is the principle artery through the area for commuters and tourists alike and is consistently congested. Lynx's express buses do not utilize exclusive lanesunavailable on the inadequate roadway-and, consequently, often ran off schedule. The resulting charges for frequent cellular calls the AVL system made to report status, given the rates set by the contracted local service provider, were far in excess from what was expected.
D-DOT, however, is testing cellular for voice communication as an alternative to an unreliable radio system. They may find the cellular tolls tolerable, at least in the short term, and preferable to a large capital investment in a new communications system. D-DOT may also receive more favorable airtime rates than did Lynx.

Reception to the cell phones by bus operators is mainly positive, according to D-DOT security staff. On the one hand, some operators do not like being responsible for the phones, which they must sign for at the beginning of their shifts and return to dispatch staff at the end of their shifts. More operators, however, prefer the reliability of the cell phones to that of the existing 2-way radio system. In an emergency situation when outside support is critical, reliable voice communication is necessary.

Another example of using cellular phone communications to enhance onboard security can be found in Dayton, Ohio. The Miami Valley Regional Transit Authority (RTA) tested a pilot project in which select students of a high school were issued cell phones preprogrammed with the number for RTA dispatch. The students were trained by the RTA and Dayton police to ride and report uncivil and criminal activities occurring onboard MTA buses. $^{8}$ The program continues today. Since bus operators do not always witness every incident that happens onboard, the students' presence provides supplemental visual monitoring. The students effectively function as undercover security "probes" for the transit system and may contribute to a more secure environment onboard the buses. In addition, the students learn values in responsibility, community service, personal safety, and respect for authority.

\section{Survey Findings}

As a security method, 2-way voice communication has a proven track record. Of the survey respondents rating 2-way radio's relative effectiveness, $25(83 \%)$ of 30 rated it as either 
"good" or "excellent." The average effectiveness score for all respondents who report using 2-way radio systems is 3.1, or slightly above "good."

Its cost, relative to other methods, was rated as either "inexpensive" or "reasonable" by 18 (72\%) of 25 respondents. The average cost score for all respondents who chose to rate their 2-way radio systems is 2.2 or slightly higher than "reasonable."

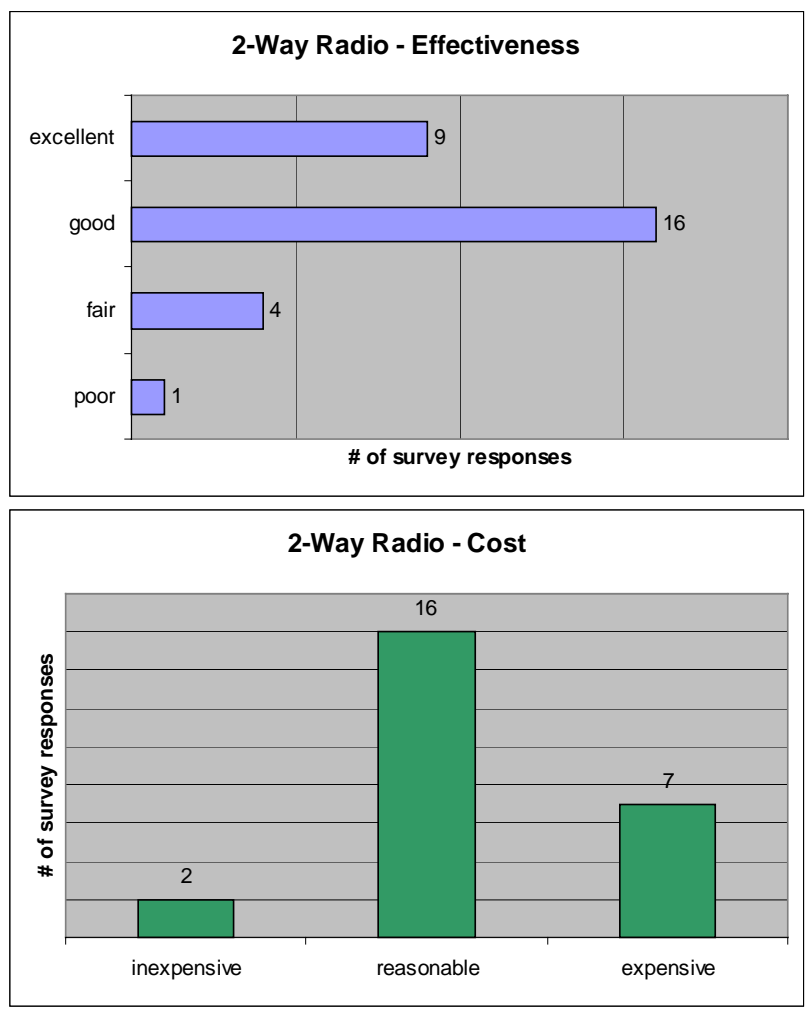




\section{PANIC BUTTON}

A panic button (a.k.a. "silent" or "covert" alarm) is usually mounted in an inconspicuous location below the operator's window and/or on the floor for foot activation. When pressed by the operator in an emergency situation, various responses may occur depending upon communication system configurations. The typical configuration alerts dispatch personnel to an undetermined problem onboard the bus. The dispatcher doesn't know the details, but agency policy dictates that police or security officers are dispatched to investigate. The outside destination sign may also change its message to request assistance from the public to alert law enforcement, unknown to an onboard criminal.

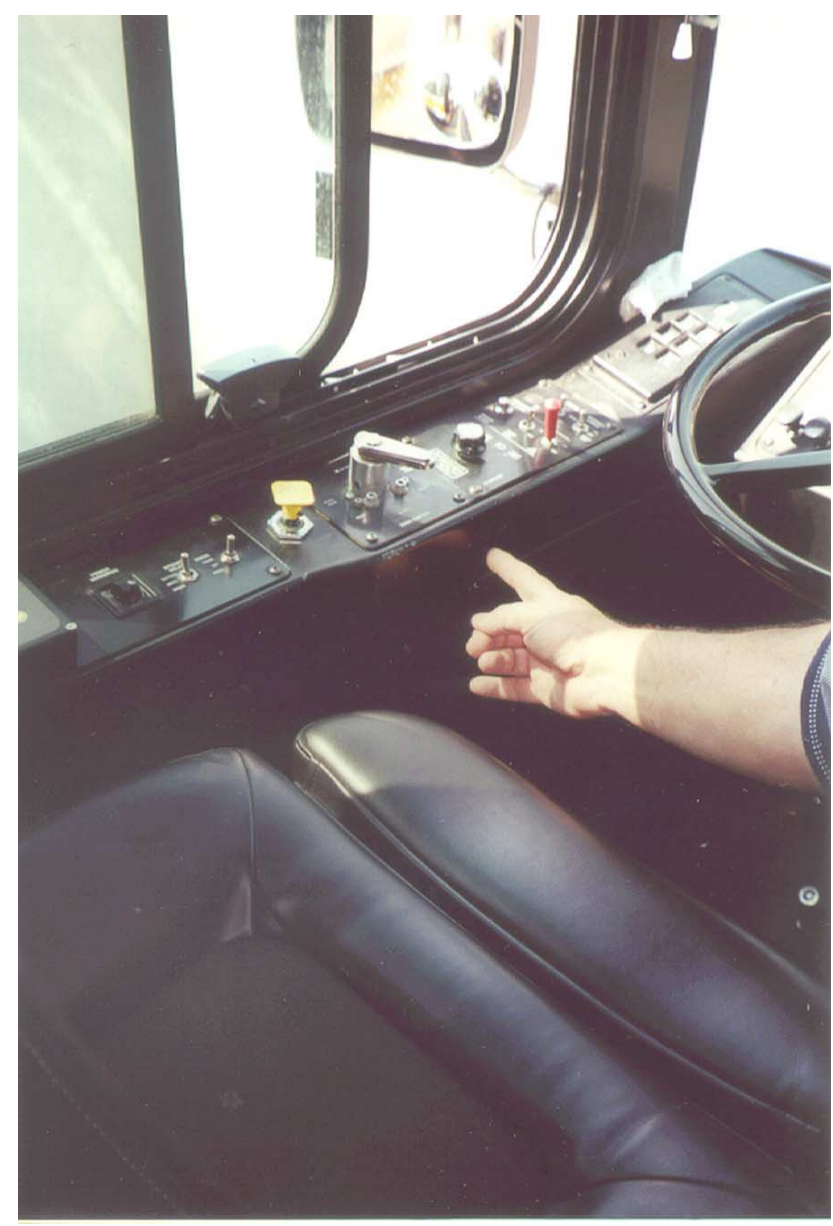

Picture 2 The panic button provides a means for the operator to alert dispatch to a serious problem without using the radio.
When combined with an onboard covert microphone or video surveillance, dispatch and security personnel may indirectly monitor the onboard situation as it occurs. In such an event, the bus operator presses the panic button and data collected by onboard cameras and microphones are transmitted via communication signals back to the agency operations staffs. Digital data from newer onboard audio and video surveillance systems is received by and distributed to users on the agency computer local area network (LAN). Off-bus personnel may listen to and view the nearly real time data wherever access to the LAN is available. In advanced systems using automatic vehicle location (AVL) technology, the problem bus and its location is instantly highlighted and reported on the monitoring dispatcher's video display. This information is then passed on to security and/or law enforcement personnel to hasten their response.

\section{Survey Findings}

A majority of respondents report that a panic button which alerts dispatch of an onboard problem is either "good" or "excellent" in effect (18 of 21 respondents) and "reasonable" in expense (12 of 16 respondents). The average effectiveness score is 3.0 or "good." The average cost score is 2.3 , slightly higher than "reasonable."

For systems in which the panic button changes the destination sign to display an emergency message, most respondents felt that its effectiveness was either "good" or "excellent" (13 of 19 respondents) and its relative cost either "inexpensive" or "reasonable" (13 of 14 respondents). The average effectiveness score is 2.7 or almost "good." The average cost score is 1.7 , just below "reasonable."

Transit staffs admit that bus operators make most activations of the panic button accidentally. Still, its availability provides one additional method bus operators may actively employ to deter or respond to onboard crime. The combination of the panic button with newer digital communications technologies has 
greatly enhanced its application and value as an onboard security feature. Transit agencies acquiring new onboard systems should make sure that those systems support a panic button.
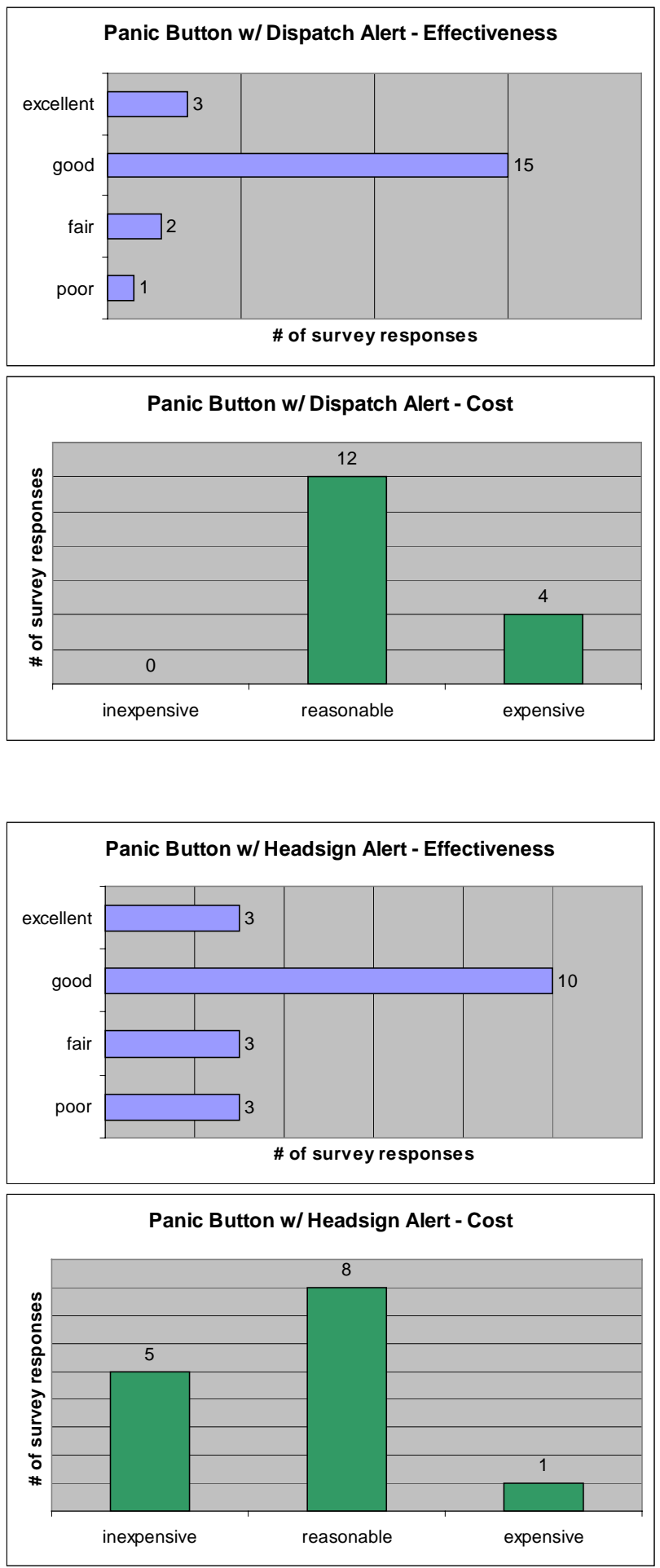


\section{CAD / AVL}

Computer aided dispatch (CAD) and automatic vehicle location (AVL) are applications of new technologies from other industries that the transit industry is beginning to adopt. Though AVL may function independently or in combination with other technologies (e.g. automatic passenger counters or "APCs"), combining it with CAD yields enormous benefits, particularly for bigger systems managing a large fleet of vehicles in a timed transfer route network over a broad geographic area.

A primary component of the system involves vehicle tracking. Though other methods exist, more systems implementing AVL technologies today opt for those based on the satellite-based global positioning system (GPS). The order by President Clinton in May 2000 for the Department of Defense to discontinue signal degradation has resulted in a tenfold increase in location accuracy for GPS users. Early pioneers in the transit industry using GPSbased AVL had to settle for the ability to locate a vehicle within approximately 100 meters. Now, these same systems can expect to locate their vehicles within about 10 meters. Furthermore, an improved system, known as "differential" GPS or DGPS, is available that uses automated correction algorithms for sub-meter location accuracy. This means the dispatcher can know-at any given time-in which city block a bus is located.

The point is that CAD/AVL systems can use GPS technology and communications systems to accurately track, in real time, the location of equipped vehicles in the fleet. Prior to AVL systems, the primary method of vehicle tracking involved the dispatcher querying a bus operator via 2-way radio. The CAD application assembles the AVL information along with other real-time data that may be collected from onboard systems-for every vehicle in the fleet - to assist dispatchers in their decision-making. For example, the CAD software can highlight which buses are running late or early. If the real-time data includes status information from probes of onboard systems-e.g. APCs, fareboxes, engines, brakes, air conditioningthe CAD/AVL system can report aberrations in these systems and hasten a response from the appropriate transit personnel.

This advantage of superior response time with CAD/AVL systems is especially important in matters of security. This is why many local governments nationwide have quickly adopted CAD/AVL systems for emergency medical services and police dispatch. As discussed earlier, depending upon configurations, a panic button that activates a covert alarm, microphone, and/or onboard video surveillance system may be an important subcomponent of a CAD/AVL system in transit buses.

For example, say a passenger, armed with a knife, approaches the bus operator and announces he is hijacking the bus. The hijacker warns the bus operator against taking any kind of action; however, the bus operator can, without raising the hijacker's suspicions, subtly hit either of the inconspicuous panic buttons, one on the left panel or the other mounted on the floor next to the brake pedal. Instantly, the bus is highlighted on the dispatcher's computer screen monitor and the CAD/AVL system also indicates the bus' position as a street address or other coded reference. The message on the outside destination sign changes to warn the public of an onboard emergency and requests they contact police. A hidden microphone onboard the threatened bus is activated. The onboard digital video cameras, ordinarily recording at one frame per second, increase their rate to eight frames per secondconsidered full motion video. The real-time audio and video may be transmitted over the advanced communications system back to the dispatcher who can now hear conversations and see movements of the hijacker, bus operator, and passengers. 


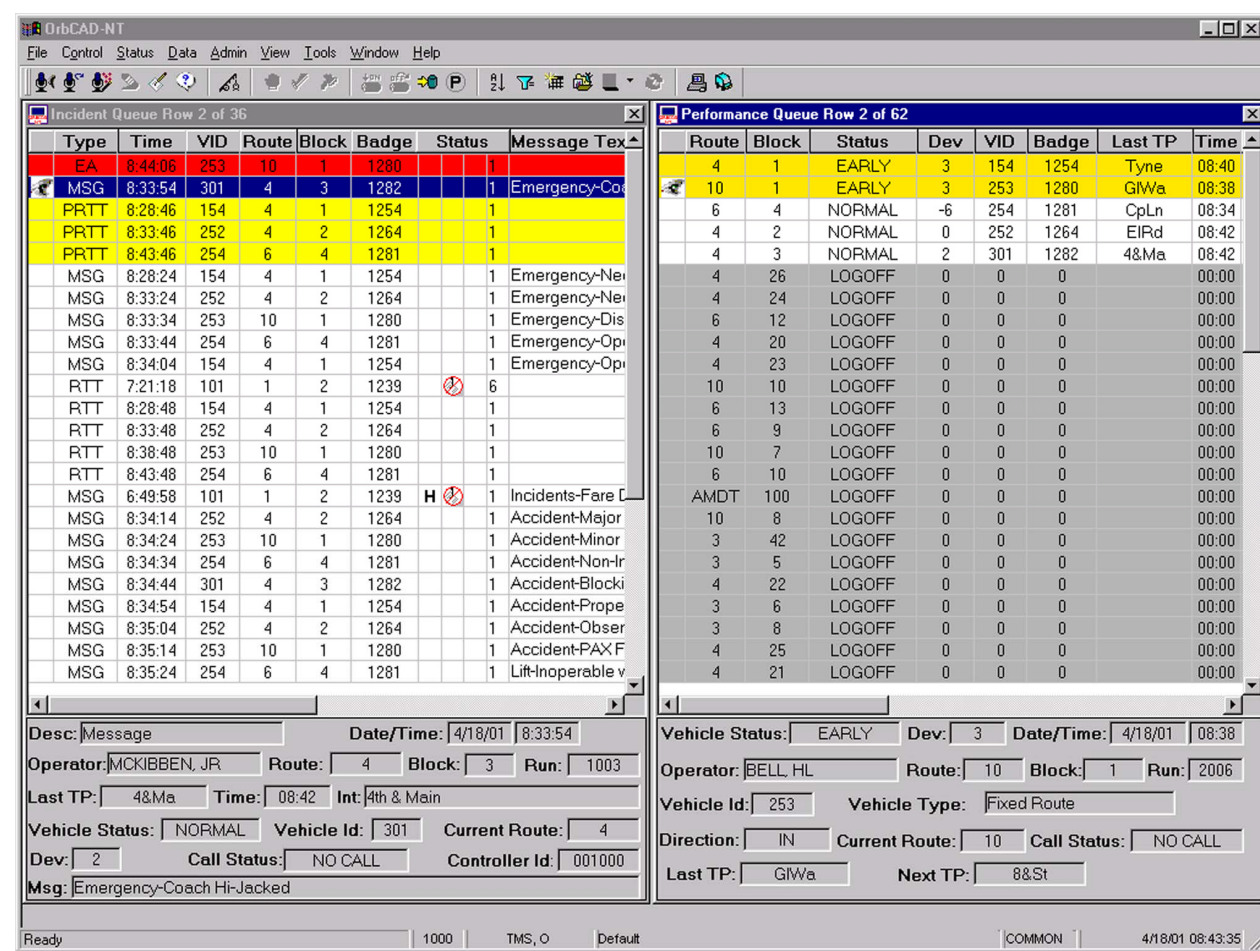

Picture 3 As viewed on a dispatcher's workstation, an emergency alarm status gets top priority over all other calls in a CAD/AVL system. (Image provided by Orbital.) mentioned in the prior hypothetical scenario (save for the onboard video surveillance) did indeed occur. The transit police intercepted the hijacked bus within three minutes. Though the suspect had alighted the bus before police arrived (but after stealing from passengers and the bus operator), he was arrested within the hour at his home because of information the police quickly obtained from a key witness, i.e. the driver of the taxicab who drove him home. ${ }^{9}$

Yet another incident occurred in Denver. A passenger armed with a knife assaulted a female bus operator on a If equipped with mobile data terminals (MDTs), transit police in patrol cars are dispatched automatically and may have access to the same onboard audio and/or video data; otherwise, the CAD/AVL system highlights the patrol car nearest the problem bus and the dispatcher contacts the police for quick response. Police are best-equipped and trained to handle hostage situations. The sooner they can arrive onsite, the quicker they can do their jobs. The more information they have concerning the situation onboard the bus, the better they can plan their response.

A similar, real, incident occurred onboard a Niagara Frontier Transportation Authority (NFTA) Metro bus. In 1998, NFTA upgraded an older radio system with an integrated CAD/AVL system on all fixed route buses, paratransit vans, road supervisor vehicles, and transit police cars. The following year, in March 1999, a man attempted to hijack a bus carrying 17 passengers. The bus operator activated the silent alarm feature and most of the actions
Regional Transportation District (RTD) bus. The CAD/AVL system enabled onsite police response within four minutes. The assailant fled upon hearing the police, but the bus operator and other passengers were potentially spared more serious injuries. ${ }^{10}$

Obviously the preceding scenarios are rare in the experience of American transit systems; however they-and even "less critical" incidents-necessitate quick response involving many complex decisions and actions. The urgency of a criminal act that involves human lives compresses these decisions and actions into a relatively short period of time. Time is crucial in responding to real-time criminal events. Efficient CAD/AVL systems promise to improve response via faster response times.

Finally, CAD/AVL systems typically utilize a database to store event information, including the location data obtained from the AVL component. In the case of crime, this stored and formatted data facilitates computer analysis using a geographic 


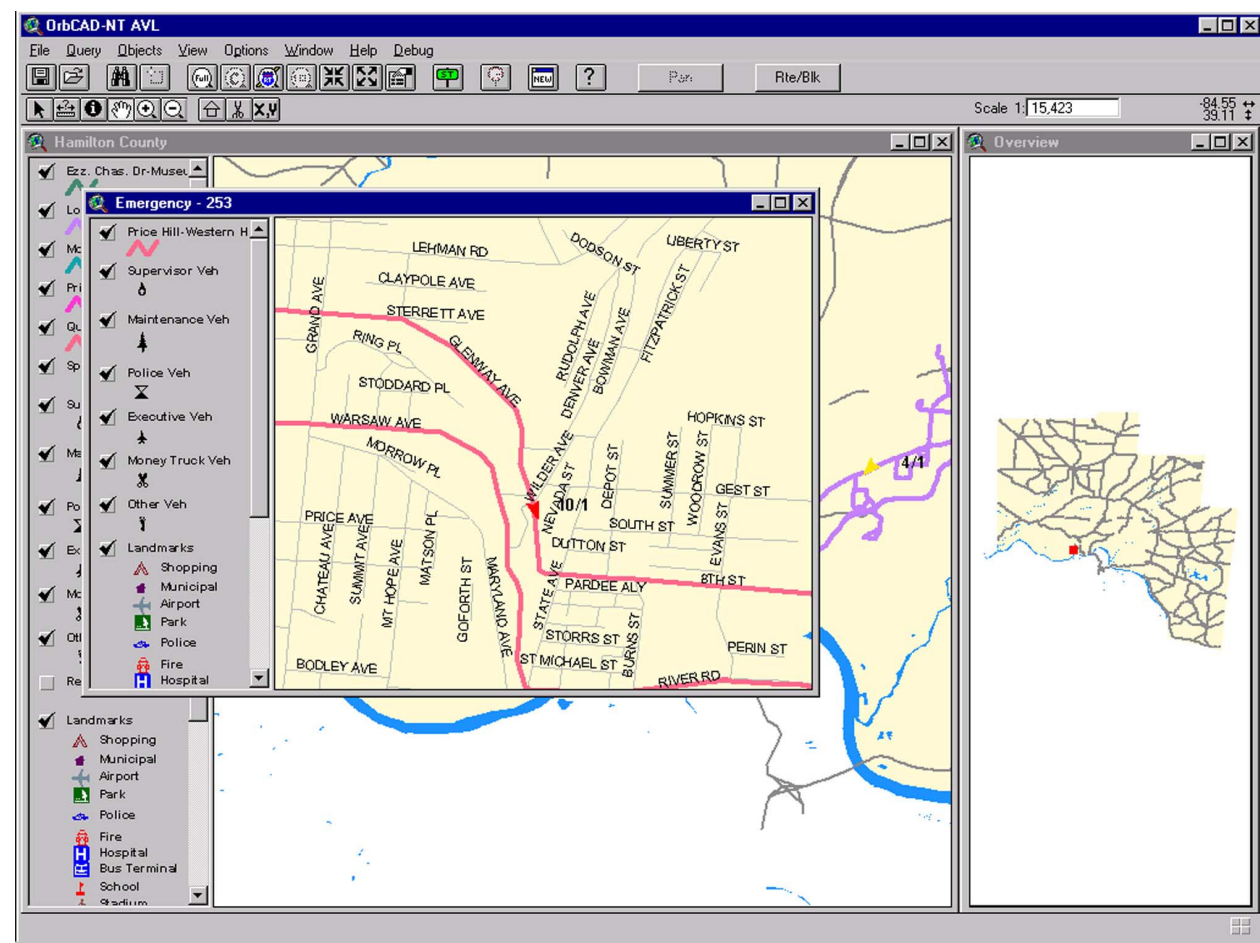

Picture 4 A CAD/AVL system can automatically track the location and heading of a bus whose operator has activated the emergency (covert) alarm. (Image provided by Orbital.) as "poor." The average effectiveness score is 3.0 or "good." Only four respondents chose to rate the relative expense of CAD/AVL. All four believe that CAD/AVL is "expensive." Strong interest in acquiring $\mathrm{CAD} / \mathrm{AVL}$ systems is indicated in the survey by 12 other respondents who report their agencies have budgeted CAD/AVL systems for implementation in the future, including 2 large, 7 medium, and 3 small systems.

The AVL component may not be available on all buses in every system; transit agencies typically conduct limited information system (GIS). An event history database can be a powerful tool used for future service planning, risk management, and resource allocation. For example, a GIS analysis of emergency event data obtained from the CAD/AVL system may produce a map indicating criminal activities concentrated in a particular area of the city or along a particular segment of a route. This map could be used to leverage supplemental police or security presence to address the crime problems. The monitored audio and video may also be recorded and stored for later access and analysis by security, law enforcement, operations, risk management, and legal staff, as necessary.

\section{Survey Findings}

Seven systems reported experience utilizing a CAD/AVL system, including four large and three medium transit agencies. Of these seven respondents, six rated the effectiveness of their CAD/AVL system as a security method as either "good" or "excellent." Only one respondent rated it operations tests before committing to full-scale implementation. Identified suppliers have included systems by Johnson Controls, Motorola, Orbital, Transtech, Siemens, and Westinghouse. Volatility in the transit supplier market, especially of newer emerging technology applications, however, yields a shorter list of suppliers today. Thus Westinghouse's system was acquired by Raytheon, which has since been acquired by Orbital. With other system acquisitions, Orbital appears to have penetrated the limited and young public transit market most extensively, boasting more than 40 projects, including a recently awarded contract, along with Motorola, for the Washington Metropolitan Area Transit Authority.

An early user of CAD/AVL in transit is Denver's Regional Transportation District (RTD). Initially installed by Westinghouse in 1994, the system was later maintained by Raytheon. According to its product literature, supplier Orbital, which finally took over upkeep from Raytheon, Denver RTD's 
CAD/AVL system was the "first large-scale implementation of CAD/AVL using GPS."11 The security of bus operators and passengers was considered among other potential benefits in the decision to implement CAD/AVL on all RTD buses. Initially the system included the benefit of a panic button and covert microphone. Later, this has facilitated the phased integration of onboard digital video surveillance.

A recent survey by the Volpe National Transportation Systems Center also documents transit agency interest in AVL systems. Of 154 transit agencies reporting AVL activities, 61 are operating, 25 are implementing, and 75 are planning. The primary service mode benefiting from AVL is fixed route service (127 systems) followed by demand response ( 75 systems). ${ }^{12}$
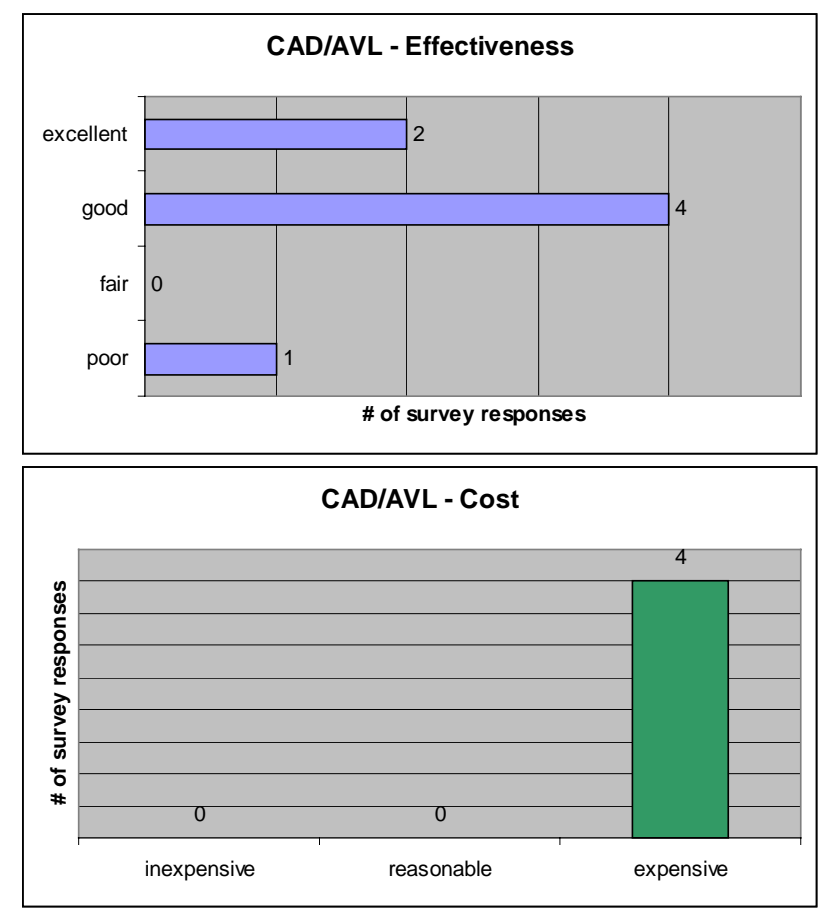


\section{ONBOARD VIDEO SURVEILLANCE}

Banks, the military, public offices, and even private interests have been using closed circuit video surveillance as an effective security method for decades. Video surveillance of passenger rail stations is a standard component of the system security plans for newer rail systems. The public transit industry has just recently begun to invest in video surveillance for monitoring onboard passenger activity, particularly along bus routes in rough service areas. This is made possible via advances in microelectronics and desktop computing due to increases in processing power, functionality, memory, miniaturization of components, and, very importantly, decreases in relative cost. Pioneers in the transit industry employed onboard closed circuit analog video tape recording systems. Based upon early favorable results, transit systems are now rushing to procure the newer digital systems that harness standard desktop computer data storage and processing techniques.

\section{System Configurations}

The onboard components include the cameras and a central processing unit (CPU). On older analog tape systems, the CPU is essentially a customized VCR (video cassette recorder) using standard VHS (video home system) tapes for storing recorded images. On the newer systems, the CPU resembles a compact standard PC (personal computer), without keyboard, mouse, and monitor, but loaded with processing software and a large removable hard drive to store the digital video. At scheduled intervals, when the hard drive is full, or when a recent onboard incident is reported or noted, either the data from the hard drive is downloaded to another device or the hard drive itself is easily replaced with a blank one.

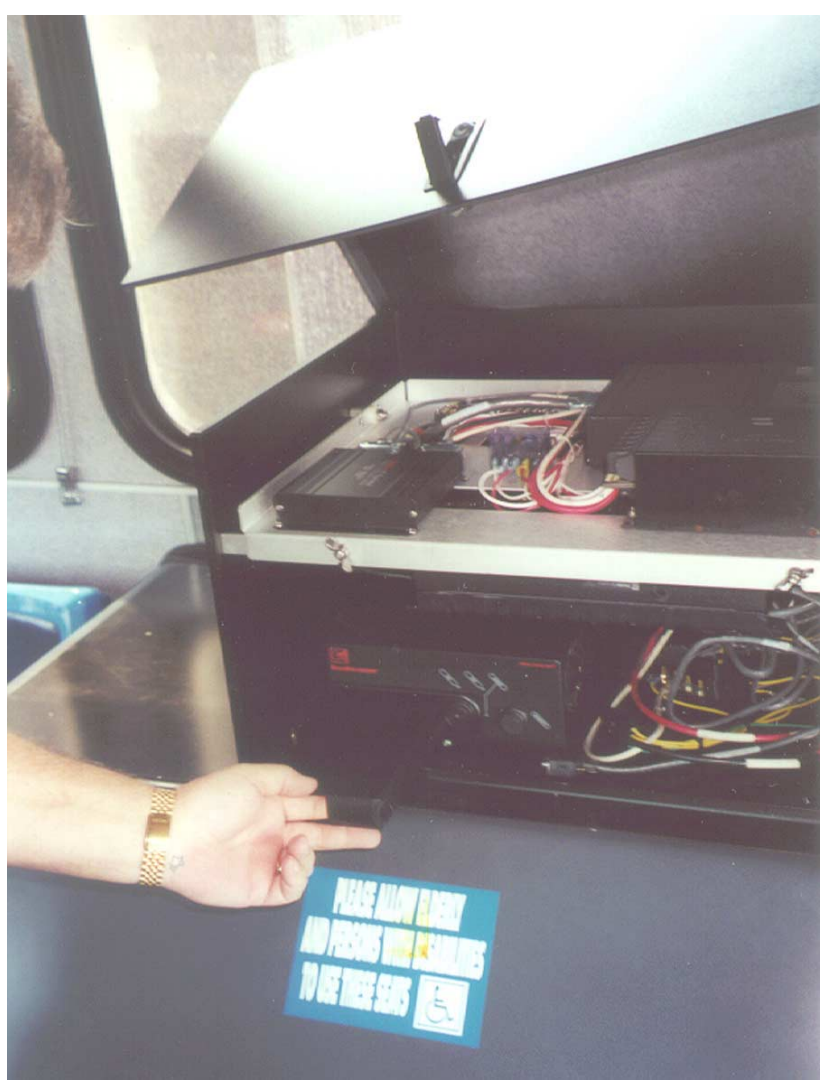

Picture 5 The onboard digital video surveillance system's CPU, including removable hard drive, is located in a secured locker above the front wheel well on this low floor bus at BCT.

On average, between three and four cameras are mounted inside a standard 40-foot transit bus, according to the survey respondents. Of 18 respondents, three agencies reported as few as two cameras per bus. Two properties reported using five cameras onboard 60-foot articulated buses. Onboard video surveillance systems for public transit buses typically support up to eight color and/or black-andwhite (cheaper) cameras.

Why the variation in the number of cameras? Primarily it's an issue of cost, as additional cameras can also impact data storage and maintenance requirements. The number of cameras a transit system chooses, however, also depends upon the relative importance of the various information benefits a surveillance system can provide a transit agency. For example, if deterring onboard crime and resolving fare disputes are the most important 
challenges for a particular transit system, two cameras may be sufficient-one mounted at the front of the bus and pointed back to capture a general view of the entire interior (see Picture 6), the other mounted above the operator's head and pointed at the farebox (see Picture 7). If a transit agency experiences significant loss due to vandalism, a third camera mounted in either the middle or back of the bus will provide greater detail of passenger activity. To reduce or minimize claims or lawsuits from accidents, cameras mounted in the back and directed at the rear door (see Picture 8) and one mounted in the front and pointed forward to the street outside the bus (see Picture 10) may be cost effective.

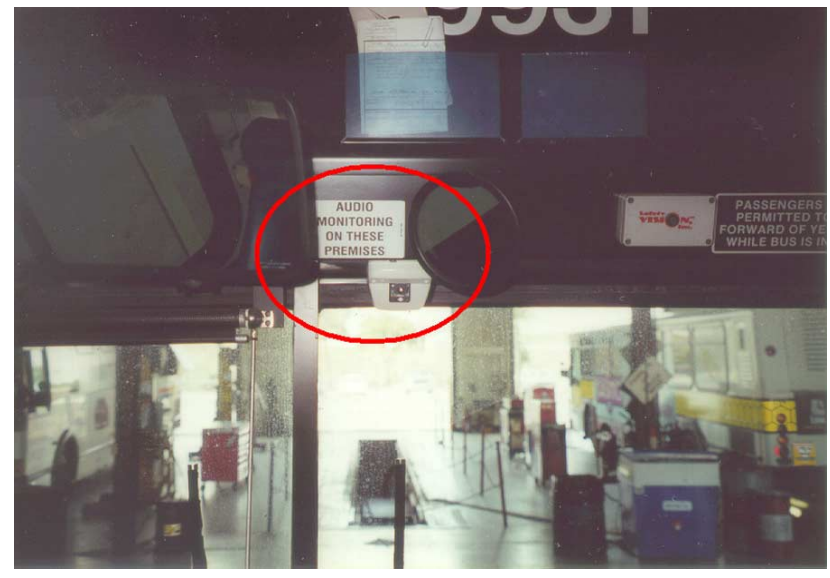

Picture 6 A camera mounted at the front of the bus provides a view of the entire interior.

A digital video surveillance system may be configured to automatically record images at a specified frame per second (fps) rate. According to a representative with supplier Kalatel, most customers record at $6 \mathrm{fps}$. However, a slower ratelike $2 \mathrm{fps}$-may be reasonable. Playing back stored sequential images recorded at slower fps rates will show very rough, "jerky" video, but for routine monitoring this may be acceptable given a transit system's particular needs. If the system is configured with a panic button activating covert video surveillance, or if a bus operator wishes to note a specific situation in more detail, the recording rate may be increased manually, to a pre-configured higher rate of, perhaps, up to $15 \mathrm{fps}$. Playback will display near real time motion video; however, the increased fps rate more quickly fills the hard drive storage. The particular situation onboard may or may not justify recording more detailed video. As prices for standard computer data storage consistently decrease over time, transit agencies employing digital video surveillance will less often face this trade-off between detailed video and available storage space.

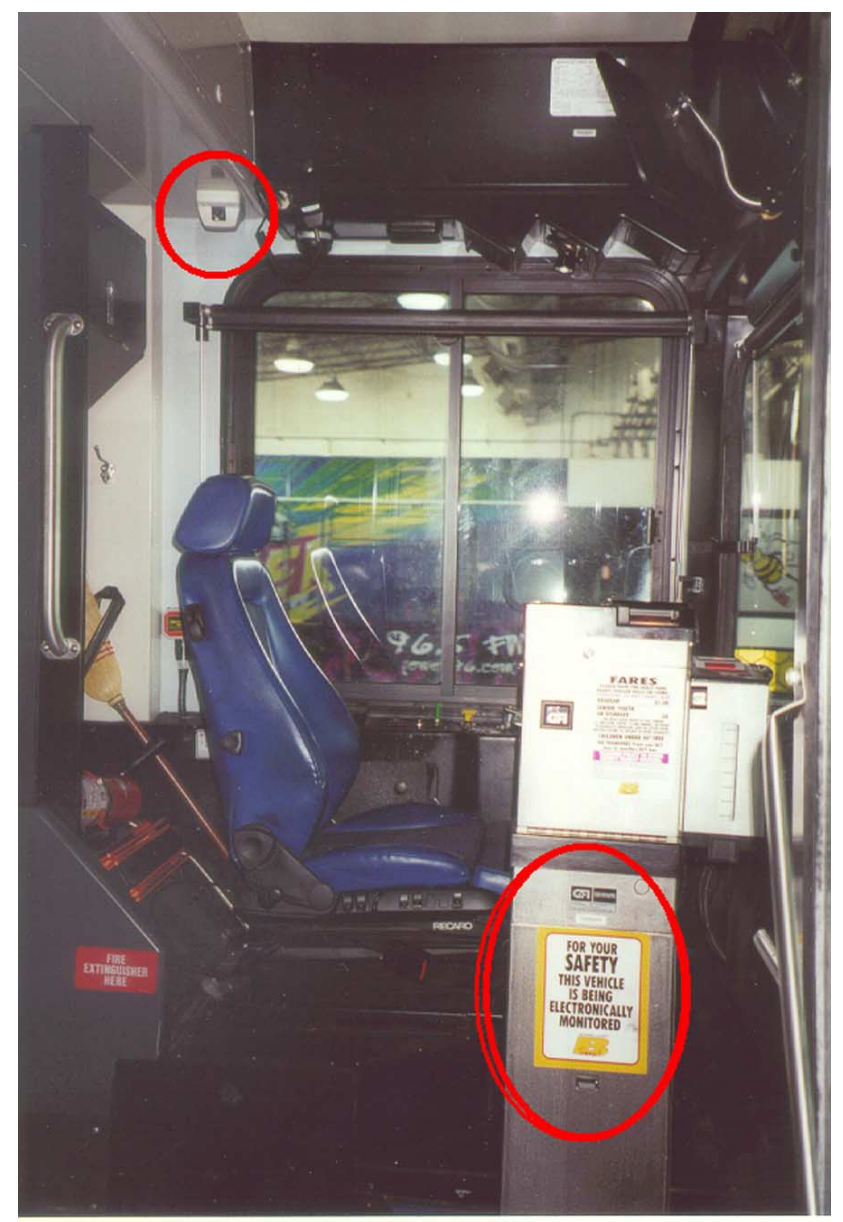

Picture 7 A camera mounted above the operator's seat provides a view of outside activity at a bus stop, boarding customers, and fare payment transactions. Note the sign on the farebox, advising customers they are being monitored.

Like CAD/AVL, onboard video surveillance promises many benefits previously unrealized to the transit industry. Again, video surveillance may function either independently or as a subcomponent of an integrated CAD/AVL system. As a security 
method, however, onboard video surveillance may be viewed as both an effective crime deterrent and a powerful tool towards capturing and prosecuting criminals.

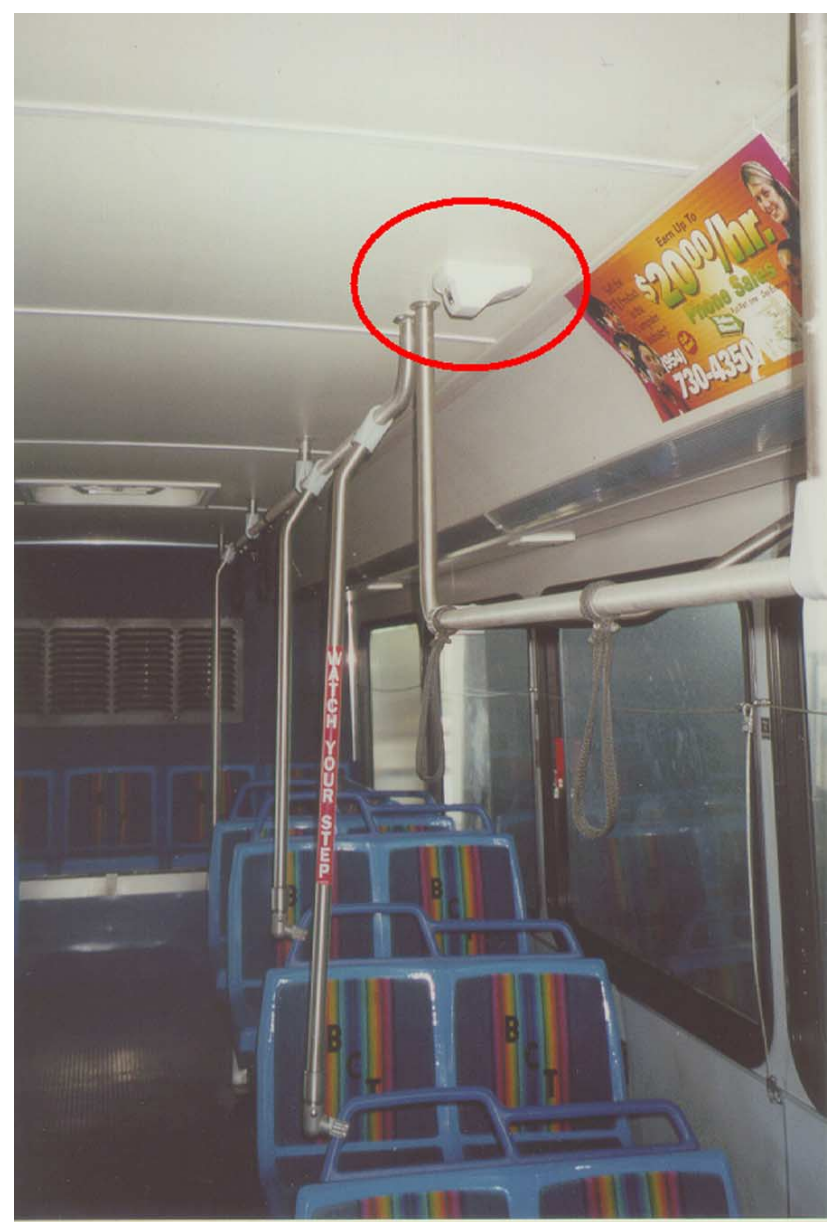

Picture 8 A camera pointed at the back door provides additional coverage of passenger activity.

It is important, for at least a couple of reasons, to post notifications onboard the bus, advising passengers that they "may" be monitored and recorded via video and audio surveillance systems (see Pictures 6, 7, and 9). First, naturally there are privacy concerns. Although the interior of a public transit bus implies a public space in which passengers choose to occupy, some may consider video surveillance unreasonably invasive. Most regular transit customers, however, would probably consider video surveillance for the purpose of security as reasonable and, in fact, welcomed, especially along routes in high crime areas.
Second, the warning signs themselves are powerful deterrents to onboard criminal activity. Whether video from security cameras of holdups at convenience stores shown on nightly television news or the popularity of the television program, "America's Most Wanted," the public, including criminals, understands that video evidence has become a key factor towards prosecuting criminals in many cases. In fact, transit customers who have been victimized by other passengers may expect to find evidence from onboard video.

Though it is tempting to include signage on all buses in the fleet, even those not equipped with video surveillance, this may not be wise. What happens when a customer is victimized onboard a bus not equipped with video surveillance, yet signs are posted stating the contrary? The customer may have the expectation that the transit agency would be able to produce critical evidence towards prosecuting the criminal. Transit agencies employing video surveillance should also seek legal advice from counsel knowledgeable in the laws of the particular state.

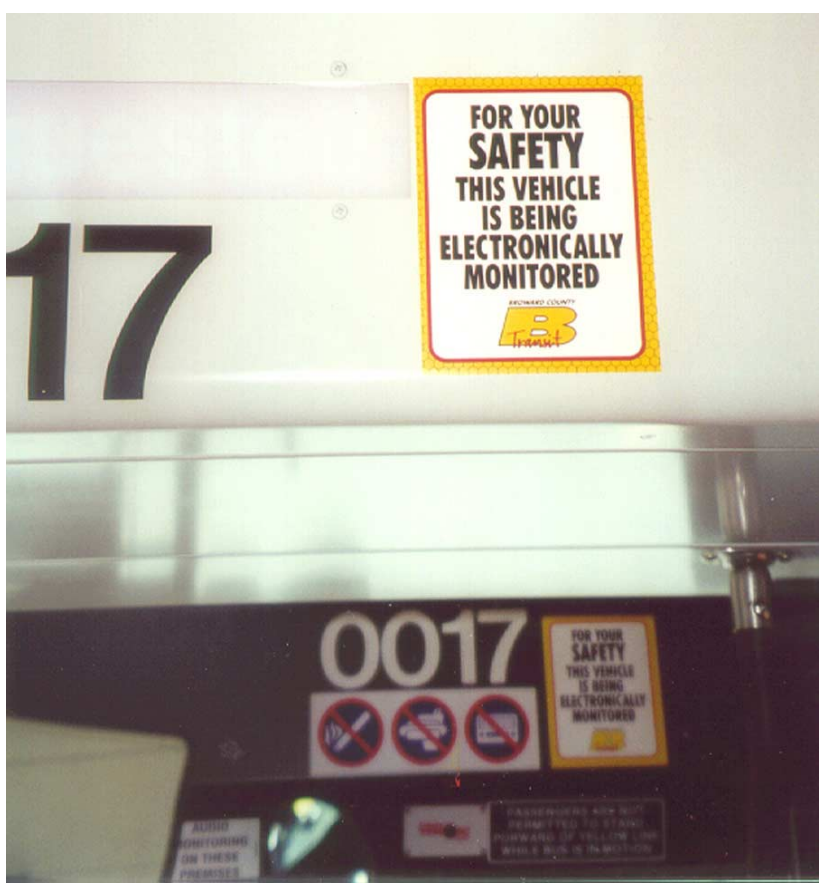

Picture 9 It is critical, for legal reasons, to inform customers of onboard surveillance. 


\section{Examples of Incidents}

None of the surveyed transit systems provided examples of potential threats or actual crimes captured by onboard video surveillance. User testimonials from one supplier, however, did include a 1998 letter from the Deputy Attorney General of Delaware who praised the use of video evidence to successfully prosecute a child sex offender. A paroled offender molested a young male onboard a bus operated by the Delaware Transit Corporation. The video surveillance system captured images recorded during the incident that were subsequently used by the Department of Justice to convict the man for this offense.
Other customer testimonials included a letter from an official with the Milwaukee County Transit System who related successful use of video images to identify high school students known to have assaulted bus operators and passengers and to assist police in their investigations of theft and vandalism incidents. SunLine Transit Agency (Thousand Palms, CA) reports successful use of video surveillance in resolving disputes between operators and customers and in reducing vandalism by supplying local police face shots of "taggers," i.e. gang members making their distinct marks on public property, including bus interiors. ${ }^{13}$

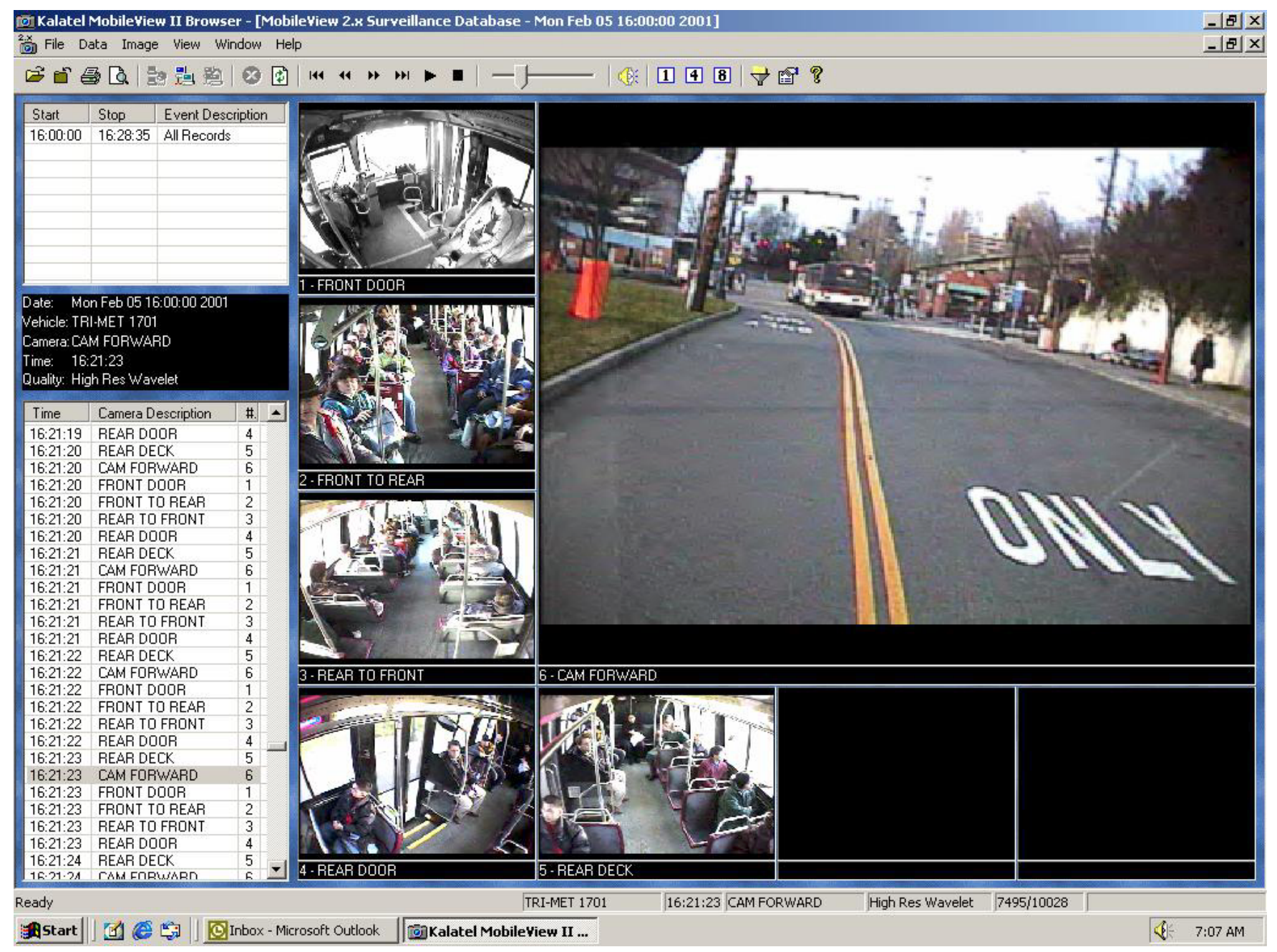

Picture 10 Additional cameras can provide greater coverage of onboard, and some exterior, activities. (Image courtesy Kalatel.) 
Prior to the use of onboard video surveillance, transit agencies had little recourse but to settle with individuals or groups who attributed their real or purported damages or injuries to the transit system's negligence. Today, video surveillance can be a powerful tool to fight unwarranted lawsuits brought forth by some devious individuals and their lawyers who anticipate extracting large sums of taxpayer monies from financially strapped public transit agencies. In one incident in Fort Lauderdale, a bus was rear ended at a slow speed and temporarily taken out of service. As the bus operator and supervisors inspected the bus outside, the onboard surveillance system recorded passengers conspiring to seek injury claims against the transit system. At one point in the recording, a woman is seen picking up a crying baby, dancing in the aisle, and singing, "We're in the money...we're in the money...." A security official with the transit system is convinced that the onboard cameras have saved the transit system (a unit of county government) hundreds of thousands of dollars in legal fees and settlement costs that would have been incurred fighting bogus lawsuits.

Onboard video surveillance systems provide obvious security benefits for both employee and patron and may be used to support bus operators in customer disputes. Still, some systems have encountered resistance from some operators, including acts of sabotage. These agencies may have policies or practices in place that ensure supervisors will not proactively or regularly scan recorded video searching for incidents in which bus operators violate company rules.

However, recorded video may also support customers' valid complaints against errant bus operators. In one Florida transit agency, a bus operator was caught on video in a compromising sexual situation with a female passenger inside a bus not in service. Apparently he didn't know that the onboard cameras continue to operate for a time after the ignition is shut off. The passenger complained to transit officials, the bus' surveillance tapes were reviewed, and the bus operator was subsequently fired.

Another transit agency in Florida has a policy that the onboard video surveillance system does not include a view of the bus operator while seated. This was agreed upon by management prior to implementation to allay the unionized bus operators' concerns for privacy and that the system would be used actively to find fault with their work and discipline them. However, if the bus operator leaves his/her seat, his/her movements are recorded the same as those of passengers.

Apparently a veteran operator either did not realize or remember this caveat as he left his seat to confront a passenger still onboard the bus at the end of the route. The bus operator instructed the passenger to alight the bus. When the passenger did not comply, the operator approached him. A verbal argument ensued and then the two exchanged blows. When the passenger still would not comply, the bus operator radioed dispatch for police back up. Upon arrival, the police listened to the bus operator's report, boarded the bus, and promptly arrested the unresponsive passenger.

However, the passenger insisted that the bus operator first assaulted him and he responded in selfdefense. The police did not take the word of the passenger, but instead believed the veteran bus operator. After three months of jail time, the public defender finally subpoenaed the video surveillance images that indicate the bus operator striking the passenger first. At last report, the public defender planned to use the video evidence to free the supposed "victim." Charges against both the bus operator and even the responding police officers, who were shown in the video potentially violating procedures, may be pending.

During a site visit to the same agency, a project staff person was shown video of a bus operator who 
demonstrated less than exemplary customer service. The operator was running behind schedule on the route's last run in the evening. At a stop a man boarded the bus and asked for route information. The operator ignored him as another man boarded and paid his fare. A seated passenger stood up and handed the inquiring man a schedule and map to consult. The man stood in the front doorway, using the bus' interior light to read the map. The bus operator complained that she was running late and had to leave. She attempted to close the door on him. A verbal argument ensued, further delaying the bus. The bus operator finally succeeded in getting the man off the bus and pulled away. The surveillance system captured the audio and video of the operator closing the door on this man while he was standing in the doorway trying to get route information from the map that another customer had provided because the operator ignored his request. This recorded incident would have made excellent training material, but the transit system's policy against actively using the system against bus operators prevented it.

\section{Survey Findings}

It seems that the newer applications of onboard technology support the notion that you get what you pay for. The few properties surveyed with $\mathrm{CAD} / \mathrm{AVL}$ thought it is effective but expensive. Similarly, respondents rating onboard video surveillance mostly feel it is either "good" or "excellent" (13 of 17 total respondents using video surveillance). The average effectiveness score is 3.2 , which is above "good."

Respondents are evenly split on the cost of video surveillance between "reasonable" and "expensive" (7 respondents each). The average cost score is, therefore, 2.5 or right in the middle of "expensive" and "reasonable."
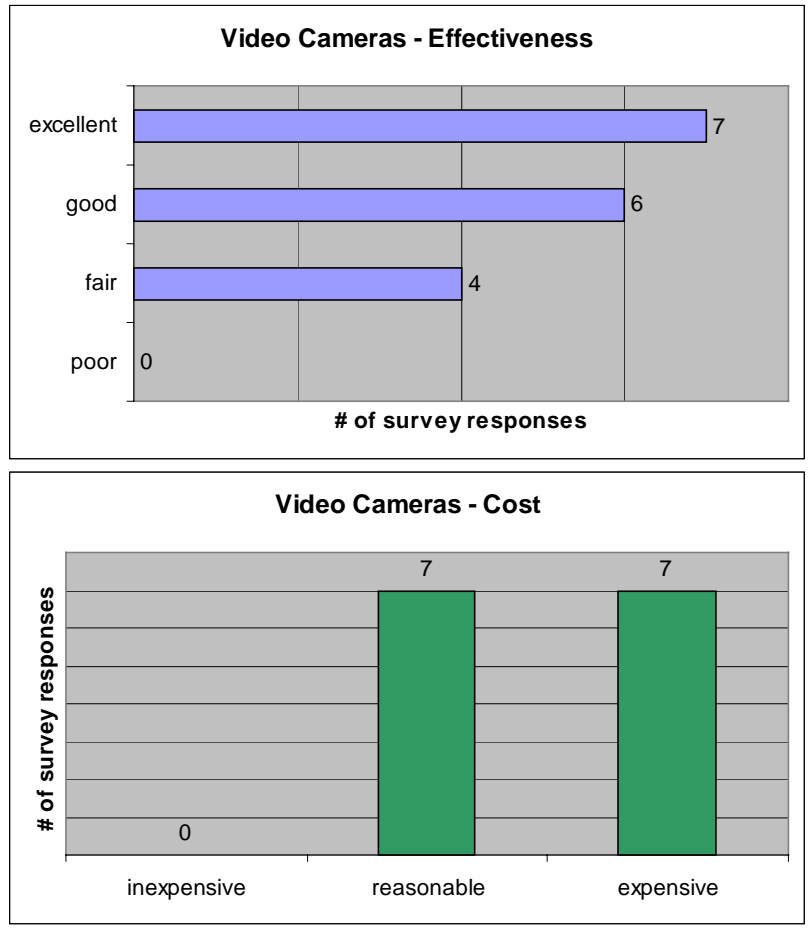


\section{POLICE \& SECURITY}

Despite the availability of technologies to deter crime and facilitate response, cameras and sensors cannot completely replace the need for warm bodies specially skilled and trained in providing security. Undoubtedly, the presence of security or police officers onboard transit buses reinforces operators' confidence in feeling secure from crime. They feel that someone with authority is looking out for them, allowing them to focus their attentions on safely operating the buses.

\section{Security Guards}

The Wackenhut Corporation of Palm Beach Gardens, Florida, provides contracted security for a number of transit systems in the U.S. According to a spokesperson, most transit clients utilize Wackenhut's elite security officers who: possess prior experience in law enforcement or are graduates of police training programs; include former members of military elite groups like the Marines, Delta Force, or Green Berets; have a two-year degree in criminal justice; and undergo a background investigation similar to sworn police. Most are armed and are assigned primarily to guard fixed facilities, like transit centers, rail stations, and parking lots. At least one client-Milwaukee County Transit System-however, utilizes uniformed Wackenhut officers for onboard bus patrols. As in many other transit systems, onboard patrols provide a visible presence of security on Milwaukee's public bus system.

The advantage of using contracted security staff over sworn police officers is primarily an issue of resource allocation. Most crime incidents onboard transit are misdemeanors, e.g. fare disputes, rowdy behavior, vandalism, eating or drinking, et. al. When confronted with an authority figure, these offenders usually either comply or leave. Contract security officers are fully trained and qualified to handle these situations. Furthermore, with citizens' powers of arrest, security officers can reasonably detain offenders until sworn police officers from the local jurisdiction arrive on scene to take over. Some states may even permit security officers to issue citations for violations of local ordinances.

The point is that, with a contracted security force dedicated to protecting the transit system, sworn police officers may be freed up for more serious crimes. This can provide significant savings for a transit system that pays for police service.

\section{Sworn Police Officers}

Just as there are a variety of ways the provision of public transit service is organized at the local level (e.g. by city, county, special district), arrangements for police protection of the transit system are similarly diverse. Depending upon the level of criminal activity the system experiences, a transit system may not regularly utilize police services. As a public service, the transit system may enjoy police coverage just as any other public facility or transportation network. For example, it is a given that any city will have police officers in cars patrolling public streets. Similarly, transit service may be viewed simply as another mode of transportation funded by the same taxpayers who also pay for and expect police protection. Therefore, police officers will protect the public's investment in transit service and facilities by enforcing public laws. A written Memorandum of Understanding may formalize this arrangement between law enforcement and transit management.

Public scrutiny of democratic government and certain political philosophies have resulted in tight budgets for nearly all public services, including law enforcement. As a result, some police departments have understandably resorted to incremental pricing of their service. That is, for each additional facility, region, event, or service police are called upon to provide protection, the labor and capital costs may be quantified. As transit service expands or as crime increases, transit agencies' needs for police services 
increase. Therefore, some transit agencies have contracts for service with law enforcement, which reimburse the police departments for their expenses incurred in providing protection. Police management has discretion over whether to form special transit police units or assign dedicated patrols to the transit system, usually based upon the transit system's needs and ability to pay.

Another option involves the transit agency contracting directly with off-duty police officers. For a growing system, this may provide the best solution in balancing needs and budgets. This option also provides flexibility for adding or reducing the numbers of police officers during the year, in contrast to an annual contract for a fixed quantity of service and officers. The Fort Worth Transportation Authority (the T) hires off-duty police officers for undercover onboard patrols.

\section{Transit Police Departments}

For greatest control over allocating law enforcement resources, a transit agency may have state authority to possess its own police force in-house. Transit police departments are primarily found in the largest metro areas where transit agencies provide extensive multi-modal services over broad geographic areas that typically encompass multiple political jurisdictions. Examples include Baltimore, Boston, Dallas, Houston, New York, Pittsburgh, and Washington. According to data from the American Public Transportation Association (APTA), there are 20 bus transit systems with their own police force in the U.S. The key to an effective transit police department is a good coordinating relationship with existing local city and county police departments.

For example, the DART Transit Police Department in Dallas hired its first officer in 1988. Now, there are over 160 officers patrolling buses, commuter rail, high occupancy vehicle (HOV) lanes, light rail, and transit centers, including the downtown transitway mall. DART Transit Police has an interlocal agreement with the Dallas County
Sheriff's Department that permits transit police direct access to county facilities for jailing prisoners seized on the DART system. Otherwise, transit police would be dependent upon county officers for transporting and processing prisoners following transfer from transit police custody.

DART relies on its transit police's Bus Patrol unit to secure the bus system. A number of plainclothes officers are assigned to ride DART buses along routes that may experience criminal activity. The onboard officers are supported by officers in patrol cars who can quickly respond with back up assistance as needed.

\section{Onboard Police Patrols}

Through a Memorandum of Understanding with the Muni, the San Francisco Police Department (SFPD) has implemented a "Bus Inspection Program" (BIP) to provide a visible police presence onboard Muni buses. The BIP stands apart from the 28 officers assigned to a special operations unit to address transit needs. Regular patrol officers in each of the city's police districts are responsible for inspecting Muni buses along routes within the district. The inspection simply involves boarding the bus, checking to see whether any problems or threats exist, talking with the operator, and getting the operator's signature on a report form for proof of the officer's inspection. The SFPD officer may choose to ride the bus for a portion of the route; either his partner rides along or meets him in the patrol car further along the route. Each patrol car team is expected to make two inspections per shift.

A similar program, named "Police-on-Board," began in 1996 in New Jersey. Agreements between the New Jersey Transit Corporation and nearly a dozen area police departments and sheriff's offices have resulted in a highly visible presence of law enforcement on NJ Transit buses. Regular patrol officers randomly board NJ Transit buses, note any problems, and receive comments from customers and operators. These random patrols supplement 
efforts by NJ Transit Police officers. As part of the initiative, NJ Transit buses feature special decals which warn would-be criminals that either uniformed or plainclothes police may board and ride the bus at any time. The result is a greater sense of security by both passengers and operators at little or no additional cost to the transit agency or police departments.

With the noted exception of Milwaukee, most onboard bus patrols are conducted by sworn police officers, rather than by contracted security personnel. Also, besides ride checks by uniformed officers like in San Francisco and New Jersey, many systems utilize plainclothes police onboard transit vehicles to target specific problems. For example, in response to customer complaints or operator reports, transit police may assign plainclothes officers to ride buses along particular routes or in particular areas. They may be looking for drug usage or dealing by criminals who feel the interior of a bus provides a haven out of view from law enforcement. Plainclothes patrols may be effective in breaking drug rings, arresting criminals consistently engaged in illegal activities, or generally deterring crime onboard. It is important to publicize both the efforts (e.g. the notification decals on NJ Transit buses) and the results. Security officials with the transit system in Phoenix work closely with the media and local high schools to advertise the activities of undercover police. Whenever arrests are made, these are also publicized to prove their effectiveness and to deter future incidents.

\section{Free Rides for Police}

Another relatively inexpensive method of increasing police presence onboard transit buses is to offer free rides. Whether on duty or off, by policy or law sworn police are generally expected to respond as law enforcement officials when they witness criminal acts. Getting police to use transit outside of regular patrols-e.g. for daily commutes and other trips-can only serve to increase onboard security.

\section{Survey Results}

The questionnaire for this synthesis report included the question,

\section{"Do you allow uniformed police to ride the} bus for free?”

Surprisingly, not every transit system offers free rides for police who are not part of an onboard patrol. Of the 31 agencies responding, 25 (80.6\%) acknowledge providing free rides for police officers. Either uniformed officers or off duty officers with identification may take advantage of the free transportation. Two surveyed systems-Phoenix and Washington-provide special fare cards that allow the transit system to track the frequency of police boardings.

Admittedly, the survey questions regarding the effectiveness and cost of security and police were poorly formatted, confusing, and thus yielded uneven responses. The survey requested evaluations of multiple combinations of both security and police-contracted, in-house, uniformed, and plainclothes. Some systems provided evaluations of security or police that they did not employ. This was discovered in follow-up phone calls. The data were corrected to the extent possible; the reader is cautioned in drawing conclusive results to apply in their own operations.

In general, both security and sworn police were rated either "good" or "excellent" in effectiveness. There were few "fair" and only one "poor" ratings. Having either security or police personnel in-house may be viewed as more effective than contracted staff. 
For the four systems with in-house security, they rated their effectiveness as mostly "excellent" with an average score of 3.8. This contrasts with an average effectiveness score of only 2.7 for contracted security. In-house security was also perceived as less expensive with an average cost score of 2.0 versus 2.3 for contracted security.

The seven respondents with in-house police were split between "excellent" and "good" in perceived effectiveness ratings; the average score is 3.4. Contracted police rated similar in effectiveness at 3.3, much higher than contracted security at 2.7. Costs for both in-house and contract police were perceived similarly close, with an average score of 2.2 for in-house police being slightly lower than 2.3 for contract police (just above "reasonable").

Interestingly, whether security staffs are uniformed or plainclothes has little impact on their perceived effectiveness, rated "good" (average score of 3.0) for both. Sworn police were rated significantly higher, however, in both uniformed (3.3) and plainclothes (3.6) forms. In fact, sworn police were consistently rated higher than security staffs.
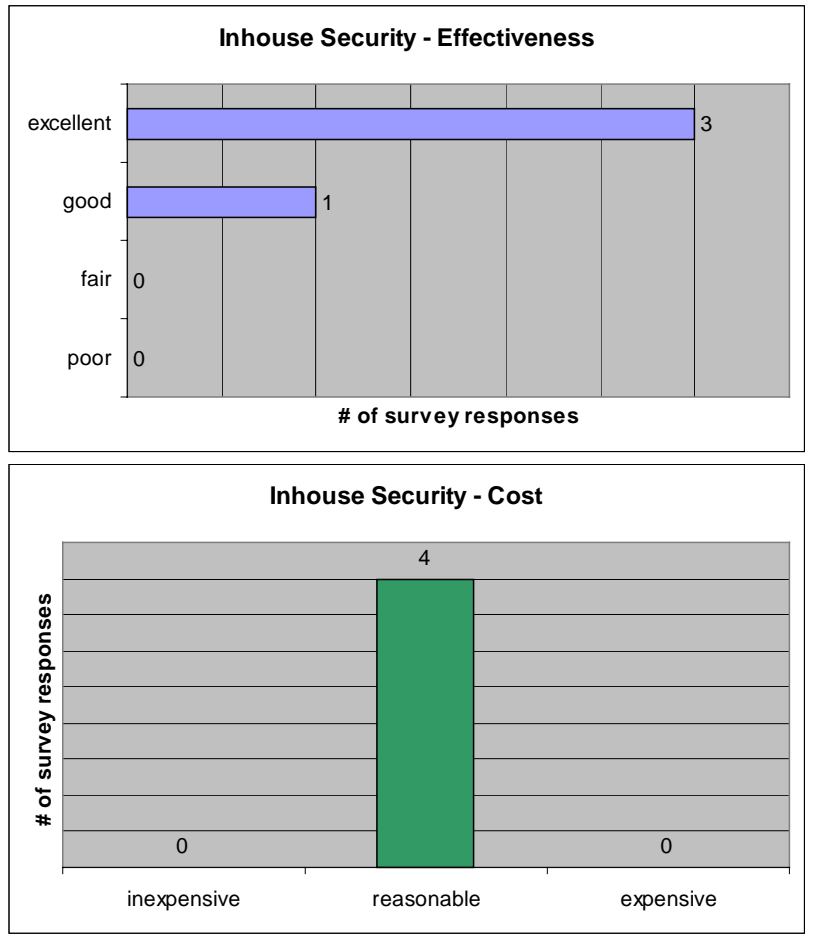
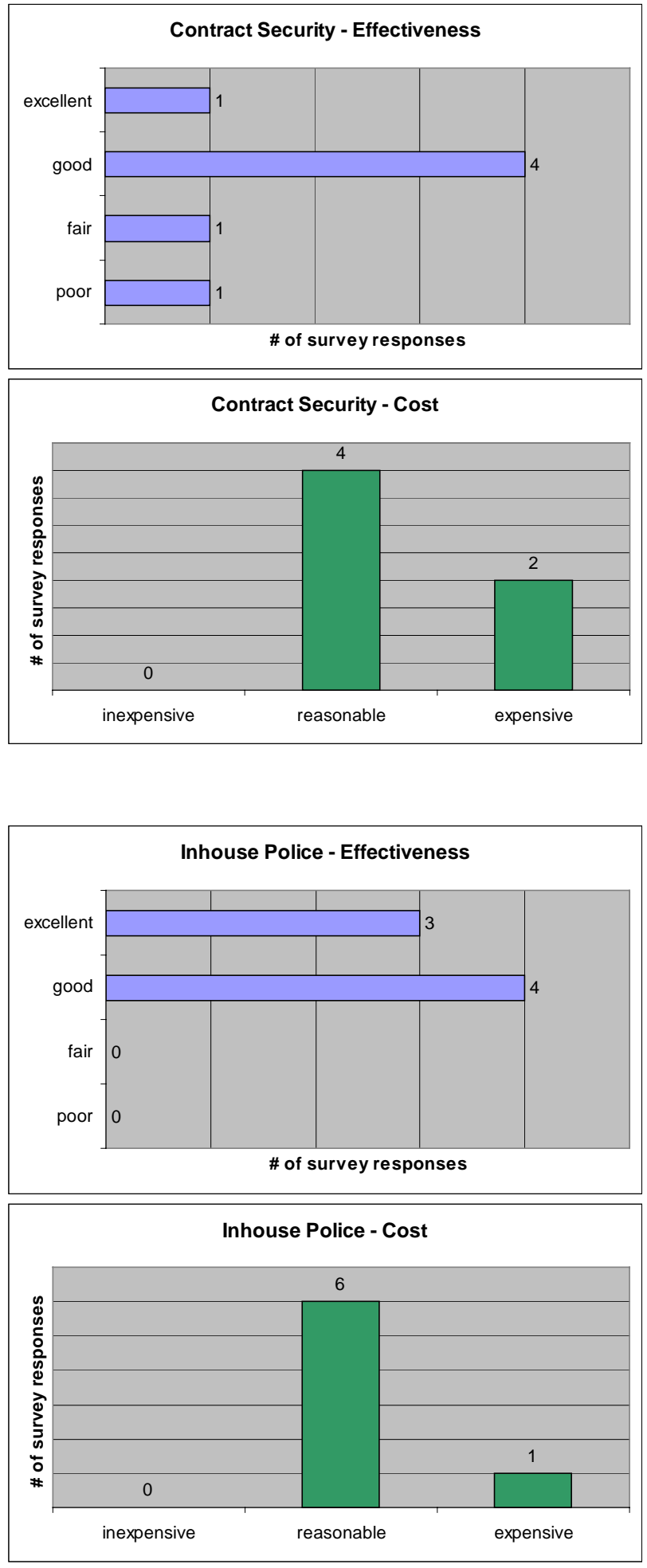

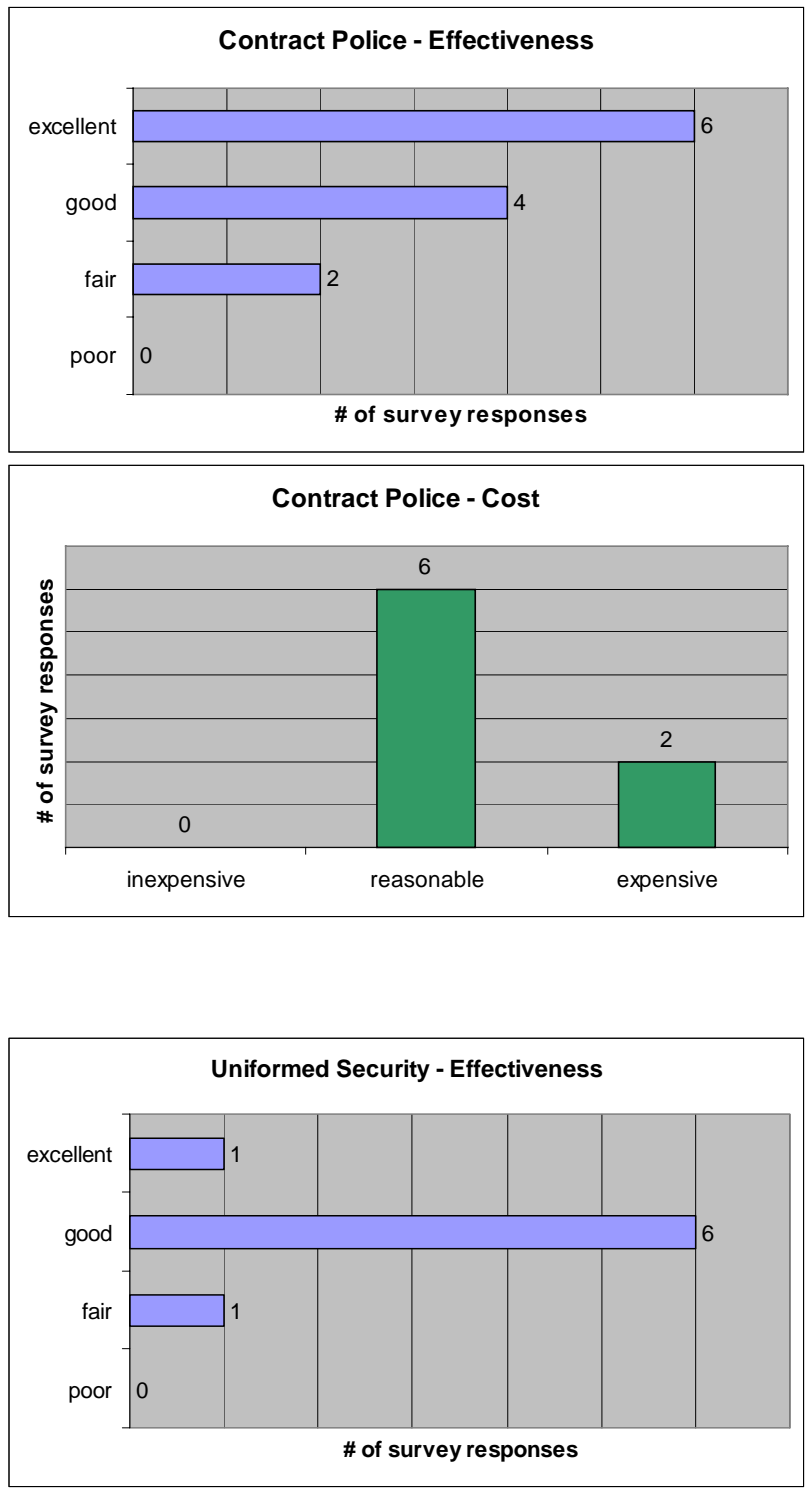
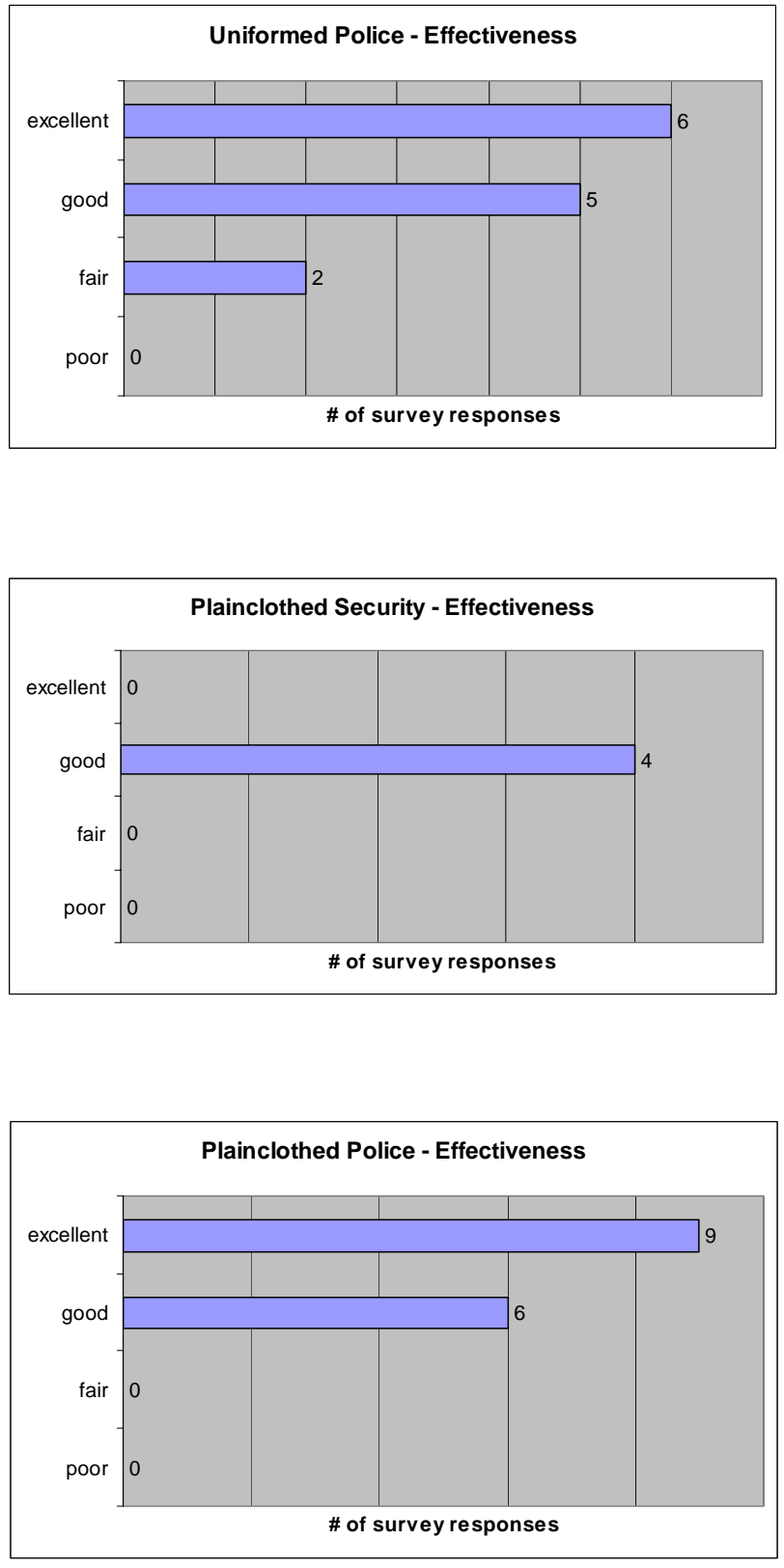


\section{OPERATOR TRAINING \& UNIFORMS}

Bus operators undergo extensive training prior to having full responsibility for operating a public transit bus alone on the streets. For example, trainees at Broward County Transit-Florida's second largest transit system-undergo eight weeks of classroom and field training before they qualify to operate a transit bus. Topics typically include bus maneuvers, defensive driving, operating onboard equipment, and customer relations. Periodic refresher courses reinforce learned skills as well as agency policies and procedures. Training programs have been developed in-house at some transit agencies. Others purchase outside materials or manpower resources. Depending upon the experience and needs of the particular transit agency, the topic of onboard security may have limited coverage or it may get significant attention in a dedicated training module.

\section{Violence Prevention Training}

Until recently, the standard mantra of the transit industry to bus operators regarding their personal security has been to avoid incidents at all costs. Operators are explicitly told not to do anything to encourage or increase the threat of violence, for the security of both themselves and passengers alike. Security training for bus operators, thus, has reflected this philosophy. Phrases like anger or conflict management, violence prevention, conflict resolution, verbal judo, tension de-escalation, and risk reduction all invoke techniques designed to minimize the risk of violence before it actually occurs.

Customers, Conflicts and You: A Transit Operator's Guide to Problem-Solving is a recently available training program that has received much attention. Developed under the sponsorship of the Transportation Research Board's Transit IDEA program, the program is unique in that it features the use of interactive CD-ROM technology to supplement guided instructor training. The program reinforces the transit industry's traditional focus on violence prevention. Ms. Debi Horen, formerly with San Francisco's Muni, developed the program based upon experience from seven participating transit agencies and the recommendations of professionals from transit, law enforcement, and mental and public health. The program underwent testing at more than 30 transit agencies and is now available through the National Transit Institute (NTI) for about \$200.

\section{Self-Defense Training}

Another philosophy in bus operator security training has gained momentum in recent years. Proponents of providing physical self-defense training to bus operators emphasize they are not abandoning the transit industry's code of violence avoidance. Rather, they feel that, given increasing incidents of violence in the workplace, it is sound policy to provide bus operators with knowledge of basic body moves or positions to defend themselves in situations in which they are obvious targets of assault.

Pierce Transit, in Tacoma, Washington, has provided such training since 1990. Designed by local law enforcement official Jesus Villahermosa, the training teaches operators how to defend themselves from assaults while seated. In fact, remaining seated is proposed as the best strategy because the source of an attack is isolated from one position only; standing up increases both the head's vulnerability to injury and the likelihood of losing balance; the panic button, radio, and other equipment resources remain within reach when seated; and greater resisting force comes from kicking while remaining in the seated position. In the event of an assault, operators are trained to respond with a number of techniques, including: loud shouts to disorient the attacker; defensive postures, blocking the attacker's strikes to the face/head with hands and forearms; upper body offensive strikes using fists, forearms, elbows, and 
the heels of palms; lower body offensive strikes using the feet to kick the attacker's knees, scraping his shins, and stomping on his toes; and powerful spin and kick moves—all from the operator's seat.

The training is receiving greater national exposure through training programs offered by NTI. One of this report's authors witnessed the techniques at the Southwest Transit Association's 21 ${ }^{\text {st }}$ Annual Conference \& Expo in January 2001. The same presentation was to be offered at NTI's "Transit Trainers Workshop 2001" in April. Pierce Transit's Safety and Training staff, including manager Steven Nunan ${ }^{\bullet}$, made the presentations.

Critics, however, believe that instructing bus operators in physical self-defense techniques may encourage them to become more aggressive when confronting potential threats. This could expose the transit agency to greater liability from individuals who may suffer injuries as a result of an operator using self-defense techniques he learned in mandatory agency-sponsored training. Pierce Transit responds that any such training must reinforce an agency policy that narrowly defines when use of the self-defense techniques is appropriate. A spokesperson for Pierce Transit also asserts that their required training program actually limits agency liability from operators who would otherwise react without training and potentially cause greater harm. ${ }^{14}$ In a decade of providing the training, Pierce Transit investigated 16 instances in which operators used the training and found their use warranted and in compliance with the agency's established "use of force" policy.

In follow-up phone calls to respondents of some transit agencies that do not provide self-defense training, uneasiness with the idea was apparent in their comments. On the one hand, the respondents were sympathetic to the challenges operators face

\footnotetext{
- Mr. Nunan has since accepted the position of Director of Training at the Chicago Transit Authority.
}

daily in their urban environments. On the other hand, they doubted the effectiveness of self-defense training in ending violence; rather, they felt its use would simply escalate it, resulting in greater injury or death. The experience of one system in Tacoma, however, may mitigate these fears. As the word gets out, self-defense training may become more common as an additional optional component of an overall security strategy.

\section{Survey Findings}

Survey respondents were more likely to provide traditional violence prevention training (20 responses) over self-defense training (4 responses). Of the respondents who reported providing violence prevention training, 15 of 20 rated its effectiveness as a security method as either "good" or "excellent" (average effectiveness score is 2.9). Most believe the cost of violence prevention training is inexpensive (11 responses) or reasonable (6 responses); none rated the cost as expensive. The average cost score is a low 1.4 .

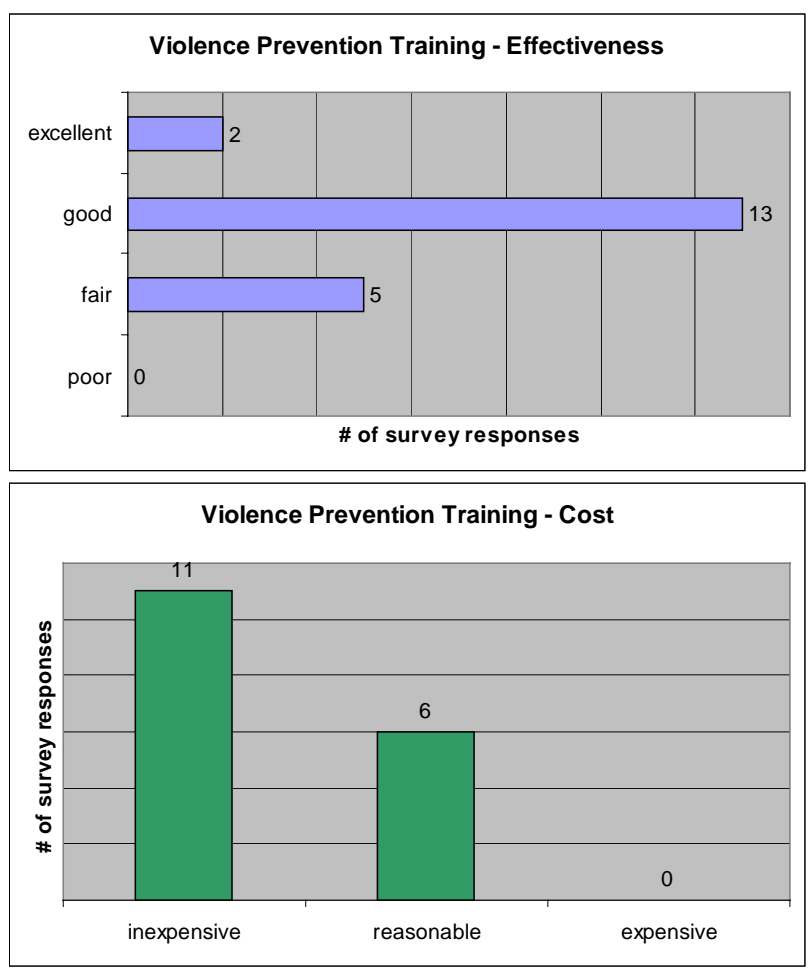


Regarding self-defense training, the few responses received were positive. Two rated its effectiveness as "fair," one each as "good" and "excellent," yielding an average effectiveness score of 2.8. All four believe the cost of providing self-defense training is "reasonable" (average score is 2.0).

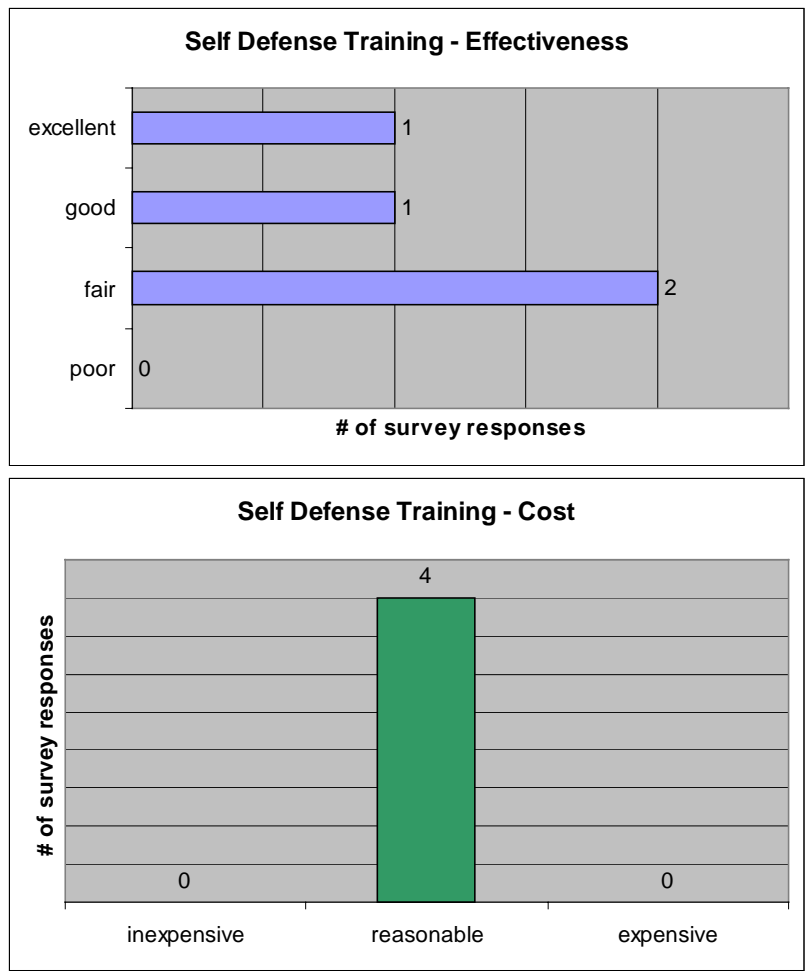

\section{A Few Words About Uniforms}

The late Jackie Gleason portrayed one of the more enduring, though not necessarily endearing, images of a public transit bus operator on the 1950s television show "The Honeymooners." Ralph Kramden operated a bus for Gotham City Transit. Unlike another fictional character in a large east coast metropolis, Kramden could not be described as "mild-mannered" in either his personal or professional life. For many Americans who have never set foot on a transit bus, they may view bus operators as strict and authoritarian. Indeed, the traditional uniform of a bus operator as worn by Ralph Kramden consisted of a tie, jacket, and a hat with a badge. The image evokes power and authority, similar to the uniform of a police officer.
In recent years, some transit agencies have followed trends in corporate workplaces and have implemented more casual dress for their operators. Instead of long sleeve shirts, ties, and pants with military-style stripes running along the legs, boarding customers may encounter bus operators in colorful polo shirts and khakis, especially in warmer climates and newer, younger systems in the South. Some examples may be found in Orlando, Tampa, Fort Lauderdale, and Lubbock.

The advantages vary, depending upon differing perspectives. Operators may prefer casual uniforms because they may feel more comfortable on the job or if they are less expensive than traditional ones. Transit management may wish to present bus operators to the public who are more approachable and friendly. In any case, marketing specialists remind us that image is very important in how various public stakeholders perceive the transit service and vehicle operators are necessarily a significant component of a system's overall image.

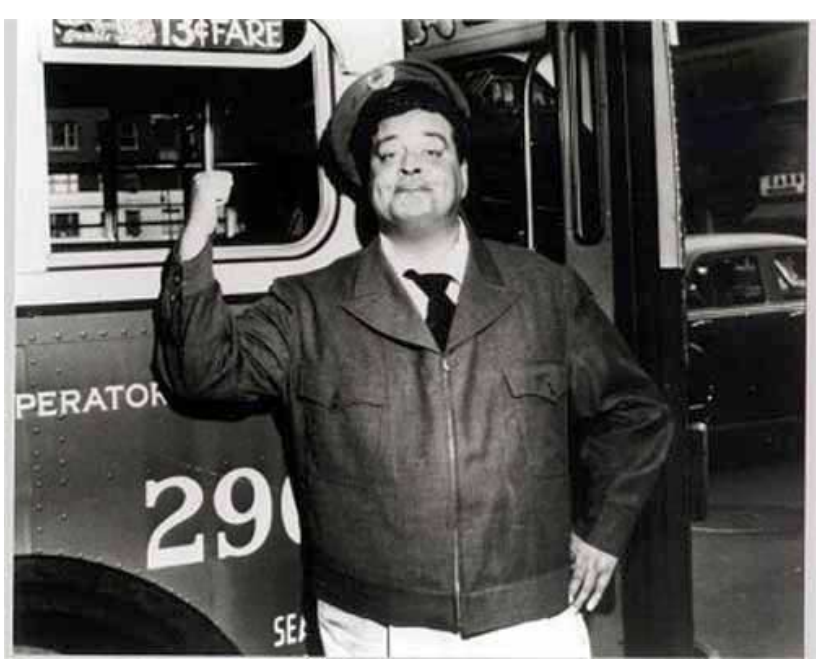

Picture 11 Does Ralph Kramden's uniform give him authority?

All of these reasons factored into the decision by Lynx (Orlando) to switch from traditional to casual uniforms in the early 1990s. Additionally, Lynx staff cited the importance of keeping their bus operators from being viewed by customers as having punitive authority. This is believed to actually 
minimize the threat of violence to bus operators from undisciplined youth and others who display little respect for authority figures. The idea is not to force a bus operator into the role of authority because he will be perceived as a target for resistance. This falls in line with traditional teaching in the transit industry for the bus operator to avoid conflict at all costs. Fare disputes within the context of an increasingly violent and armed society should not result in injuries or deaths.

Lynx reports that there was initial opposition to casual uniforms from veteran operators. They either did not feel comfortable in the uniforms or they wanted to retain the image of authority the more formal uniforms conveyed. However, in central Florida's tourism economy and favorable climate, the colorful and attractive polo shirts soon won them over.

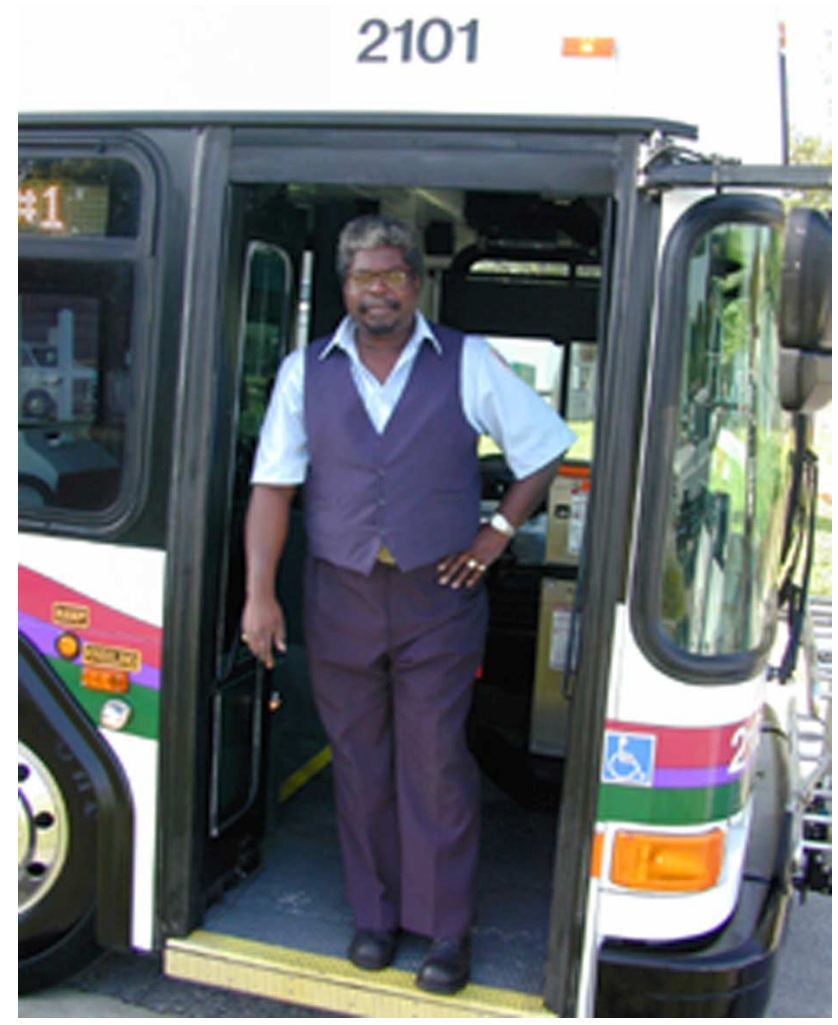

Picture 12 A more traditional uniform is one option for bus operators at HARTline in Tampa.

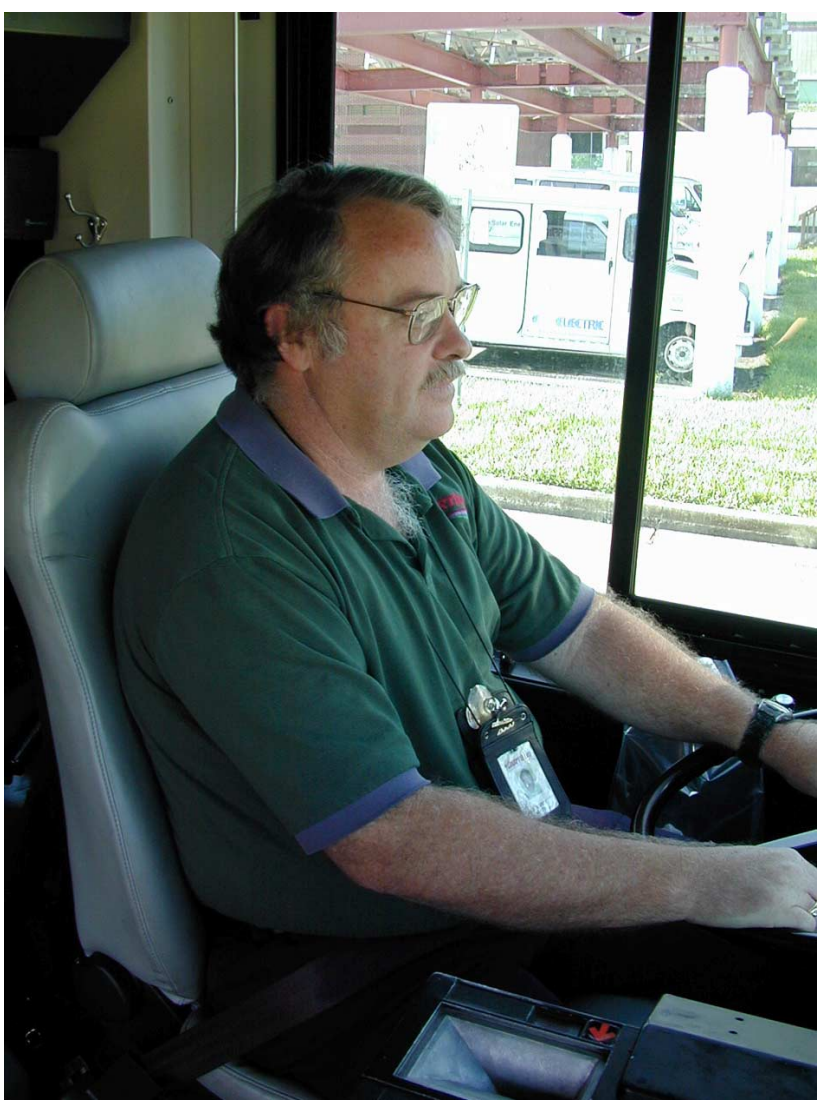

Picture 13 Another uniform option at HARTline. A number of transit systems are switching to more casual, and colorful, uniforms for the comfort of bus operators, as well as to promote a more customer friendly appearance.

No studies or evidence were found in the literature review that specifically supports casual uniforms for bus operators as a technique in violence prevention. Some survey respondents cited local marketing surveys that suggests customers prefer casual over formal operator uniforms. Well-designed and attractive uniforms could also be viewed positively in relation to crime prevention through environmental design (CPTED) principles (refer to “CPTED \& Security Audits”). 


\section{CAB ENCLOSURES}

In the most striking example of keeping bus operators secure from crime, two transit systemsMiami-Dade Transit (MDT) and San Francisco Municipal Railway (Muni) - have begun to outfit buses with partial enclosures around the bus operator workstation. The enclosure is actually a door hinged from the fixed modesty panel behind the operator. The lower portion is metal and extends up from the floor to about the height of the operator's seat. From that point and up the door is Plexiglas and is angled back towards the top of the modesty panel. The design for MDT buses does not actually result in a full enclosure of the workstation; rather, the door extends forward to a lower vertical support bar adjacent to the farebox. The space over the farebox, between the Plexiglas panel and the front windshield, is open.

The supplier for MDT's buses with the enclosures is North American Bus Industries (NABI). In the mid 1990s, MDT officials visited NABI's body fabrications facilities in Budapest, Hungary. NABI also arranged for tours of the local transit agency, BKV. It was onboard BKV buses that the MDT officials discovered fully enclosed bus operator work areas. Mindful of assaults on operators in Miami, MDT management pursued a similar design modification for its bus orders with NABI. Since 1997 all new low-floor buses MDT receives from NABI feature the enclosures. Early designs tested at MDT had larger Plexiglas panels extending to the ceiling; they have since been cut back to facilitate transfer distribution from the operator to customer.

According to NABI, Miami is the only site among its American clients where buses feature the enclosures. Each add-on enclosure costs approximately $\$ 1,800$ to $\$ 2,000$ per bus including installation. A third-party supplier in Hungary manufactures the enclosure/door and includes it as a component with the body for assembly in NABI's U.S. headquarters in Alabama.

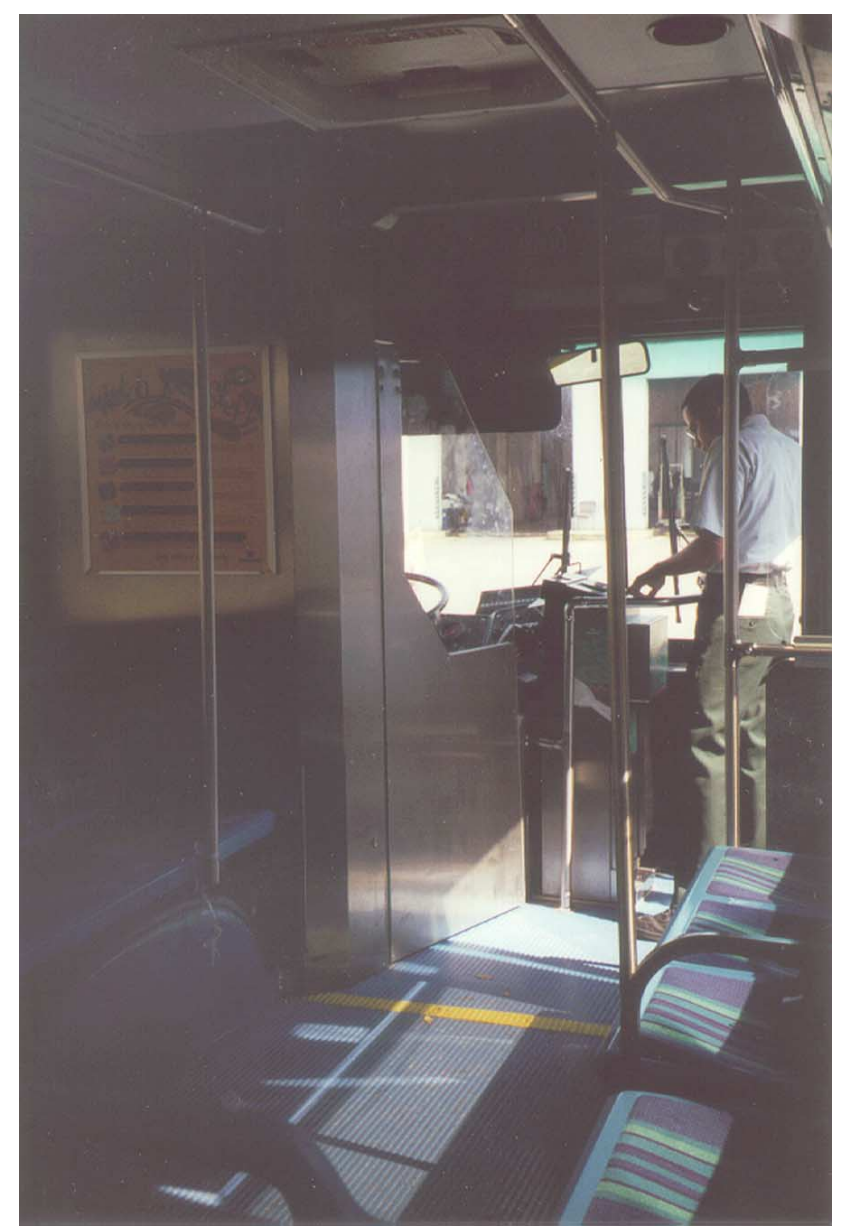

Picture 14 The door and Plexiglas panel increasingly seen on MDT buses.

Similar enclosures may now also be seen on some newer buses in San Francisco. Muni has an order with Neoplan for 235 buses that include the enclosure, including both 40-foot standard and 60foot articulated. Because these buses from Neoplan are all high-floor, the enclosure necessarily varies from those on MDT low-floor buses supplied by NABI. Also, Muni's version is more fully enclosed than MDT's. To date, Muni has received more than 160 of the new buses from Neoplan and has begun to introduce them into revenue service.

A spokesperson for Muni has indicated the push for the enclosures came equally from two sources-the bus operators' union as well as management. Muni bus operators have been the victims of increasing assaults in recent years, many relatively minor but some serious. Due to these assaults, Muni, which is 
a department of the municipal government of San Francisco, has paid in excess of $\$ 10$ million in workers' compensation claims and lost productivity. Thus, the enclosures are viewed as a cost-effective method of protecting bus operators and reducing costs to the transit system.

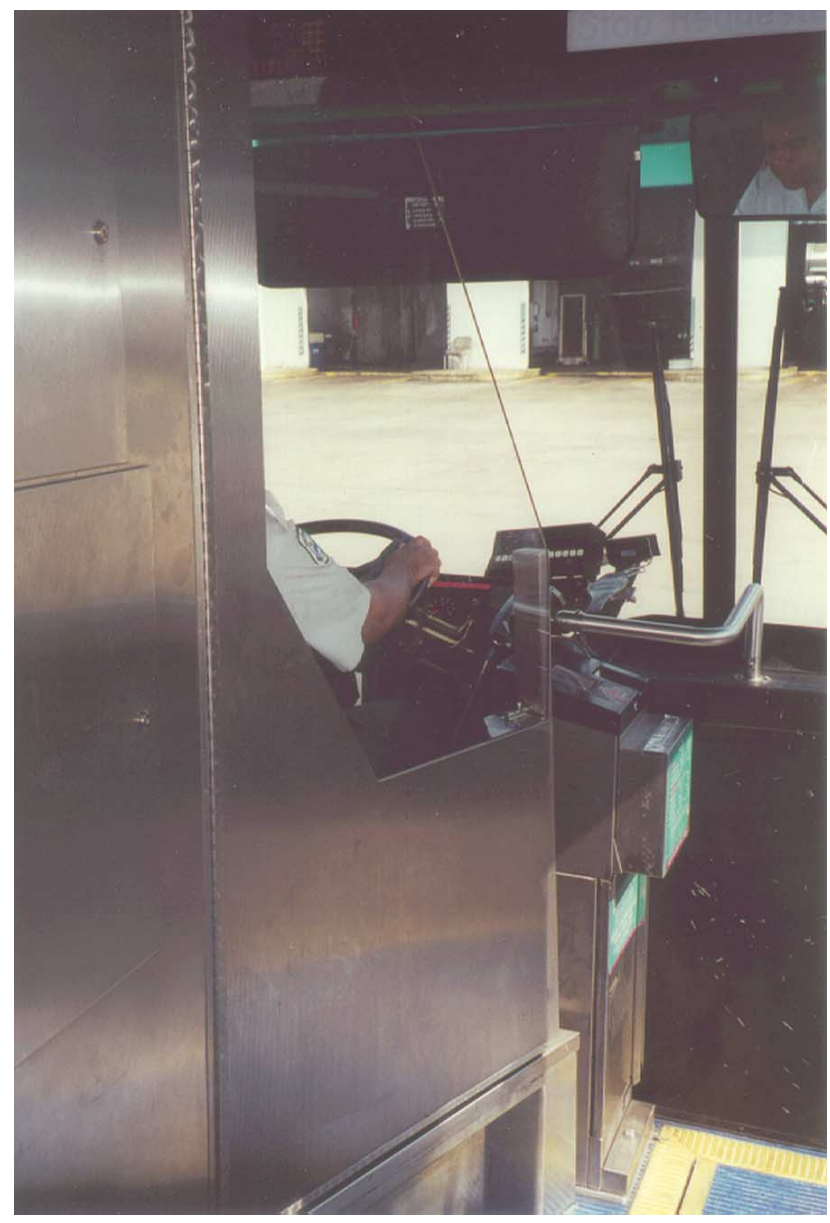

Picture 15 The door and panel is designed to address potential threats from the operator's blind spot.

Officials with NJ Transit are interested in the experiences of both Muni and MDT. In April 2001 they visited San Francisco to see the enclosures and talk with Muni staff. Internal discussions began with the Transit Police Department and the operators' union. They, too, are concerned with increasing assaults on bus operators. NJ Transit buses have radios but do not feature video surveillance. Also, agreements with many local law enforcement agencies provide a significant visible police presence onboard (see "Police \& Security").

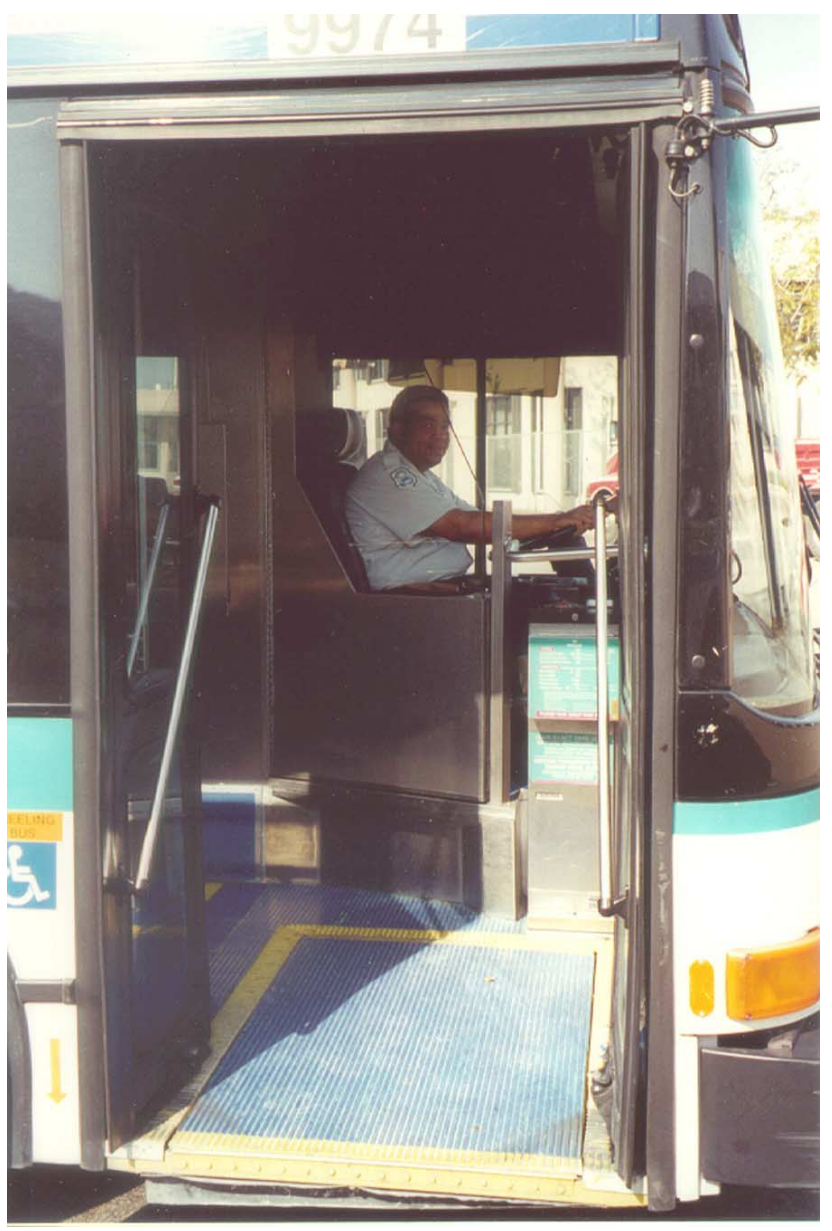

Picture 16 From a customer perspective, would you feel secure boarding this bus?

\section{Pros and Cons}

Even with their potential for increased protection, the enclosures are not without critics, however, even from the bus operators they are designed to protect. During a site visit to inspect the enclosures, project staff heard from numerous MDT bus operators who had both positive and negative comments. On the one hand, the enclosures can protect bus operators from minor assaults, especially along difficult routes. In some areas, it is not uncommon for bus operators to serve as targets for rowdy youth throwing objects such as rocks and even feces and bags of urine at bus operators, particularly when the front door is open to admit customers or when the youth alight the bus. Halloween night is not a pleasant experience for some MDT bus operators who have learned to be wary of becoming victims of 
eggings. Muni supervisors report similar incidents in the San Francisco bay area.

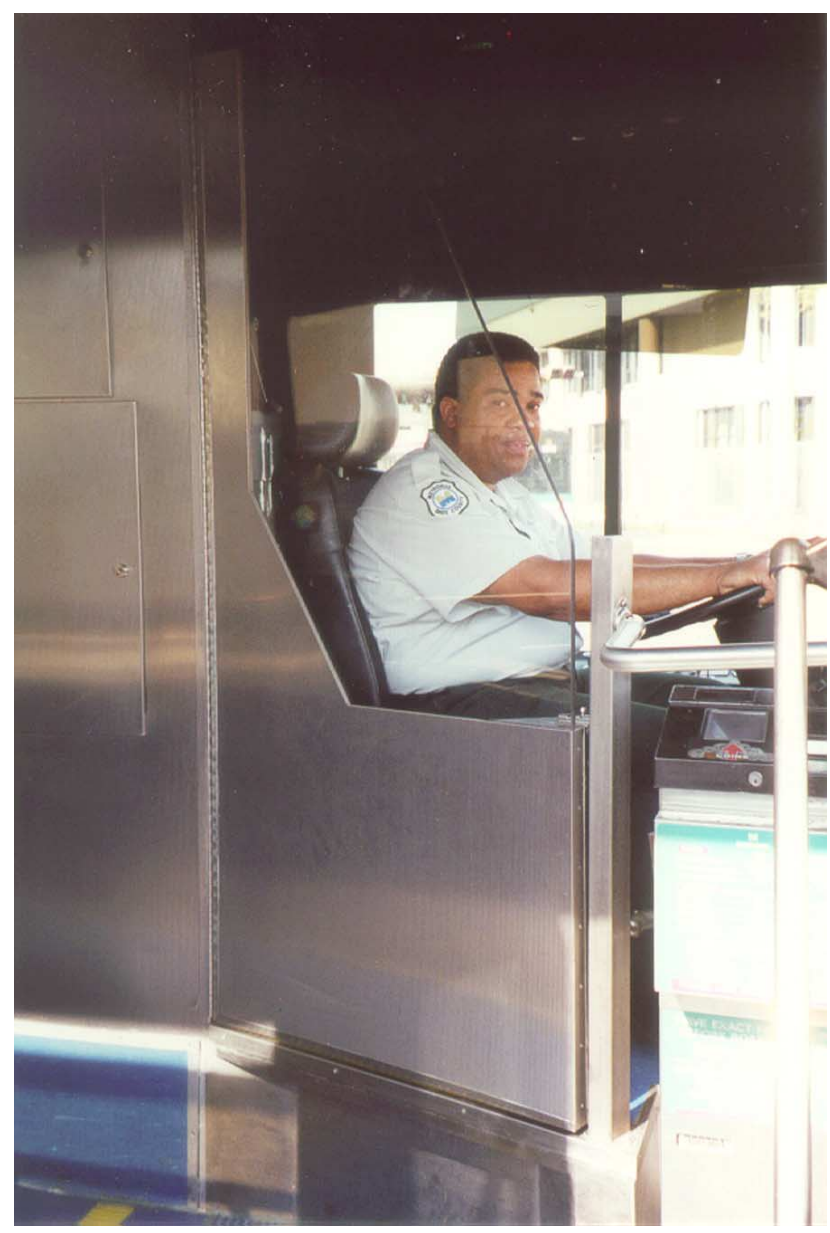

Picture 17 Critics say this is no way to provide superior customer service on transit.

Some bus operators also feel that the enclosures discourage potential assaults from irritated customers. As previously discussed in the Introduction, unlike a train operator, bus operators are fully exposed to passengers who frequently approach them with questions, complaints, or just idle conversation. Customers may become easily irritated over a fare dispute or other problem.

Imagine a disgruntled customer who had a bad day at work, waits in the rain at a bus stop without a shelter, and the bus arrives 15 or more minutes late because of a wreck, traffic congestion, a breakdown of the bus, or some other reason beyond the bus operator's control. When boarding the bus, the angry customer is not unlikely to have a few choice words for the bus operator, a target who serves as the only physically present representative of the transit system at which the customer can vent his frustrations. Some MDT bus operators believe the enclosure will make the customer think twice before attacking.

Other bus operators feel the enclosure enables them to more fully focus on the tasks of safely operating the bus, certainly a prime component of their job descriptions. Some also cite the protection the enclosure affords them from contracting contagious maladies from their customers. At least one operator related incidents of customers sneezing or spitting on her.

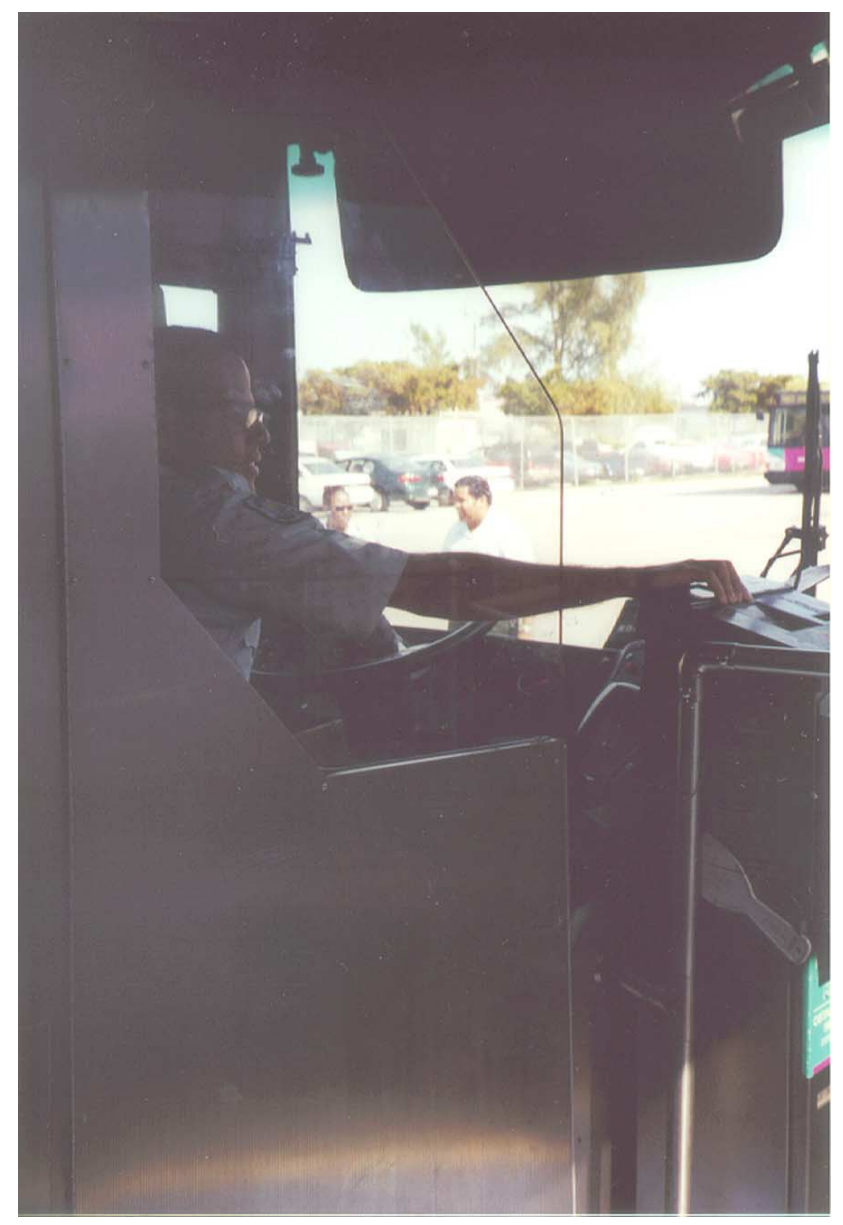

Picture 18 Some MDT operators complain of wrist injuries from customers grabbing transfers from the operators' hands around the Plexiglas panel. A simple design modification-similar to a bank teller's window-may address this concern. 


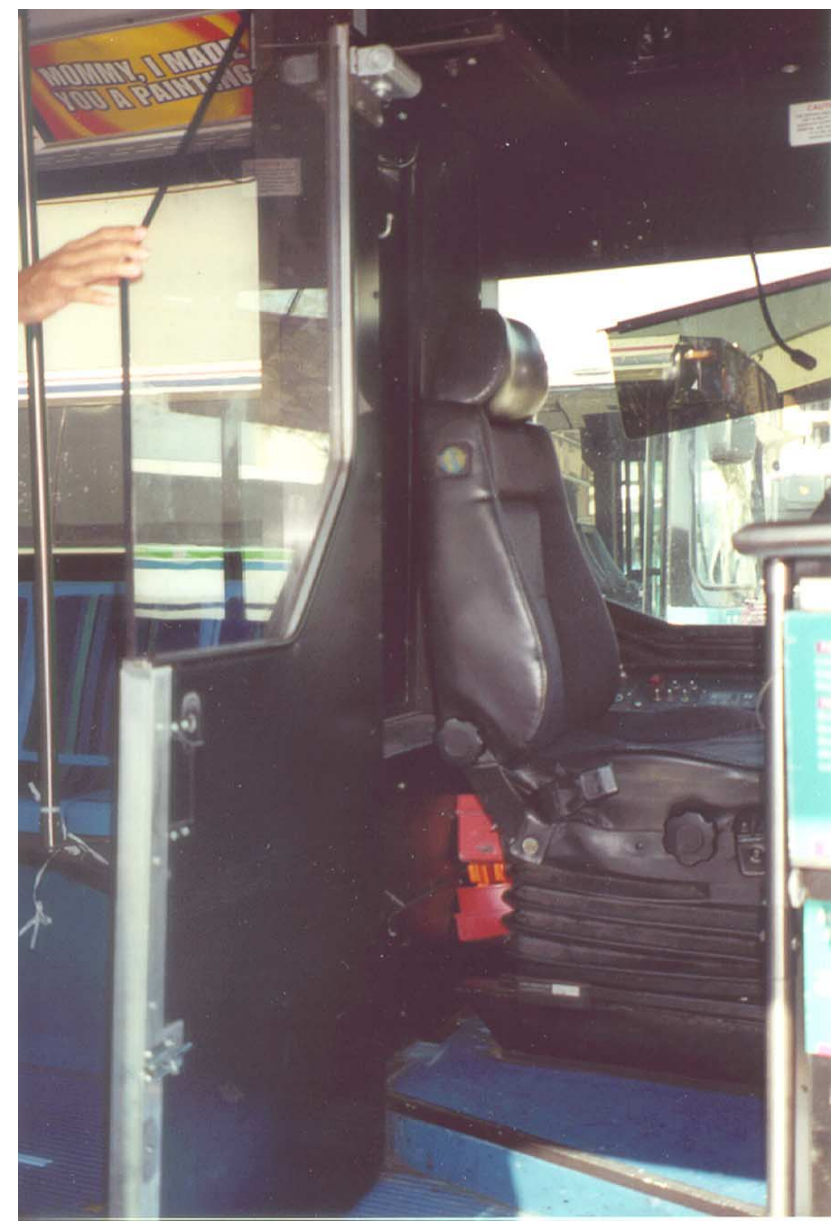

Picture 19 Some MDT operators tie the doors open. The door may also present an obstacle for maintenance cleaning staff.

The partial enclosure, however, will not fully protect the bus operator from harm if someone really wants to attack him. Some MDT operators expressed concern they may become an easier target for criminal acts against them, particularly because the enclosure is not complete. An attacker may reach around the Plexiglas panel in the open area above the farebox and forward towards the windshield. Though the attacker must get closer, he can still point weapons around the panel or project objects at the operator. The bus operator, however, would have no means of escape other than climbing out the side window-easier said than done. A gruesome thought-imagine the result of a Molotov cocktail hurled into the operator's cab. The MDT doors feature sliding pin locks-necessary to prevent an assailant from opening the door, but which may make a quick escape more difficult for the operator.

Many operators also complain of feeling confined or isolated. They may suffer from claustrophobia. Some complain of an uncomfortably warm environment. The enclosures may limit the effectiveness of the onboard air conditioning system that was designed for buses without the add-on enclosures.

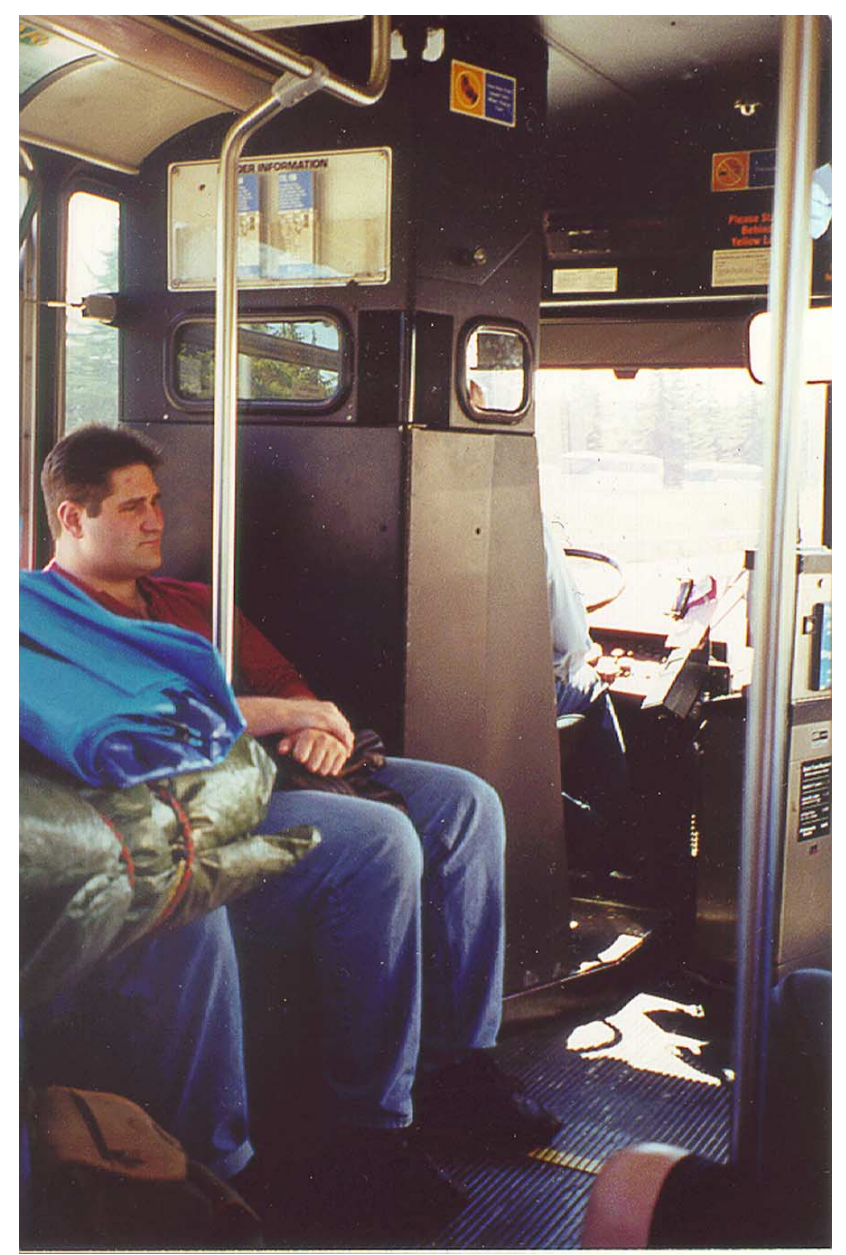

Picture 20 King County Metro's articulated buses supplied by Breda provide a small extension of the modesty panel towards the front. This reduces glare from interior lighting at night, but is not an explicit security feature.

Bus operators with King County's Metro in Seattle were unimpressed with a cab enclosure that was

\footnotetext{
- The supplier DENSO recently developed an A/C unit specifically to address the environment of fully enclosed operator cabs on some European buses.
} 
tested on a bus for a time. Their complaints included many of those voiced by MDT operators. In the end, they just didn't feel comfortable relinquishing the overall positive relationships they enjoyed with their customers. Due to the provision of superior levels and high quality transit service, there is strong public support in Seattle. Bus transit is regularly used by a wide variety of people in the Seattle area, including a significant number of whitecollar employees and middle class persons. Though they still experience isolated occasional assaults, Metro bus operators may be characteristically protective of their valued relationships with their customers.

The customer service aspect cannot be ignored. What perceptions might differing patrons have of riding a bus in which the bus operator is isolated from them? How would regular patrons respond? Would they or prospective patrons be less inclined to ride a bus with the operator enclosures? How similar or different are bus patrons and rail patrons regarding their acceptance of isolation from the operator? According to MDT staff, no complaints have been received to date. More study is needed in the wake of this new feature.

Enclosing bus operators will not prevent every assault - either real or perceived. Other proactive methods, like video surveillance and onboard police/security, may be more effective. Those bus and train operators who have been threatened and protected by enclosures, however, have become advocates. Some risk managers in the transit industry, seeing the additional view of economic sense, are joining to support them.

\footnotetext{
- The reader is advised of the forthcoming study, "Assessment of Operational Barriers and Impediments to Transit Use" sponsored by the National Center for Transit Research.
} 


\section{BUS AD WRAP}

You've seen them moving along city streets. Is it a bus or a moving billboard? It's both. "Bus/full/ad wrap" advertising on American transit buses is increasingly common. A special wrap covering composed of many tiny dots, loosely spaced, allows large-scale artwork to cover the outside of a bus, including the windows. Riding customers sitting close to the windows can still see out, but those outside the bus cannot see in; rather, they see whatever design has been approved by the transit agency for public view, including paid advertising comparable in size to a billboard.

Selling advertising on bus exteriors can significantly boost locally generated revenues beyond the customary fares collected from passengers. Gateway Outdoor Advertising, which contracts with numerous transit agencies nationwide, collects between $\$ 2,900$ (in smaller markets) and $\$ 16,000$ (in Manhattan) per month per bus from clients who advertise on transit bus exteriors using full wrap ads. In their Miami market, Gateway collects $\$ 7,900$ per month per bus. A portion of these fees is returned to Miami-Dade Transit for the use of its buses as moving billboards.

Lynx, the Orlando-based transit agency serving three counties in tourist-rich central Florida, runs its advertising in-house with commissioned sales representatives, thus keeping all of the $\$ 4,000$ per month per bus fees within the agency. One bus with a preferred 12-month contract provides Lynx with annual gross revenues of $\$ 48,000$. If only half of its 168 peak-service bus fleet were covered in ad wrap, the agency could potentially earn more than $\$ 4$ million in one year-about 8\% of Lynx's 1999 operating budget and enough to significantly expand service or purchase about a dozen new standard buses.

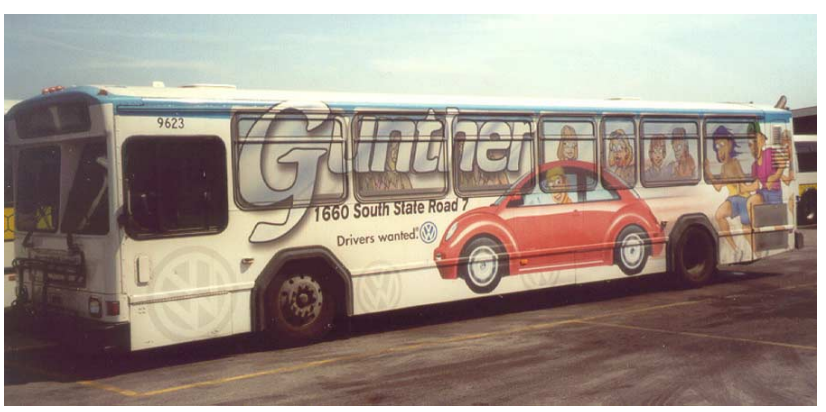

Picture 21 A typical transit bus with full wrap advertising. Note the operator's window is left uncovered.

Thus, full wrap advertising is big money for those transit agencies that most fully take advantage of it. As the Federal Transit Administration has phased out most operating subsidies during the 1990s, especially for larger systems, transit agencies have been scrambling to find additional local revenues to cover these losses without having to raise passenger fares. Furthermore, some transit agencies have received praise from citizens and public officials for attractive, eye-pleasing designs and artwork, fostering goodwill from a constituency that typically may not fully recognize the benefits of publicly funded mass transit service. An added, unspoken "benefit" is that the non-riding public cannot look into buses and see the spare passenger capacity that may exist along some routes, especially during offpeak service hours. A transit system may be viewed as an efficient public operation by virtue of both the public's ignorance of empty buses as well as the creative method of maximizing revenues. In contrast, other transit systems have been sharply criticized for violating the local community's trust as a caretaker of public property because of gaudy bus designs that contribute to an overall commercialization of life. Unless specifically exempted, wrapped buses may violate the spirit of anti-billboard ordinances and laws designed to keep commercialization at bay and out of residential neighborhoods.

But does full wrap advertising contribute to crime onboard transit buses? That is the basis for debate among transit staff. Marketing staff members are 
usually the concept initiators with support from administration. Winning over skeptical operations, maintenance, and security personnel can be challenging. In the end, the potential for substantial added revenues is hard to resist. Unfortunately, there are no published studies investigating any connection between full wrap bus advertising and actual criminal activity.

There is, however, evidence that suggests customers may feel insecure and/or perceive the potential for crime as greater on buses with full wrap advertising. It is true that, although riding customers can see out the windows, the view may be described as blurry, as if one required a stronger eyeglass prescription. Customers waiting at bus stops cannot see into the bus before boarding; therefore, they enter the enclosed bus environment unaware of potential onboard conditions such as crowding and/or rowdy behavior by undisciplined youth. A customer makes the decision to either board, wait for the next bus, or make alternative arrangements without complete information. For the new or potential transit customer, this perception may be powerful enough to discourage him/her from using the service.

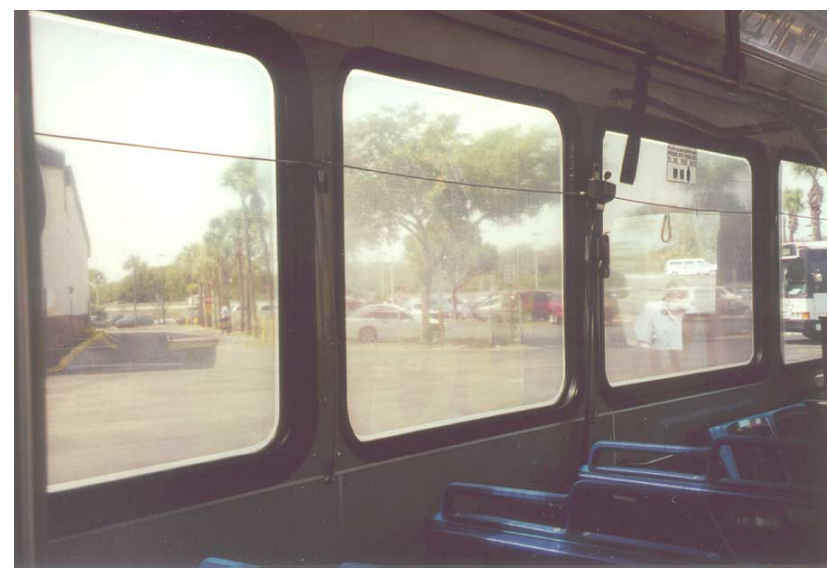

Picture 22 From inside an ad wrapped bus, the outside view appears blurred. The distortion is worse at night for customers trying to see landmarks or read street signs. The interior is darkened due to both tinted glass and full wrap advertising. Would a return to clear glass lead to a more secure environment?

In her recent research on bus and bus stop design for a document to be published by the Federal Transit
Administration, Ph.D. candidate Anne Lusk (University of Michigan, Taubman College of Architecture and Urban Planning) used on-site observations, written onboard customer surveys, visual preference surveys, and focus groups to gather user and non-user perceptions of personal security onboard buses and at bus stops. The study examined the subjects' perceptions in relation to various environmental elements including, but not limited to, colors, window views, cleanliness, interior lighting, and advertising.

For the visual preference survey, the study targeted three distinct population groups-bus riders, potential bus riders, and non-riders. The participants viewed 70 slides of actual bus stops and bus designs from various sources. Their comments indicated a consistent preference for large clear glass windows, free from paint and advertising, which provide clear sight lines into the bus from outside. Relating to security, their comments included the need to see into the bus before boarding to judge the interior environment as secure or risky, as well as a desire for witness eyes from outside the bus monitoring, and thus potentially deterring, onboard criminal activity. The study participants indicated a strong distaste for the slides showing buses with windows covered with advertising.

There is much more to the study than summarized here, and the reader is encouraged to consider its review. The purpose of the study was to discover common, proven, customer-based design preferences that bus manufacturers could reference to produce more attractive buses for communities with public transit service, resulting in increased patronage. 


\section{Survey Findings}

The questionnaire for this synthesis report included the question,

"Do your buses utilize "wrap around/full cover/Contra Vision" advertising? If yes, what is your assessment of its influence on onboard crime?"

Of the 31 agencies responding, 27 (87.1\%) report having buses with full wrap advertising. Its relation to onboard crime, however, is overwhelmingly discounted in their comments. Some transit security officials are uncomfortable with full wrap advertising, but acknowledge they have little or no evidence to support their concerns. In spite of this, some transit policy boards are deciding to terminate full wrap advertising.

The publicly elected Board of Directors for the Denver RTD recently addressed the issue of full wrap advertising. For years, the RTD contracted with a private advertising firm to bring in additional revenues from selling full wrap advertising on bus exteriors. As the profitability and, thus, proliferation of full wrap ads increased, so did customer complaints. Some customers were concerned about their security when boarding full wrap ad buses without being able to see into them first. Near the end of calendar year 2000, the Board passed a resolution reaffirming a stipulation of the existing advertising contract that disallows advertising placement higher than six inches from the bottom of transit vehicle windows. The full wrap ads are being phased out.

At AC Transit in Oakland, discussions with the sheriff resulted in a change in agency policy governing exterior advertising-bus windows may no longer be covered. A representative with Broward County Transit in Fort Lauderdale also acknowledged "mixed feelings" concerning full wrap advertising among the local police departments whose officers must respond blindly to incidents onboard ad buses. The Phoenix Transit System has gone so far as to conduct limited tests of an infrared visualization system used by firefighters and police in low visibility situations to counter the zero visibility afforded by full wrap buses the police would face when responding to an onboard crime. An alternative in this scenario would be the use of the real time covert surveillance feature available on onboard digital video surveillance systems (refer to the section, "Onboard Video Surveillance").

In an interesting twist on the concern that full wrap advertising may contribute to criminal activity, the Massachusetts Bay Transportation Authority (MBTA) has successfully utilized a full wrap ad bus at a bus transfer facility to monitor illegal drug sales transactions and other crimes. MBTA police are positioned inside the non-revenue service bus parked at the terminal. When unsuspecting sellers and buyers complete their deal, the police are there to quickly arrest the criminals on site. Contra Vision, the Atlanta-based supplier for Lynx's bus wrap, even promotes its product for covert surveillance applications in various environments.

As it relates to the security of bus operators, there is little or no evidence that full wrap advertising contributes to offenses against them; however, it may violate the principles of crime prevention through environmental design (CPTED; refer to "CPTED \& Security Audits") and can contribute to the perception of an insecure workplace. Transit agencies utilizing full bus wrap advertising should be sensitive to this and objectively monitor potential problems. 


\section{CPTED \& SECURITY AUDITS}

Promoters of crime prevention through environmental design (CPTED) concepts claim that unconscious perceptions or forthright observation of physical surroundings can influence criminal activity. Thus an urban area in which buildings are neglected, windows broken, yards untended, or criminal activity regularly occurs in plain public view sends a message that residents and/or law enforcement are not concerned with what occurs there. A criminal may perceive it as a "free-for-all" area in which he can carry out criminal acts without fear of punishment.

Applying this argument to public transit, the way transit vehicles and facilities are designed and presented may affect the personal security of both employees and patrons. With the probable exception of taste, the human senses play a significant role in patrons' perceptions of their experiences with public transit service. Lighting, colors, views, sounds, and even smells-these may all work together toward attracting and keeping customers. Conversely, they may repel potential customers if they are perceived as unpleasant.

\section{Survey Findings}

The questionnaire for this synthesis report included the question,

"Has your agency utilized environmental design techniques (e.g. layout, lighting, colors, etc.) to minimize violence on board buses?"

Only five (16\%) of 31 respondents claimed to have knowingly implemented strategies aimed at improving the onboard environment of buses. Of these five, four relate to enhanced interior lighting, i.e. keeping it on throughout the service day or adding more lighting, resulting in brighter interiors.

King County Metro reports its buses utilize pink fluorescent interior lighting. Presumably, this would soften the harshness typical of fluorescent lighting, which unfavorably distorts the appearance of natural skin tones. However, the Metro spokesperson discounts its impact on onboard crime.

AC Transit reports that discussions with the sheriff resulted in the removal of exterior advertising covering the windows on its buses. This proactive move contrasts with the reactive move by Denver's RTD Board of Directors to prohibit exterior advertising six inches above the bottom of bus windows. In the former instance, the transit agency took action to prevent crime on advice of local law enforcement; in the latter, customer concerns for security resulted in the corrective response by the transit agency.

Unlike rail facilities, applying CPTED principles onboard transit buses has not grabbed industry attention. An exception may be specialty or premium services, like rubber-wheeled trolleys in numerous city business districts. The exteriors of MTA low-floor buses used on Metro Rapid service in Los Angeles appear clean, uncluttered, free of advertising, and feature clear glass windows. Did the planners consciously apply CPTED principles or do these vehicles simply exhibit sound and attractive design principles lacking in standard transit vehicles? Newer research in environmental design in transit (e.g. Ms. Anne Luske's report referenced in the prior section on "Bus Ad Wrap") may be revealing.

More typical are transit systems utilizing CPTED techniques in the design of major fixed capital projects, e.g. light rail stations, park \& ride lots, and bus transfer stations. This may involve lighting, facility layout, and landscaping. AC Transit, Port Authority of Allegheny County, Phoenix Transit System, and the Central Florida Regional Transportation Authority (Lynx) all report the intentional use of CPTED design principles in bus terminals and other passenger facilities. Light rail 
transit systems in Denver and St. Louis have applied CPTED principles at light rail stations.

\section{FTA Security Audit Program}

The Intermodal Surface Transportation Efficiency Act of 1991 amended the existing Federal Transit Act to require the Federal Transit Administration (FTA) to issue regulations creating a state-based safety oversight program for rail fixed guideway systems. The resulting regulations are codified in 49 CFR 659 as the "State Safety Oversight Program." The focus on rail systems is understandable given federal investments, passenger capacity, and public visibility.

Transit systems operating rail are required to develop an approved System Safety Program Plan. Essentially the plan identifies the roles and responsibilities of various staffs, departments, and agencies as well as the policies and procedures for implementing and maintaining safety and security in the transit system. The security of patrons and employees is included in the plan. Since bus and rail service are invariably integrated-at least to a minimal extent-within the transit agency, bus service may also benefit from the plan, though only rail systems are required by law to participate.

In support of the System Safety Program but also for all transit systems regardless of their size or modes of service operated, the FTA offers free security audits. The audits are conducted by a private contractor and are voluntary for all systems, though audits are a required feature of the overall System Safety Program for rail properties. The FTA began offering the audits in 1997.

According to the FTA, the objectives of the security audits are to:

1. "provide assistance to transit agencies in developing and initiating system security program plans;
2. evaluate the level of preparedness of each system;

3. share best practices used by other transit police/security and operations personnel to enhance security for passengers and employees; and

4. evaluate the quality of security provided by transit systems for passengers, employees, and system facilities." 15 


\section{LAWS, PENALTIES, \& RULES}

Laws designed to protect transit employees primarily deal with punishing criminals after they have already committed an offense. By their nature emotionally motivated and therefore somewhat variable, violent acts are rarely preventable by words on paper. Still, there have been incidents proven as "pre-meditated" acts. To some extent, knowledge of laws and penalties may serve to foster both an environment and public attitudes that do not tolerate criminal activity on public transit service.

\section{Survey Findings}

The questionnaire for this synthesis report included the question,

"Does your city/county/district/state provide special penalties for violent perpetrators against bus operators?"

Respondents for a number of agencies were able to answer "yes" and either cite or summarize the laws. From their answers, simple web-based research obtained, in most instances, the text of the laws. Selected portions of these laws are provided in Appendix D of this report. Further research also uncovered efforts to pass laws, successful uses of civility "codes of conduct," and agency policies posted onboard transit vehicles.

\section{Attempted Legislation}

Arizona has tried to pass legislation to protect transit passengers and operators every year since 1992. A coalition of Arizona transit systems, labor unions, transit advocacy groups, and politicians have led various efforts. The most recent attempt has passed the House. The historical pattern has been that the bill typically passes the House and then dies in the Senate. Blame for failure can be attributed to organized efforts by gun rights advocates. Also, anti-crime efforts have been at odds with the Carry Concealed Weapon (CCW) permit law. Although the $\mathrm{CCW}$ does allow public entities to restrict them if the weapons may be checked, no transit system is going to allow bus operators to serve as "checkers" of firearms onboard transit vehicles.

In New York State, Senate Bill 5294 was proposed in May or June 1997 but did not advance further.

In the U.S. Congress, the Protect America's Transit Workers and Riding Public Act (House Bill 1080), sponsored by Earl Blumenauer (D-OR), was introduced 11 March 1999 and sent to the Committee on the Judiciary. It was subsequently referred to the Subcommittee on Crime on 24 September 1999. While the original bill did not move out of committee, Rep. Blumenauer's office worked with the Amalgamated Transit Union and Transportation Infrastructure Committee to have portions of the bill included in a larger "Terrorism Preparedness Bill" (HR 4210) that passed the House but not the Senate. This included an amendment that would require the federal government to research the extent of transit crime, and develop a strategy for protecting workers, passengers, and transit systems from such incidents.

A spokesperson from Rep. Blumenauer's office wrote, "We are looking at our options for this Congress to work on this important issue. There is some opposition in Congress to federalizing more crimes, so we are also exploring options to raise awareness and information on the extent of transit crimes, specifically against workers and passengers."

\section{Successful Legislation (Laws)}

There are a number of states that have successfully passed laws addressing the security of transit employees. Typically, the laws result in higher classifications of offenses against transit employees and/or patrons, compared to offenses against unclassified persons. Because of higher offenses, the penalties, including fines and/or jail time are also substantially increased. 
The California Penal Code covers both employees and patrons on transit property, including vehicles and stations. In general, battery on all persons occupying public transit property (i.e. vehicles and stations) is punishable by a maximum $\$ 2,000$ fine and/or a year in jail. However, the penalties are substantially higher if the criminal is aware that his victim is either a passenger or a transit employee doing his job. In such a case, the criminal is subject to a maximum $\$ 10,000$ fine and/or a year in jail. If the victim sustains injury, the punishment may also add time in a state prison of 16 months, 2 years, or 3 years.

The Florida Statutes cover public transit operations employees. If they are victims of assault or battery while on duty, the offense is reclassified to a higher standard. For an assault, the offense is reclassified to a first-degree misdemeanor, instead of seconddegree. Battery goes from first-degree misdemeanor to third-degree felony. Aggravated assault changes a third-degree felony charge to second-degree. Aggravated battery upgrades second-degree felony to one of first-degree. Finally, the use of firearms during the offense subjects the criminal to a minimum of either three or eight year's imprisonment, depending upon the type of firearm.

The state of Massachusetts has a couple of laws that may apply to public transit bus operators. One law addresses criminals who interfere with the operation of vehicles carrying "passengers for hire" by either damaging the vehicle or disabling the vehicle operator. If this law applies, the penalties include a maximum fine of $\$ 10,000$ and/or imprisonment of up to 20 years. Another law addresses assault and battery on "certain public servants" doing their job at the time of the assault. Associated punishment includes jail time between 90 days and two and onehalf years or a fine of between $\$ 500$ and $\$ 5,000$.

In 1997, the State of Nevada's Revised Statutes were updated to include increased penalties for assaults on many public servants, including transit vehicle operators. The statutes provide judges with specific sentencing guidelines depending upon unique circumstances. Offenses are classified as either assaults (attempts at violence) or batteries (actual violence). Classifications and penalties for assaults range from misdemeanors to felonies with maximum fines of $\$ 5,000$ and/or prison terms between one and six years, depending upon whether a weapon was involved. Batteries carry stiffer consequences ranging from misdemeanors to felonies with maximum fines of $\$ 10,000$ and/or prison terms between two and fifteen years. What is particularly interesting about the Nevada Statutes is that transit vehicle operators are included among police, fire fighters, corrections officers, court officials, school employees, and taxicab drivers.

The Pennsylvania Consolidated Statutes lists public transit employees as a victim class for aggravated assaults, which include both attempts and actual violence. The standard for classification- "serious bodily injury"-is different, however, for on-duty transit employees. For other public servants, only "bodily injury" is necessary for charging an offender under Section 2702. An offense against transit employees is classified higher as a first-degree felony (versus second-degree felony for other public servants). The burden lies on the prosecutor to convince the court of the criminal's intent to cause or actions causing "serious" bodily injury; otherwise, the lower classification of mere "bodily injury"-which does not include transit employees-may not apply.

Texas Penal Code does not specifically identify public transit vehicle operators as a victim class in the section on assaults. Rather, the broad term of "public servants" may apply. These public servants must be in uniform or wearing a badge that identifies them as such. For assaults against public servants while performing their duties, offenses are reclassified from misdemeanors to third-degree felonies. 
A final example of state laws may be found in the Revised Code of Washington. Transit operations employees are covered, including operators, supervisors, mechanics, and security personnel. Additionally, the law mentions employees of both public and private transit companies, including contracted service providers. Assaults against these individuals are classified as felonies.

\section{Code of Conduct}

Communicating the contents of special laws and transit agency policies to the public is a simple and relatively low-cost method of crime prevention. These rules are established to reinforce standards of public behavior and maintain a pleasant environment for the comfort of all patrons.

A common way of informing transit patrons is posting laws or agency rules for patrons onboard transit vehicles. Most anyone who has boarded a transit bus has seen signs advising them not to smoke, drink, eat, and/or play loud music. For some transit systems, rules are agency-imposed. The expectation agency management hopes to establish in the minds of patrons is that if you choose to use this service, you will follow the rules. Again, for some systems, these reminders are sufficient.

Lynx, in Orlando, posts the ten "Customer Commandments" onboard its buses:

"1. Thou shalt not smoke on LYNX, for it breaketh State Law.

2. Thou shalt not play the radio too loudly, for it offendeth other ears.

3. Thou shalt not eat or drink on LYNX, for it encourageth bugs to ride.

4. Thou shalt not curse or profane on LYNX, for reasoneth number 2.

5. Thou shalt wear shoes and a shirt to cover thy body.
6. Thou shalt remain seated while LYNX moves, to protect thy and others body.

7. Thou shalt request a stop 1 block before thou needest to depart LYNX.

8. Thou shalt use exact fare, for thy driver can not makest change.

9. Thou shalt present thy I.D. if thou art a discount fare passenger

10. Thou shalt not distract thy driver while the bus art in motion." 16

In other systems, particularly those serving larger urban areas with non-homogenous populations or where law enforcement has been lax, these rules may need to be codified in municipal ordinances and/or state laws. For example, local ordinances exist in St. Louis and Detroit that support rules of conduct onboard transit vehicles. Violators are typically subject to fines. Local municipal ordinances may be necessary and/or preferable where state laws either do not exist or do not apply to the unique characteristics of public transit service.

In Washington State, a list of eight specific behaviors is spelled out in state law. The offenses include smoking, littering, playing loud music, spitting, carrying destructive agents, obstructing access to or impeding the operation of transit service, behaving inappropriately, and vandalizing property. Violating any of these prohibitions results in a misdemeanor charge, punishable by a maximum fine of $\$ 1,000$ and/or 90 days in jail.

Pierce Transit, in Tacoma, posts an "Unlawful Bus Conduct" notice that summarizes the state laws onboard every bus. In addition to the eight offenses listed above, the notice also includes references to state laws prohibiting drinking alcoholic beverages on transit property and punishments for assaulting a transit operator. With these public notices, patrons onboard Pierce Transit vehicles have a clear 
understanding of what behavior is unacceptable and will not be tolerated. Furthermore, the force of law and punishment backs up these rules. 


\section{REFERENCES}

${ }^{1}$ Interview with Mr. William J. Sorrells, Safety \& Training Manager, Broward County Transit, West Pompano Beach, FL, 23 February 2001.

2 "Police seek motives in Seattle bus shooting," CNN.com, 29 November 1998.

3 "Driver keeps rider off her bus," Orlando Sentinel, 02 August 2000.

4 "Port Authority, Pittsburgh Police Seek Suspect," (Press Release) Port Authority of Allegheny County, January 2001.

5 "One killed, six injured as hijacked LA transit bus crashes," CNN.com, 02 May 2001; and "1 Killed, 7 Hurt as Hijacked MTA Bus Plows Into Vehicles," by Edward J. Boyer and Hector Becerra, latimes.com, 03 May 2001.

${ }^{6}$ TCRP Synthesis 33 - Practices in Assuring Employee Availability: A Synthesis of Transit Practice by Joel Volinksi for the Transportation Research Board. Washington, DC: National Academy Press, 1999, p. 11.

${ }^{7}$ National Transit Database Reporting Manual, 1999, p. 221.

8 "Miami Valley Enlists Students in Cell Phone Security Program,” Passenger Transport, 26 January 1998, p. 6.

9 "Technology Helps Thwart Bus Hijacking in Buffalo," Passenger Transport, 29 March 1999, p.3, and "Buffalo Is Riding the Wave of Information Technology,"

Passenger Transport, 08 May 2000, p. 31.

10 "CAD/AVL Provides Security to Bus Drivers, Passengers," Passenger Transport, 22 December 1997, p. 4.

${ }^{11}$ Transit Projects, Orbital Transportation Management Systems, 12 April 2000.

${ }^{12}$ Advanced Public Transportation Systems Deployment in the United States, Update by Robert F. Casey, January 1999, p. 1-3.

13 "Successful Uses of On-board Digital Video," Prima Facie, Inc.
14 “It's Time To Do A Better Job of Protecting Bus Drivers," Passenger Transport, 29 March 1999, pp. 1, 7.

15 "Office of Safety and Security Audit Program," Transit Security Newsletter, Issue No. 12. Washington, DC: Federal Transit Administration, March 1999, p. 1.

${ }^{16} \mathrm{http} / / /$ www.golynx.com/services/commandments.htm 


\section{APPENDIX A: BIBLIOGRAPHY}

Balog, John N., Anne N. Schwarz, and Bernard C. Doyle. Transit Security Procedures Guide. Washington, DC: Federal Transit Administration, December 1994.

Balog, John N., Anne N. Schwarz, and Bernard C. Doyle. Transit System Security Program Planning Guide. Washington, DC: Federal Transit Administration, January 1994.

Boyd, M. Annabelle, M. Patricia Maier, and Patricia J. Kenney. Perspectives on Transit Security in the 1990s: Strategies for Success. Washington, DC: U.S. Department of Transportation, June 1996.

Boyd, M. Annabelle and M. Patricia Boyd. Transit Security Handbook. Washington, DC: U.S. Department of Transportation, May 1998.

Casey, Robert F. Advanced Public Transportation Systems Deployment in the United States. Washington, DC: U.S. Department of Transportation, January 1999.

Casey, Robert F., et. al. Advanced Public Transportation Systems: The State of the Art Update '98. Washington, DC: U.S. Department of Transportation, January 1998.

John A. Volpe National Transportation Systems Center. "Transit System Security Planning Seminar." Washington, DC: Federal Transit Administration, June 1996.

Lusk, Anne. Bus and Bus Stop Designs Related to Perceptions of Crime. Washington, DC: Federal Transit Administration (Report No. FTA-MI-26-7004-2001.1), 2001.

Mauri, Ronald A., Nancy A. Cooney, and Garry J. Prowe. Transit Security: A Description of Problems and Countermeasures. Washington, DC: U.S. Department of Transportation, October 1984.

Needle, Jerome A. and Renée M. Cobb, J.D. Synthesis of Transit Practice 21: Improving Transit Security. Washington, DC: Transportation Research Board, 1997.

NTI Transit Trainers Workshop 2001. "Keeping Operators Safe: A Comprehensive Approach." Session workbook, South West Transit Association's 21st Annual Conference \& Expo. Oklahoma City, 23 January 2001.

Powell, Kathryn C. “Transit Security in the 90's - Conference Summary.” Washington, DC: U.S. Department of Transportation, October 1996.

Reed, Thomas B., Richard R. Wallace, and Daniel A. Rodriguez. Transit Passenger Perceptions Regarding Transit-Related Crime Reduction Measures. Ann Arbor: University of Michigan, 19 November 1999. (Paper presented at the Transportation Research Board 79th Annual Meeting, Washington, DC, 13-9 January 2000.)

Reporting Manual for the 1999 National Transit Database Report Year. Washington, DC: Federal Transit Administration, 1999. 
Rumford, William B., Jr., Ph.D. and Frances Cooper. "Report and Recommendations." Transit Security: Exploring New Concepts in Managing Social Problems Workshop, Oakland, CA, 16-18 September 1992. Washington, DC: U.S. Department of Transportation.

Shen, L. David, Diana I. Ospina, Fang Zhao, and Hesham Elbadrawi, 1997. Analyses of Technologies and Methodologies Adopted by U.S. Transit Agencies to Enhance Transit Security. Miami: Lehman Center for Transportation Research, December 1997.

Wallace, Richard R., Daniel Rodriguez, and Thomas B. Reed. Transit Crime and Transit Vehicle Operators: A View from the Drivers' Seat. Ann Arbor: University of Michigan, 19 November 1999. (Paper presented at the Transportation Research Board 79th Annual Meeting, Washington, DC, 13-9 January 2000.) 


\section{Passenger Transport Articles}

1999

04 Jan

22 Mar

29 Mar

29 Mar

21 Jun

$19 \mathrm{Jul}$

1998

26 Jan

$02 \mathrm{Feb}$

$16 \mathrm{Feb}$

24 Aug

09 Nov

$09 \mathrm{Nov}$

$09 \mathrm{Nov}$

$09 \mathrm{Nov}$

$09 \mathrm{Nov}$

$09 \mathrm{Nov}$

09 Nov

$09 \mathrm{Nov}$

$09 \mathrm{Nov}$

1997

03 Feb

05 May

16 Jun

16 Jun

$07 \mathrm{Jul}$

13 Oct

$03 \mathrm{Nov}$

$10 \mathrm{Nov}$

$01 \mathrm{Dec}$

$08 \mathrm{Dec}$

$22 \mathrm{Dec}$

1996

08 Jan

$08 \mathrm{Apr}$

13 May

$22 \mathrm{Jul}$

$22 \mathrm{Jul}$

$22 \mathrm{Jul}$

$22 \mathrm{Jul}$

$22 \mathrm{Jul}$

02 Sep

$09 \mathrm{Dec}$ p. 6 "Improved Security in West Midlands."

p. 2 "Blumenauer Proposal Protects Transit Workers Against Violence."

p. 3 "Technology Helps Thwart Bus Hijacking in Buffalo."

p. 7 "Port Authority Police Creates Detective Unit."

p. 8 "Monterey Hosts Seminar on Threat Management."

p. 12 "NJ Transit and Hoboken Police Launch Cooperative Security Plan."

p. 6 "Miami Valley Enlists Students In Cell Phone Security Program"

p. 12 "Regional Police Ride Free on WMATA's Safety Program."

p. 12 "New Jersey Transit Expands 'Police-on-Board' Initiative."

p. 5 "10 IndyGo Buses Add Digital Cameras."

p. 5 "NJ Transit's 'Police-on-Board' Program Expands."

p. 5 "Personal Security: A Prime Target For Bus Operators."

p. 6 "High-Tech Tools Can Keep Transit Police in Control."

p. 7 "The Evolving Role of Policing, Security in Transit."

p. 8 "MBTA Initiative Deals with Crowds."

p. 9 "MBTA Moves on Abatement Project."

p. 10 "'Proactive' Is Watchword for GCRTA's Transit Police."

p. 11 "DART's Growing Police Force: A Commitment to Passenger Safety."

p. 11 "On Board Video Is Valuable Tool In Deterring, Prosecuting Crime."

p. 7 "WMATA Cites Decrease in Serious Crime."

p. 36 "NJ Transit Launches Cooperative Policing."

p. 3 "New York State Plan Would Make Assaults on Bus Drivers Felonies."

p. 7 "Survey: Transit is Secure in Houston."

p. 5 "WMATA Sponsors Seminar on Counter-Terrorism Operations."

p. 12 "Crime Prevention Is Priority for WMATA."

p. 1 "L. A. MTA Contracts Policing With City, County Agencies."

p. 4 "Md. MTA Installs Cameras for Surveillance Aboard Buses."

p. 6 "Cameras Planned On Las Vegas Buses."

p. 7 "TCRP Issues Guidelines for Bus Operator Workstations."

p. 4 "CAD/AVL Provides Security To Bus Drivers, Passengers."

\section{p. 2 "Dallas Adopts Gun Safety Program."}

p. 12 "Santa Clara Revamps Security Patrol."

p. 12 "Police/Security Workshop Scheduled."

p. 4 "Pittsburgh Transit, City Police Join Forces To Reduce Crime."

p. 6 "Video Camera Equipment Fights Crime, Lowers Costs."

p. 6 "WMATA Police Enforce 'Zero Tolerance' Policy."

p. 7 "Community Policing, Technology Considered at Session."

p. 8 "BC Transit Enhances Security."

p. 14 "Houston Metro Reaps Safety and Security Benefits of ITS."

p. 3 "Houston Metro Police Will Stay Independent 


\section{Hyperlinks for Contacts \& Other References}

\section{American Public Transportation Association (APTA)}

- The international transit advocacy organization

- http://www.apta.com/

\section{APTA Info Center}

- Includes links to annual indices to Passenger Transport articles and the "Catalog of Member Products and Services"

- http://www.apta.com/info/

\section{Blumenauer, Earl}

- US Congressman representing Oregon's $3^{\text {rd }}$ District and transit advocate who proposed federal legislation providing protection for transit employees, HB 1080 — "Protect America's Transit Workers and Riding Public Act"

- http://www.house.gov/blumenauer/press_releases/pr070.htm

\section{Contra Vision}

- Supplies full wrap bus advertisement material

- http://www.contravision.com/

\section{DENSO Sales UK Ltd}

- Supplies bus operator air conditioning systems

- $\quad$ http://www.denso-europe.com/index.asp

\section{Gateway Outdoor Advertising}

- Sells advertising space on transit facilities

- http://www.gatewayoutdoor.com/

\section{Gavin de Becker, Inc}

- Consultant \& author regarding threat assessment, violence management, workplace violence, etc.

- http://www.gdbinc.com/index.htm

\section{Greyhound}

- The nation's primary intercity bus transportation company

- http://www.greyhound.com/

\section{Kalatel}

- Supplies onboard video surveillance systems

- http://www.kalatel.com/

\section{Loronix}

- Supplies onboard video surveillance systems

- http://www.Ioronix.com/

\section{Motorola}

- Supplies integrated mobile communications systems, including CAD/AVL

- http://www.motorola.com/home/ 


\section{National Transit Database (NTD)}

- The comprehensive source of operating and financial data for federally-funded transit agencies

- http://www.ntdprogram.com/NTD/ntdhome.nsf/?Open

\section{National Transit Institute (NTI)}

- Provides training courses in "Workplace Violence" and supplies a CD-based bus operator training course, "Customers, Conflicts, and You"

- http://www.ntionline.com/

\section{National Transportation Library}

- The U.S. Department of Transportation's online, digital repository of transportation literature

- http://ntl.bts.gov/

\section{NEOPLAN USA Corporation}

- Supplies buses with operator enclosures to Muni

- http://www.neoplanusa.com/

\section{North American Bus Industries (NABI)}

- Supplies buses with operator security panels/doors to MDT

- http://www.transit-center.com/NABI/index.html

\section{Orbital}

- Supplies CAD/AVL systems; acquired Raytheon (who formerly acquired Westinghouse) and Harris "Fleetlynx" systems

- http://www.orbital.com/TMS/PublicTransit/index.html

\section{Pinkerton}

- Supplies uniformed and armed security personnel to transit

- http://www.pinkertons.com/

Prima Facie, Inc

- (See "Safety Vision Inc")

\section{Radio Engineering Industries Inc (REI)}

- Supplies onboard video surveillance systems

- http://www.radioeng.com/

\section{Safety Vision Inc}

- Supplies onboard video surveillance systems; recently acquired Prima Facie, Inc

- http://www.safetyvision.com/

\section{Siemens Transportation Systems}

- Supplies "TransitMaster" integrated mobile communication system, including CAD/AVL

- http://www.ilgsystems.com/

\section{Silent Witness}

- Supplies onboard video surveillance systems

- http://www.silentwitness.com/ 
Transit Cooperative Research Program (TCRP)

- Sponsors transit research

- http://www.tcrponline.org/

Transportation Safety Institute (TSI)

- Provides training course, "Transit System Security"

- http://www.tsi.dot.gov/

\section{Ultrak}

- Supplies onboard video surveillance systems

- http://www.ultrak.com/

\section{Wackenhut}

- Supplies uniformed and armed security personnel to transit

- http://www.wackenhut.com/security.htm 


\section{Questionnaire}

located at the Center for Urban Transportation Research at the University of South Florida

How

Ep

\section{Bus Operator Security Questionnaire}

Dear Transit Security official:

The National Center for Transit Research-funded by the U.S. Department of Transportation-is gathering data on how transit agencies provide security for bus operators. The results will be included in a synthesis report available to transit professionals nation wide. For more information, go to http://www. hctr.usf.edu/cops.htm.

We would appreciate your taking the time to complete this questionnaire to the best of your ability and returning it as soon as possible. We know your time is valuable; completing the survey should take about 10 minutes.

NOTE: Your answers may become part of the published final report. As a benefit, you will receive a copy of the final findings report when it becomes available.

Thank you for your time.

\section{Contact Information}

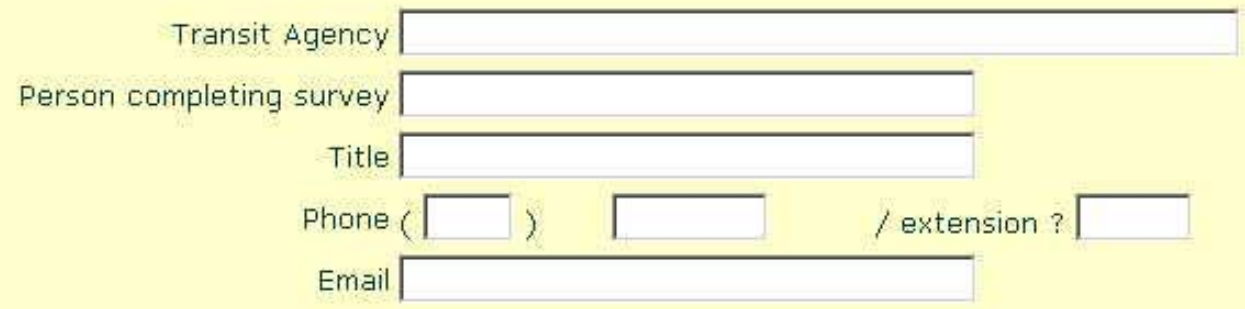

Security Methods / Techniques

1. Please indicate all of the following methods (a through $h$ ) your agency currently employs by rating both their relative 
Security Methods / Techniques

1. Please indicate all of the following methods (a through h) your agency currently employs by rating both their relative effectiveness (pink column) and relative cost (green column) and checking the appropriate box. If not yet implemented, but budgeted for implementation in the future, please only check the box in the far right (blue) column, If the method is neither currently employed nor budgeted for the future, please do not check any boxes.

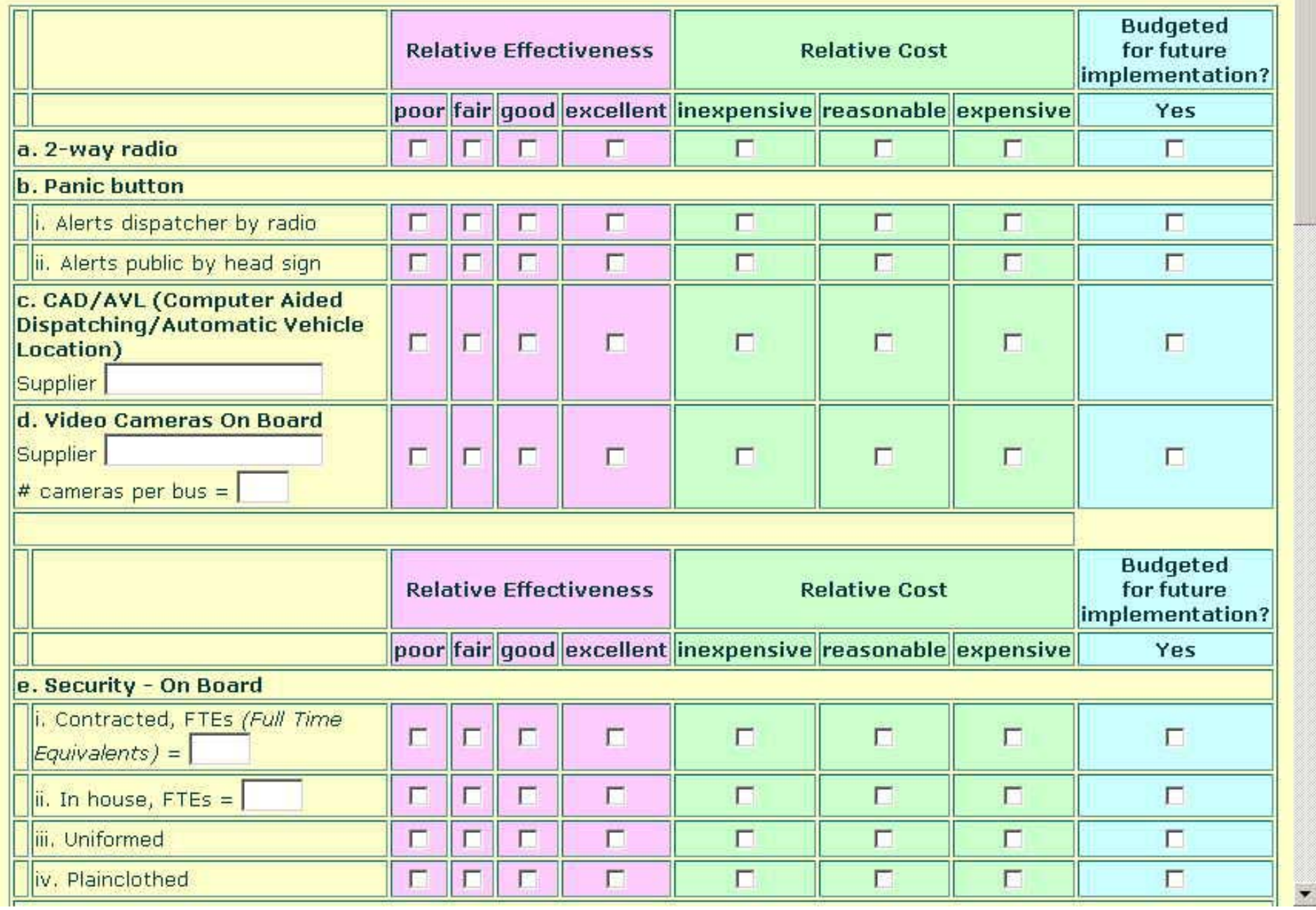

Cops, Cameras, and Enclosures

Appendix B: Survey Form \& Responses Summary 


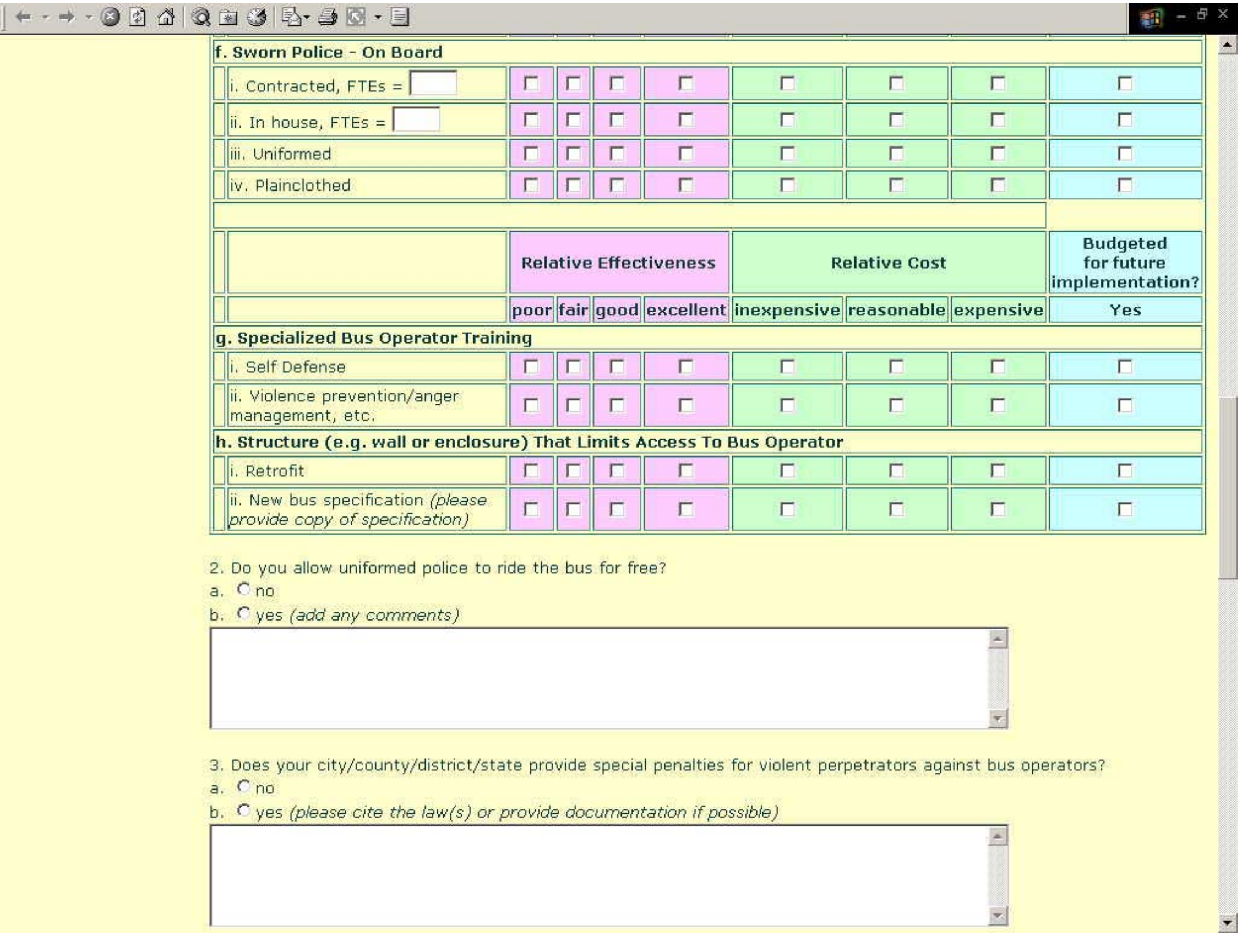

Cops, Cameras, and Enclosures

Appendix B: Survey Form \& Responses Summary 
4. Do your buses utilize "wrap around/full cover/contravision" advertising?

a. $C$ no

b. CIf yes, what is your assessment of its influence on on-board crime?

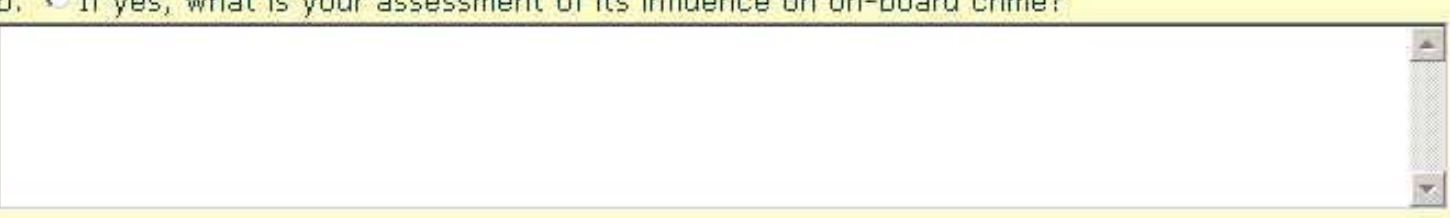

5. Has your agency utilized environmental design techniques (e.g. layout, lighting, colors, etc.) to minimize violence on board buses?

a. Ono

b. $C$ yes (please describe efforts and assess their effectiveness)

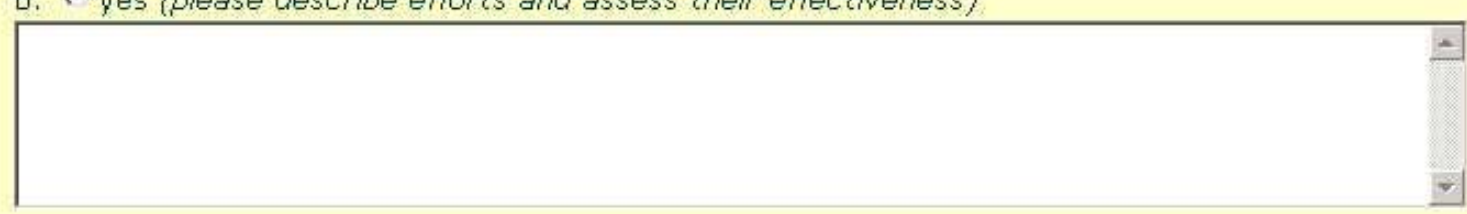

6. Has security of bus operators been raised as a major issue in labor-management meetings that required action on the part of management?

a. $\mathrm{s}$ no

b. $C$ yes (please explain)

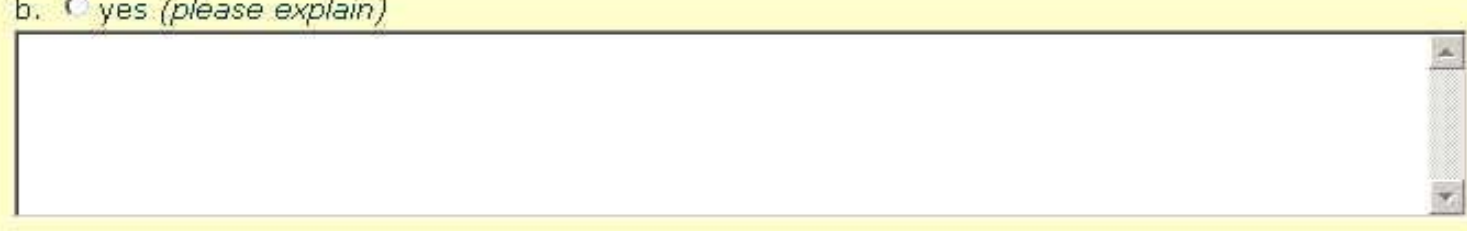

7. Can you provide specific examples (e.g. narrative, report, statistics, newspaper article, etc.) in which security techniques have helped prevent or minimize violent crime on board buses?

a. $C$ no

b. C yes (please describe or send copy)

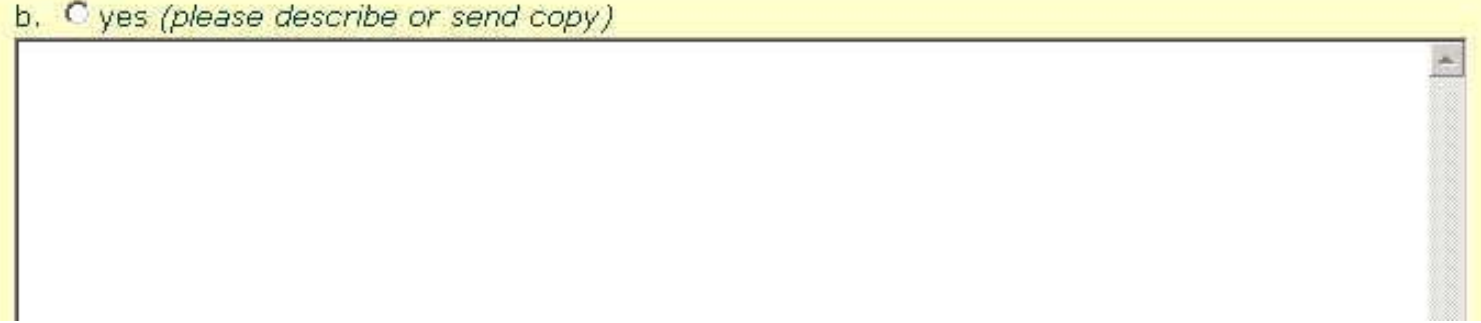




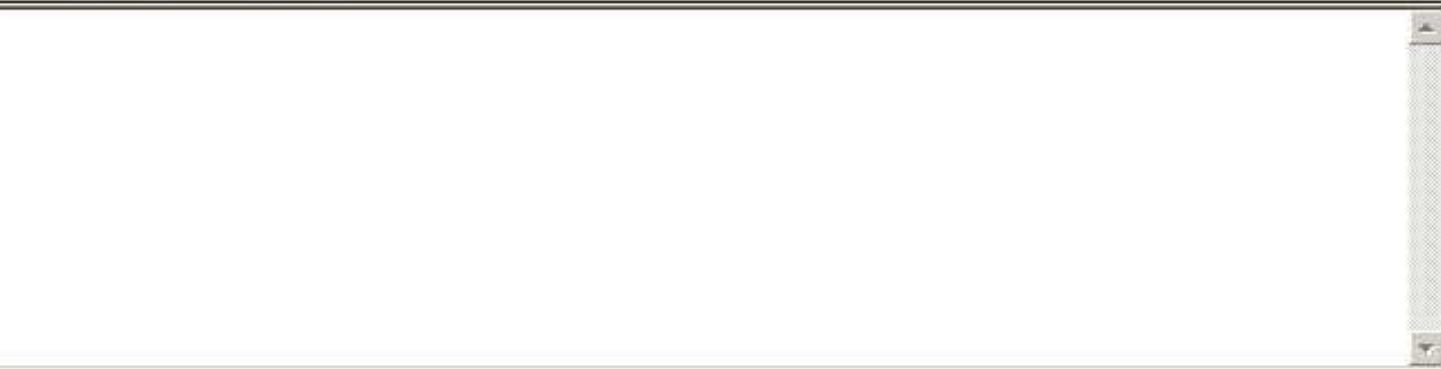

Please provide any comments, opinions, examples, etc, from your experience with keeping bus operators secure from crime.

Thank you for your time

Submit Answers or Clear Form

OR Mail or FAX completed survey and any additional materials to:

$$
\begin{aligned}
& \text { Darin Allan } \\
& \text { Center for Urban Transportation Research } \\
& \text { College of Engineering / CUT } 100 \\
& \text { University of South Florida } \\
& 4202 \text { E Fowler Ave } \\
& \text { Tampa, FL 33620-5375 } \\
& \text { FAX: (813) 974-5168 } \\
& \text { Telephone: (813) 974-2850 }
\end{aligned}
$$


Summary of Surveyed Transit Agencies' Security Methods (1 of 3)

\begin{tabular}{|c|c|c|c|c|c|c|c|c|c|c|c|}
\hline State & Primary City & Transit Agency & Size & $\begin{array}{l}\text { 2-way } \\
\text { Radio }\end{array}$ & $\begin{array}{c}\text { Panic } \\
\text { Button - } \\
\text { Dispatch }\end{array}$ & $\begin{array}{c}\text { Panic } \\
\text { Button - } \\
\text { Headsign }\end{array}$ & CAD/AVL & $\begin{array}{l}\text { Onboard } \\
\text { Video } \\
\text { Cameras }\end{array}$ & $\begin{array}{l}\text { Contract } \\
\text { Security }\end{array}$ & $\begin{array}{l}\text { Inhouse } \\
\text { Security }\end{array}$ & $\begin{array}{c}\text { Uniformed } \\
\text { Security }\end{array}$ \\
\hline$A Z$ & Phoenix & Phoenix Transit System & medium & $\mathrm{x}$ & $\mathrm{X}$ & $\mathrm{X}$ & $\mathrm{F}$ & $x$ & $\mathrm{X}$ & $\mathrm{x}$ & $\mathrm{X}$ \\
\hline $\mathrm{CA}$ & Oakland & AC Transit & large & $\mathrm{X}$ & & & & $\mathrm{X}$ & & & \\
\hline $\mathrm{CA}$ & Sacramento & Sacramento Regional Transit District (RT) & medium & $x$ & $\mathrm{~F}$ & $\mathrm{~F}$ & $\mathrm{~F}$ & $\mathrm{~F}$ & $\mathrm{X}$ & & $\mathrm{X}$ \\
\hline $\mathrm{CA}$ & San Diego & San Diego Transit Corporation & medium & $\mathrm{X}$ & $\mathrm{X}$ & & $\mathrm{X}$ & $\mathrm{X}$ & $\mathrm{X}$ & & $\mathrm{X}$ \\
\hline CA & San Francisco & Municipal Railway (MUNI) & \begin{tabular}{|l|} 
large \\
\end{tabular} & $x$ & $x$ & & $x$ & $\mathrm{X}$ & & & \\
\hline $\mathrm{CO}$ & Denver & Regional Transit District (RTD) & large & $\mathrm{X}$ & $\mathrm{X}$ & & $\mathrm{X}$ & $\mathrm{X}$ & & & \\
\hline $\mathrm{DC}$ & Washington & WMATA (Metro) & large & $\mathrm{X}$ & $\mathrm{X}$ & $\mathrm{X}$ & $\mathrm{F}$ & & & & \\
\hline FL & Bradenton & Manatee County Area Transit (MCAT) & small & $\mathrm{X}$ & & & $\mathrm{F}$ & $\mathrm{F}$ & & & \\
\hline $\mathrm{FL}$ & Clearwater & Pinellas Suncoast Transit Authority (PSTA) & medium & $x$ & & $\mathrm{X}$ & $\mathrm{F}$ & & & & \\
\hline FL & Daytona & Votran & small & $\mathrm{X}$ & $\mathrm{X}$ & & & $\mathrm{X}$ & & & \\
\hline $\mathrm{FL}$ & Fort Lauderdale & Broward County Transit (BCT) & medium & $x$ & $\mathrm{X}$ & $\mathrm{X}$ & $\mathrm{X}$ & $\mathrm{X}$ & $\mathrm{X}$ & & $\mathrm{X}$ \\
\hline FL & Fort Myers & Lee County Transit (LeeTran) & small & $\mathrm{X}$ & & & & & & & \\
\hline FL & Gainesville & Regional Transit System (RTS) & small & $\mathrm{X}$ & $\mathrm{F}$ & $\mathrm{X}$ & $\mathrm{F}$ & $\mathrm{F}$ & & & \\
\hline FL & Jacksonville & Jacksonville Transportation Authority (JTA) & medium & $\mathrm{X}$ & $\mathrm{X}$ & & $\mathrm{F}$ & & & $\mathrm{F}$ & $\mathrm{F}$ \\
\hline $\mathrm{FL}$ & Miami & Miami-Dade Transit Agency (MDTA) & large & $\mathrm{X}$ & $\mathrm{X}$ & $\mathrm{X}$ & $\mathrm{X}$ & $\mathrm{x}$ & & & \\
\hline $\mathrm{FL}$ & Orlando & Central FL RTA (Lynx) & medium & $\mathrm{X}$ & $\mathrm{X}$ & $\mathrm{X}$ & $\mathrm{F}$ & $\mathrm{X}$ & $\mathrm{X}$ & & \\
\hline $\mathrm{FL}$ & Pensacola & Escambia County Area Transit (ECAT) & small & $\mathrm{X}$ & & $\mathrm{X}$ & & $\mathrm{F}$ & & & \\
\hline $\mathrm{FL}$ & Sarasota & Sarasota County Area Transit (SCAT) & small & $\mathrm{X}$ & $\mathrm{F}$ & $\mathrm{X}$ & $\mathrm{F}$ & & & & \\
\hline $\mathrm{FL}$ & West Palm Beach & Palm Tran & small & $\mathrm{X}$ & $\mathrm{X}$ & $\mathrm{X}$ & & $\mathrm{X}$ & & & \\
\hline MA & Boston & Massachusetts Bay TA (MBTA) & large & $x$ & $x$ & & & $\mathrm{x}$ & & & \\
\hline MD & Baltimore & Maryland Mass Transit Administration (MTA) & large & & & & & & & & \\
\hline $\mathrm{Ml}$ & Detroit & Detroit DOT (D-DOT) & large & $\mathrm{X}$ & $\mathrm{X}$ & $\mathrm{X}$ & $\mathrm{F}$ & $\mathrm{F}$ & & & \\
\hline $\mathrm{MO}$ & St Louis & Bi-State Development Agency (BSDA) & large & $x$ & $\mathrm{X}$ & $\mathrm{X}$ & & $\mathrm{X}$ & & & \\
\hline NM & Albuquerque & City of Albuquerque Transit (Sun Tran) & medium & $x$ & $x$ & $x$ & & $x$ & $\mathrm{~F}$ & $x$ & $\mathrm{x}$ \\
\hline $\mathrm{OH}$ & Cleveland & Greater Cleveland (RTA) & large & $x$ & $x$ & $x$ & $\mathrm{~F}$ & & & & \\
\hline PA & Pittsburgh & Port Authority of Allegheny County & large & $\mathrm{X}$ & $\mathrm{X}$ & $\mathrm{X}$ & & $\mathrm{X}$ & & $\mathrm{X}$ & $\mathrm{X}$ \\
\hline $\mathrm{TX}$ & Dallas & Dallas Area Rapid Transit (DART) & large & $\mathrm{X}$ & $\mathrm{X}$ & $\mathrm{X}$ & & $\mathrm{X}$ & & & \\
\hline TX & Fort Worth & Fort Worth Transportation Authority (The T) & medium & $\mathrm{X}$ & $\mathrm{X}$ & $\mathrm{X}$ & $\mathrm{F}$ & $\mathrm{F}$ & & & \\
\hline $\mathrm{TX}$ & San Antonio & VIA Metropolitan Transit & medium & $\mathrm{X}$ & $\mathrm{X}$ & $\mathrm{X}$ & $\mathrm{X}$ & $\mathrm{X}$ & $\mathrm{X}$ & & $\mathrm{X}$ \\
\hline WA & Everett & Community Transit & medium & $\mathrm{X}$ & $\mathrm{F}$ & $\mathrm{X}$ & $\mathrm{F}$ & $\mathrm{X}$ & $\mathrm{X}$ & $\mathrm{X}$ & $\mathrm{X}$ \\
\hline WA & Seattle & King County (Metro) & large & $x$ & $\mathrm{X}$ & & $x$ & $\mathrm{~F}$ & & & \\
\hline \multicolumn{4}{|c|}{ TOTALS - Method Currently Employed (X) } & 30 & 21 & 19 & 7 & 17 & 7 & 4 & 8 \\
\hline \multicolumn{4}{|c|}{ TOTALS - Method Budged for Future (F) } & 0 & 4 & 1 & 13 & 7 & 1 & 1 & 1 \\
\hline
\end{tabular}


Summary of Surveyed Transit Agencies' Security Methods (2 of 3)

\begin{tabular}{|c|c|c|c|c|c|c|c|c|c|c|}
\hline State & Primary City & Transit Agency & Size & $\begin{array}{l}\text { Plainclothed } \\
\text { Security }\end{array}$ & $\begin{array}{c}\text { Contract } \\
\text { Police }\end{array}$ & $\begin{array}{c}\text { Inhouse } \\
\text { Police }\end{array}$ & $\begin{array}{c}\text { Uniformed } \\
\text { Police }\end{array}$ & $\begin{array}{l}\text { Plainclothed } \\
\text { Police }\end{array}$ & $\begin{array}{c}\text { Self } \\
\text { Defense } \\
\text { Training }\end{array}$ & $\begin{array}{l}\text { Violence } \\
\text { Prevention } \\
\text { Training }\end{array}$ \\
\hline AZ & Phoenix & Phoenix Transit System & medium & $\mathrm{X}$ & $x$ & & $\mathrm{X}$ & $\mathrm{X}$ & & $\mathrm{X}$ \\
\hline $\mathrm{CA}$ & Oakland & AC Transit & large & & $\mathrm{X}$ & & $\mathrm{X}$ & $\mathrm{X}$ & & $\mathrm{X}$ \\
\hline $\mathrm{CA}$ & Sacramento & Sacramento Regional Transit District (RT) & medium & & $\mathrm{X}$ & & $\mathrm{X}$ & & $\mathrm{F}$ & $\mathrm{X}$ \\
\hline $\mathrm{CA}$ & San Diego & San Diego Transit Corporation & medium & $\mathrm{X}$ & & & & & $\mathrm{X}$ & $\mathrm{x}$ \\
\hline $\mathrm{CA}$ & San Francisco & Municipal Railway (MUNI) & large & & $\mathrm{X}$ & & $x$ & $\mathrm{X}$ & $\mathrm{X}$ & $\mathrm{x}$ \\
\hline $\mathrm{CO}$ & Denver & Regional Transit District (RTD) & large & & $\mathrm{X}$ & & $\mathrm{X}$ & $\mathrm{X}$ & & $\mathrm{X}$ \\
\hline $\mathrm{DC}$ & Washington & WMATA (Metro) & large & & & $\mathrm{X}$ & & $\mathrm{X}$ & & \\
\hline FL & Bradenton & Manatee County Area Transit (MCAT) & small & & & & & & & $\mathrm{F}$ \\
\hline $\mathrm{FL}$ & Clearwater & Pinellas Suncoast Transit Authority (PSTA) & medium & & & & & & & $\mathrm{F}$ \\
\hline $\mathrm{FL}$ & Daytona & Votran & small & & & & & & & \\
\hline $\mathrm{FL}$ & Fort Lauderdale & Broward County Transit (BCT) & medium & $\mathrm{X}$ & $\mathrm{X}$ & & $\mathrm{x}$ & $\mathrm{X}$ & & \\
\hline $\mathrm{FL}$ & Fort Myers & Lee County Transit (LeeTran) & small & & & & & & & $\mathrm{X}$ \\
\hline $\mathrm{FL}$ & Gainesville & Regional Transit System (RTS) & small & & & & & & & $\mathrm{X}$ \\
\hline FL & Jacksonville & Jacksonville Transportation Authority (JTA) & medium & & $\mathrm{F}$ & & $\mathrm{F}$ & & & $\mathrm{X}$ \\
\hline $\mathrm{FL}$ & Miami & Miami-Dade Transit Agency (MDTA) & large & & & & & & & $\mathrm{X}$ \\
\hline $\mathrm{FL}$ & Orlando & Central FL RTA (Lynx) & medium & & $\mathrm{X}$ & & $\mathrm{X}$ & $\mathrm{X}$ & & $\mathrm{X}$ \\
\hline $\mathrm{FL}$ & Pensacola & Escambia County Area Transit (ECAT) & small & & & & & & & $\mathrm{X}$ \\
\hline $\mathrm{FL}$ & Sarasota & Sarasota County Area Transit (SCAT) & small & & & & & & & $\mathrm{X}$ \\
\hline $\mathrm{FL}$ & West Palm Beach & Palm Tran & small & & & & & & & \\
\hline MA & Boston & Massachusetts Bay TA (MBTA) & large & & & $\mathrm{X}$ & $\mathrm{X}$ & $\mathrm{X}$ & $\mathrm{x}$ & \\
\hline MD & Baltimore & Maryland Mass Transit Administration (MTA) & large & & & & & & & \\
\hline $\mathrm{Ml}$ & Detroit & Detroit DOT (D-DOT) & large & & $\mathrm{X}$ & & & $\mathrm{X}$ & & $\mathrm{X}$ \\
\hline MO & St Louis & Bi-State Development Agency (BSDA) & large & & $\mathrm{X}$ & & $\mathrm{X}$ & $\mathrm{X}$ & & $\mathrm{x}$ \\
\hline NM & Albuquerque & City of Albuquerque Transit (Sun Tran) & medium & $\mathrm{F}$ & & & & & $\mathrm{X}$ & $x$ \\
\hline $\mathrm{OH}$ & Cleveland & Greater Cleveland (RTA) & large & & $X$ & & $\mathrm{X}$ & $\mathrm{X}$ & $\mathrm{F}$ & $\mathrm{F}$ \\
\hline $\mathrm{PA}$ & Pittsburgh & Port Authority of Allegheny County & large & & & $x$ & $\mathrm{X}$ & $x$ & & $\mathrm{X}$ \\
\hline TX & Dallas & Dallas Area Rapid Transit (DART) & large & & & $\mathrm{X}$ & $\mathrm{X}$ & $\mathrm{X}$ & & \\
\hline TX & Fort Worth & Fort Worth Transportation Authority (The T) & medium & & & $\mathrm{X}$ & & & & $\mathrm{X}$ \\
\hline $\mathrm{TX}$ & San Antonio & VIA Metropolitan Transit & medium & & & $\mathrm{X}$ & & $\mathrm{X}$ & & $\mathrm{X}$ \\
\hline WA & Everett & Community Transit & medium & $\mathrm{X}$ & $\mathrm{x}$ & & & & & $\mathrm{X}$ \\
\hline WA & Seattle & King County (Metro) & large & & $\mathrm{X}$ & $\mathrm{x}$ & $\mathrm{X}$ & $\mathrm{X}$ & $\mathrm{F}$ & $\mathrm{F}$ \\
\hline \multicolumn{4}{|c|}{ TOTALS - Method Currently Employed (X) } & 4 & 12 & 7 & 13 & 15 & 4 & 20 \\
\hline \multicolumn{4}{|c|}{ TOTALS - Method Budged for Future (F) } & 1 & 1 & 0 & 1 & 0 & 3 & 4 \\
\hline
\end{tabular}


Summary of Surveyed Transit Agencies' Security Methods (3 of 3)

\begin{tabular}{|c|c|c|c|c|c|c|c|c|c|c|}
\hline State & Primary City & Transit Agency & Size & $\begin{array}{c}\text { Structural } \\
\text { Retrofit }\end{array}$ & $\begin{array}{c}\text { New Bus } \\
\text { Structure } \\
\text { Specification }\end{array}$ & $\begin{array}{l}\text { Police } \\
\text { Ride } \\
\text { Free }\end{array}$ & Laws & $\underset{\text { Wrap }}{\text { Ad }}$ & $\begin{array}{l}\text { CPTED } \\
\text { Onboard } \\
\text { Buses }\end{array}$ & $\begin{array}{l}\text { Labor } \\
\text { Concern }\end{array}$ \\
\hline$A Z$ & Phoenix & Phoenix Transit System & medium & & & yes & no & yes & no & yes \\
\hline $\mathrm{CA}$ & Oakland & AC Transit & large & & & yes & yes & yes & yes & no \\
\hline $\mathrm{CA}$ & Sacramento & Sacramento Regional Transit District (RT) & medium & & & yes & yes & yes & no & yes \\
\hline $\mathrm{CA}$ & San Diego & San Diego Transit Corporation & medium & & & yes & no & yes & yes & yes \\
\hline $\mathrm{CA}$ & San Francisco & Municipal Railway (MUNI) & large & $\mathrm{X}$ & $\mathrm{X}$ & yes & no & yes & no & yes \\
\hline $\mathrm{CO}$ & Denver & Regional Transit District (RTD) & large & & & yes & yes & no & no & yes \\
\hline $\mathrm{DC}$ & Washington & WMATA (Metro) & large & $\mathrm{X}$ & & yes & no & no & no & no \\
\hline $\mathrm{FL}$ & Bradenton & Manatee County Area Transit (MCAT) & small & & & no & no & yes & no & no \\
\hline FL & Clearwater & Pinellas Suncoast Transit Authority (PSTA) & medium & & & no & no & yes & no & no \\
\hline FL & Daytona & Votran & small & & & yes & no & yes & no & no \\
\hline $\mathrm{FL}$ & Fort Lauderdale & Broward County Transit (BCT) & medium & & & yes & yes & yes & no & yes \\
\hline FL & Fort Myers & Lee County Transit (LeeTran) & small & & & no & no & yes & no & no \\
\hline $\mathrm{FL}$ & Gainesville & Regional Transit System (RTS) & small & & & yes & no & yes & no & no \\
\hline FL & Jacksonville & Jacksonville Transportation Authority (JTA) & medium & & & yes & yes & yes & no & no \\
\hline $\mathrm{FL}$ & Miami & Miami-Dade Transit Agency (MDTA) & large & $\mathrm{x}$ & $\mathrm{X}$ & yes & yes & yes & yes & yes \\
\hline $\mathrm{FL}$ & Orlando & Central FL RTA (Lynx) & medium & & $\mathrm{X}$ & yes & yes & yes & no & no \\
\hline $\mathrm{FL}$ & Pensacola & Escambia County Area Transit (ECAT) & small & & & no & no & yes & no & no \\
\hline $\mathrm{FL}$ & Sarasota & Sarasota County Area Transit (SCAT) & small & & & no & no & yes & no & no \\
\hline $\mathrm{FL}$ & West Palm Beach & Palm Tran & small & & & yes & yes & yes & no & no \\
\hline MA & Boston & Massachusetts Bay TA (MBTA) & large & & & yes & yes & yes & no & no \\
\hline MD & Baltimore & Maryland Mass Transit Administration (MTA) & large & & & yes & no & yes & no & yes \\
\hline $\mathrm{Ml}$ & Detroit & Detroit DOT (D-DOT) & large & & & yes & yes & no & no & yes \\
\hline $\mathrm{MO}$ & St Louis & Bi-State Development Agency (BSDA) & large & & & yes & no & yes & no & no \\
\hline NM & Albuquerque & City of Albuquerque Transit (Sun Tran) & medium & $\mathrm{X}$ & $\mathrm{F}$ & no & no & no & yes & no \\
\hline $\mathrm{OH}$ & Cleveland & Greater Cleveland (RTA) & large & & & yes & yes & yes & no & yes \\
\hline PA & Pittsburgh & Port Authority of Allegheny County & large & & & yes & yes & yes & no & no \\
\hline TX & Dallas & Dallas Area Rapid Transit (DART) & large & & & yes & no & yes & no & yes \\
\hline TX & Fort Worth & Fort Worth Transportation Authority (The T) & medium & & & yes & no & yes & no & no \\
\hline TX & San Antonio & VIA Metropolitan Transit & medium & & & yes & yes & yes & yes & no \\
\hline WA & Everett & Community Transit & medium & $\mathrm{F}$ & & yes & yes & yes & yes & yes \\
\hline WA & Seattle & King County (Metro) & large & & & yes & no & yes & yes & yes \\
\hline \multicolumn{4}{|c|}{ TOTALS - Method Currently Employed (X) } & 4 & 3 & 25 & 14 & 27 & 7 & 13 \\
\hline \multicolumn{4}{|c|}{ TOTALS - Method Budged for Future (F) } & 1 & 1 & & & & & \\
\hline
\end{tabular}


APPENDIX C: NTD FORM 405

Transit Safety and Security Form (405)

NTD ID ID $\square \square \square$ Page 2 of 2

Required from transit agencies serving UZAs of 200,000 or more population

Mode $\square \square$ Form 005 Included Based on the Uniform Crime Reporting Handbook

\begin{tabular}{|l|c|}
\hline \multicolumn{2}{|c|}{ Security Items } \\
\hline $\begin{array}{c}\text { Lime } \\
\text { No. }\end{array}$ & Part 1. Offenses \\
\hline & Violent Crime \\
& Homicide \\
01 & Patrons \\
02 & Employees
\end{tabular}

Others

Forcible rape

Patrons

Employees

Others

Robbery

Patrons

Employees

Others

Aggravated assault

Patrons

Employees

Others

Property Crime

Burglary

Larceny/theft

Patrons

Employees

Others

Motor vehicle theft

Patrons

Employees

Others

Arson

Part II. Offenses (Arrests)

Other assaults

Vandalism

Sex offenses

Drug abuse violations

Driving under the influence

Drunkenness

Disorderly conduct

Trespassing

Fare evasion

Curfew and loitering laws

Total Transit Property Damage

Date Prepared $\square \square / \square \square / \square \square \square \square$

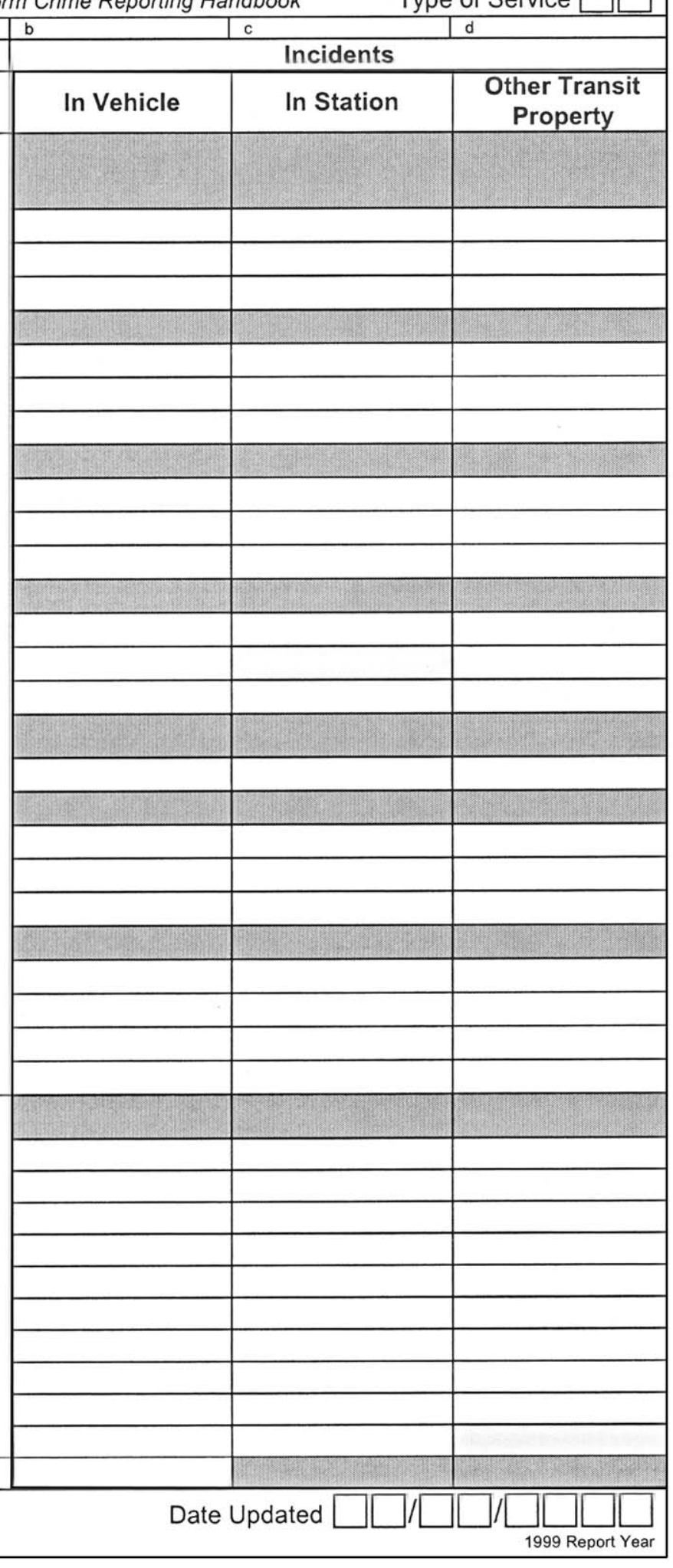




\section{APPENDIX D: STATE LAWS}

California Penal Code

http://www.leginfo.ca.gov/cgibin/displaycode?section=pen \&group $=00001$ -01000 \&file $=\mathbf{2 4 0}-\mathbf{2 4 8}$

(Selected text)

Part 1. Of Crimes and Punishments

Title 8. Of Crimes Against the Person

Chapter 9. Assault and Battery

$\S 243.3$. When a battery is committed against the person of an operator, driver, or passenger on a bus, taxicab, streetcar, cable car, trackless trolley, or other motor vehicle, including a vehicle operated on stationary rails or on a track or rail suspended in the air, used for the transportation of persons for hire, or against a schoolbus driver, or against the person of a station agent or ticket agent for the entity providing the transportation, and the person who commits the offense knows or reasonably should know that the victim, in the case of an operator, driver, or agent, is engaged in the performance of his or her duties, or is a passenger the offense shall be punished by a fine not exceeding ten thousand dollars $(\$ 10,000)$, or by imprisonment in a county jail not exceeding one year, or by both that fine and imprisonment. If an injury is inflicted on that victim, the offense shall be punished by a fine not exceeding ten thousand dollars $(\$ 10,000)$, or by imprisonment in a county jail not exceeding one year or in the state prison for 16 months, or two or three years, or by both that fine and imprisonment.

$\S 243.35$. (a) Except as provided in Section 243.3, when a battery is committed against any person on the property of, or in a motor vehicle of, a public transportation provider, the offense shall be punished by a fine not to exceed two thousand dollars $(\$ 2,000)$, or by imprisonment in a county jail not to exceed one year, or by both the fine and imprisonment.

(b) As used in this section, "public transportation provider" means a publicly or privately owned entity that operates, for the transportation of persons for hire, a bus, taxicab, streetcar, cable car, trackless trolley, or other motor vehicle, including a vehicle operated on stationary rails or on a track or rail suspended in air, or that operates a schoolbus. (c) As used in this section, "on the property of" means the entire station where public transportation is available, including the parking lot reserved for the public who utilize the transportation system.

\section{Florida 2000 Statutes}

\section{http://www.leg.state.fl.us/Welcome/index.cf} m

(Selected text)

Title XLVI. Crimes

Chapter 784. Assault; Battery; Culpable Negligence

$\S 784.07$ Assault or battery of law enforcement officers, firefighters, emergency medical care providers, public transit employees or agents, or other specified officers; reclassification of offenses; minimum sentences. -

(1) As used in this section, the term:

(d) "Public transit employees or agents" means bus operators, train operators, revenue collectors, security personnel, equipment maintenance personnel, or field supervisors, who are employees or agents of a transit agency as described in $\mathrm{s}$. 812.015(1)(1).

(2) Whenever any person is charged with knowingly committing an assault or battery upon a law enforcement officer, a firefighter, an emergency medical care provider, a traffic accident investigation officer as described in s. 316.640, a traffic infraction enforcement officer as described in s. 316.640 , a parking enforcement specialist as defined in s. 316.640, or a security officer employed by the board of trustees of a community college, while the officer, firefighter, emergency medical care provider, intake officer, traffic accident investigation officer, traffic infraction enforcement officer, parking enforcement specialist, public transit employee or agent, or security officer is engaged in the lawful performance of his or her duties, the offense for which the person is charged shall be reclassified as follows:

(a) In the case of assault, from a misdemeanor of the second degree to a misdemeanor of the first degree.

(b) In the case of battery, from a misdemeanor of the first degree to a felony of the third degree.

(c) In the case of aggravated assault, from a felony of the third degree to a felony of the 
second degree. Notwithstanding any other provision of law, any person convicted of aggravated assault upon a law enforcement officer shall be sentenced to a minimum term of imprisonment of 3 years.

(d) In the case of aggravated battery, from a felony of the second degree to a felony of the first degree. Notwithstanding any other provision of law, any person convicted of aggravated battery of a law enforcement officer shall be sentenced to a minimum term of imprisonment of 5 years.

(3) Any person who is convicted of a battery under paragraph (2)(b) and, during the commission of the offense, such person possessed:

(a) A "firearm" or "destructive device" as those terms are defined in s. 790.001, shall be sentenced to a minimum term of imprisonment of 3 years.

(b) A semiautomatic firearm and its highcapacity detachable box magazine, as

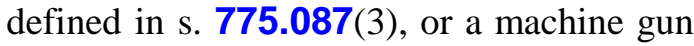
as defined in s. $\mathbf{7 9 0 . 0 0 1}$, shall be sentenced to a minimum term of imprisonment of 8 years.

Notwithstanding s. 948.01, adjudication of guilt or imposition of sentence shall not be suspended, deferred, or withheld, and the defendant is not eligible for statutory gain-time under s. $\mathbf{9 4 4 . 2 7 5}$ or any form of discretionary early release, other than pardon or executive clemency, or conditional medical release under s. $\mathbf{9 4 7 . 1 4 9}$, prior to serving the minimum sentence.

\section{Massachusetts General Laws Annotated}

Copyright (C) West Group 1997 No claim to original U.S. Govt. works

(Selected text)

\section{MGLA 159A § 31}

Part 1. Administration of the Government

Title XXII. Corporations

Chapter 159A. Common Carriers of Passengers by Motor Vehicle

Current through $19962^{\text {nd }}$ Annual Session

$\S 31$. Wrongful interference with operation of school bus or vehicle carrying passengers for hire; penalties
Whoever willfully, with intent to endanger the safety of any person on board or any person who he believes will board the same, or with a reckless disregard for the safety of human life, damages, disables, destroys, tampers with, or places or causes to be placed any explosive or other destructive substance in, upon, or in proximity to, any motor vehicle which is being used for the carriage of passengers for hire or for the transporting of school children; or whoever, with intent to endanger the safety of any person on board or any person who he believes will board the same, or with a reckless disregard for the safety of human life, willfully disables or incapacitates any driver or person employed in connection with the operation of such motor vehicle, shall be punished by a fine of not more than ten thousand dollars or by imprisonment for not more than twenty years, or by both such fine and imprisonment.

\section{Massachusetts General Laws}

http://www.state.ma.us/legis/laws/mgl/26513D.htm

(Selected text)

Part IV. Crimes, Punishments and Proceedings in Criminal Cases

Title I. Crimes and Punishments

Chapter 265. Crimes Against the Person

$\S 13 \mathrm{D}$. Assault and battery upon certain public servants

Whoever commits an assault and battery upon any public employee when such person is engaged in the performance of his duties at the time of such assault and battery, shall be punished by imprisonment for not less than ninety days nor more than two and onehalf years in a house of correction or by a fine of not less than five hundred nor more than five thousand dollars.

\section{Nevada Revised Statutes}

SB 264

(Became law 10/01/97)

ASSAULT AND BATTERY

NRS 200.471 Assault penalties.

1. As used in this section: Definitions; 
(a) "Assault" means an unlawful attempt, coupled with a present ability, to commit a violent injury on the person of another.

(b) "Officer" means:

(1) A person who possesses some or all of the powers of a peace officer;

(2) A person employed in a full-time salaried occupation of fire fighting for the benefit or safety of the public;

(3) A member of a volunteer fire department;

(4) A jailer, guard, matron or other correctional officer of a city or county jail; or

(5) A justice of the supreme court, district judge, justice of the peace, municipal judge, magistrate, court commissioner, master or referee, including a person acting pro tempore in a capacity listed in this subparagraph.

(c) "School employee" means a licensed or unlicensed person employed by a board of trustees of a school district pursuant to NRS 391.100.

(d) "Taxicab" has the meaning ascribed to it in NRS 706.8816.

(e) "Taxicab driver" means a person who operates a taxicab.

(f) "Transit operator" means a person who operates a bus or other vehicle as part of a public mass transportation system.

2. A person convicted of an assault shall be punished:

(a) If paragraph (c) of this subsection does not apply to the circumstances of the crime and the assault is not made with use of a deadly weapon, or the present ability to use a deadly weapon, for a misdemeanor.

(b) If the assault is made with use of a deadly weapon, or the present ability to use a deadly weapon, for a category B felony by imprisonment in the state prison for a minimum term of not less than 1 year and a maximum term of not more than 6 years, or by a fine of not more than $\$ 5,000$, or by both fine and imprisonment.

(c) If the assault is committed upon an officer, a school employee, a taxicab driver or a transit operator who is performing his duty and the person charged knew or should have known that the victim was an officer, school employee, taxicab driver or transit operator, for a gross misdemeanor, unless the assault is made with use of a deadly weapon, or the present ability to use a deadly weapon, then for a category B felony by imprisonment in the state prison for a minimum term of not less than 1 year and a maximum term of not more than 6 years, or by a fine of not more than $\$ 5,000$, or by both fine and imprisonment.

(Added to NRS by 1971, 1384; A 1981, 903; 1985,$248 ; 1989,1010 ; 1991,124,774 ; 1995,21$, $1190,1321 ; 1997,434 ; 1999,140)$

NRS 200.481 Battery: Definitions; penalties.

1. As used in this section:

(a) "Battery" means any willful and unlawful use of force or violence upon the person of another.

(b) "Child" means a person less than 18 years of age.

(c) "Officer" means:

(1) A person who possesses some or all of the powers of a peace officer;

(2) A person employed in a full-time salaried occupation of fire fighting for the benefit or safety of the public;

(3) A member of a volunteer fire department;

(4) A jailer, guard, matron or other correctional officer of a city or county jail or detention facility; or

(5) A justice of the supreme court, district judge, justice of the peace, municipal judge, magistrate, court commissioner, master or referee, including, without limitation, a person acting pro tempore in a capacity listed in this subparagraph.

(d) "School employee" means a licensed or unlicensed person employed by a board of trustees of a school district pursuant to NRS 391.100.

(e) "Taxicab" has the meaning ascribed to it in NRS 706.8816.

(f) "Taxicab driver" means a person who operates a taxicab.

(g) "Transit operator" means a person who operates a bus or other vehicle as part of a public mass transportation system.

2. Except as otherwise provided in NRS 200.485, a person convicted of a battery, other than a battery committed by an adult upon a child which constitutes child abuse, shall be punished:

(a) If the battery is not committed with a deadly weapon, and no substantial bodily harm to the victim results, except under circumstances where a greater penalty is provided in paragraph (d) or in NRS 197.090, for a misdemeanor.

(b) If the battery is not committed with a deadly weapon, and substantial bodily harm to the victim results, for a category $\mathrm{C}$ felony as provided in NRS 193.130. 
(c) If the battery is committed upon an officer, school employee, taxicab driver or transit operator and:

(1) The officer, school employee, taxicab driver or transit operator was performing his duty;

(2) The officer, school employee, taxicab driver or transit operator suffers substantial bodily harm; and

(3) The person charged knew or should have known that the victim was an officer, school employee, taxicab driver or transit operator,

for a category B felony by imprisonment in the state prison for a minimum term of not less than 2 years and a maximum term of not more than 10 years, or by a fine of not more than $\$ 10,000$, or by both fine and imprisonment.

(d) If the battery is committed upon an officer, school employee, taxicab driver or transit operator who is performing his duty and the person charged knew or should have known that the victim was an officer, school employee, taxicab driver or transit operator, for a gross misdemeanor, except under circumstances where a greater penalty is provided in this section.

(e) If the battery is committed with the use of a deadly weapon, and:

(1) No substantial bodily harm to the victim results, for a category B felony by imprisonment in the state prison for a minimum term of not less than 2 years and a maximum term of not more than 10 years, and may be further punished by a fine of not more than $\$ 10,000$.

(2) Substantial bodily harm to the victim results, for a category B felony by imprisonment in the state prison for a minimum term of not less than 2 years and a maximum term of not more than 15 years, and may be further punished by a fine of not more than $\$ 10,000$.

(f) If the battery is committed by a prisoner who is in lawful custody or confinement, without the use of a deadly weapon, whether or not substantial bodily harm results, for a category B felony by imprisonment in the state prison for a minimum term of not less than 1 year and a maximum term of not more than 6 years.

(g) If the battery is committed by a prisoner who is in lawful custody or confinement with the use of a deadly weapon, and:

(1) No substantial bodily harm to the victim results, for a category B felony by imprisonment in the state prison for a minimum term of not less than
2 years and a maximum term of not more than 10 years.

(2) Substantial bodily harm to the victim results, for a category B felony by imprisonment in the state prison for a minimum term of not less than 2 years and a maximum term of not more than 15 years.

(Added to NRS by 1971, 1385; A 1973, 1444; 1975,$1063 ; 1977,736 ; 1979,213,1427 ; 1981,12$, $614 ; 1983,673 ; 1985,248,2171 ; 1987,515 ; 1989$, 1178 ; 1991, 154, 774; 1995, 22, 903, 1191, 1321, $1335 ; 1997,435,1180,1813 ; 1999,141)$

\section{Pennsylvania Consolidated Statutes}

http://members.aol.com/StatutesP8/18PA270 2.html

(Selected text)

Title 18. Crimes and Offenses

Chapter 27. Assault

$\S 2702$. Aggravated assault

(a) Offense defined.--A person is guilty of aggravated assault if he:

1. attempts to cause serious bodily injury to another, or causes such injury intentionally, knowingly or recklessly under circumstances manifesting extreme indifference to the value of human life;

2. attempts to cause or intentionally, knowingly or recklessly causes serious bodily injury to any of the officers, agents, employees or other persons enumerated in subsection (c) or to an employee of an agency, company or other entity engaged in public transportation, while in the performance of duty;

3. attempts to cause or intentionally or knowingly causes bodily injury to a any of the officers, agents, employees or other persons enumerated in subsection (c), in the performance of duty;

4. attempts to cause or intentionally or knowingly causes bodily injury to another with a deadly weapon; or

5. attempts to cause or intentionally or knowingly causes bodily injury to a teaching staff member, school board member, or other employee, including a student employee, of any elementary or secondary publicly-funded educational 
institution, any elementary or secondary private school licensed by the Department of Education or any elementary or secondary parochial school while acting in the scope of his or her employment or because of his or her employment relationship to the school.

6. attempts by physical menace to put any of the officers, agents, employees or other persons enumerated in subsection (c), while in the performance of duty, in fear of imminent serious bodily injury.

(b) Grading.--Aggravated assault under subsection (a)(1) and (2) is a felony of the first degree. Aggravated assault under subsection (a)(3), (4), (5) and (6) is a felony of the second degree.

\section{Texas 2000 Penal Code}

\section{http://www.cowtown.net/Cop_Shop/chapter_ 22.html - Assault \\ (Selected text)}

Title V. Offenses Against the Person

Chapter 22. Assaultive Offenses

$\S 22.01$. Assault

(a) A person commits an offense if the person:

(1) intentionally, knowingly, or recklessly causes bodily injury to another, including the person's spouse;

(2) intentionally or knowingly threatens another with imminent bodily injury, including the person's spouse; or

(3) intentionally or knowingly causes physical contact with another when the person knows or should reasonably believe that the other will regard the contact as offensive or provocative.

(b) An offense under Subsection (a)(1) is a Class A misdemeanor, except that the offense is a felony of the third degree if the offense is committed against:

(1) a person the actor knows is a public servant while the public servant is lawfully discharging an official duty, or in retaliation or on account of an exercise of official power or performance of an official duty as a public servant;

(d) For purposes of Subsection (b), the actor is presumed to have known the person assaulted was a public servant if the person was wearing a distinctive uniform or badge indicating the person's employment as a public servant.

\section{Revised Code of Washington}

\section{http://wsl.leg.wa.gov/wsladm/rcw.htm \\ (Selected text)}

\section{RCW 9A.36.031}

Assault in the third degree.

(1) A person is guilty of assault in the third degree if he or she, under circumstances not amounting to assault in the first or second degree:

(b) Assaults a person employed as a transit operator or driver, the immediate supervisor of a transit operator or driver, a mechanic, or a security officer, by a public or private transit company or a contracted transit service provider, while that person is performing his or her official duties at the time of the assault; or ...

(2) Assault in the third degree is a class C felony.

RCW 9.91.025

Unlawful bus conduct.

(1) A person is guilty of unlawful bus conduct if while on or in a municipal transit vehicle as defined by RCW 46.04.355 or in or at a municipal transit station and with knowledge that such conduct is prohibited, he or she:

(a) Except while in or at a municipal transit station, smokes or carries a lighted or smoldering pipe, cigar, or cigarette;

(b) Discards litter other than in designated receptacles;

(c) Plays any radio, recorder, or other soundproducing equipment except that nothing herein shall prohibit the use of such equipment when connected to earphones that limit the sound to individual listeners or the use of a communication device by an employee of the owner or operator of the municipal transit vehicle or municipal transit station;

(d) Spits or expectorates;

(e) Carries any flammable liquid, explosive, acid, or other article or material likely to cause harm to others except that nothing herein shall prevent a person from carrying a cigarette, cigar, or pipe lighter or carrying a firearm or ammunition in a way that is not otherwise prohibited by law;

(f) Intentionally obstructs or impedes the flow of municipal transit vehicles or passenger traffic, 
hinders or prevents access to municipal transit vehicles or stations, or otherwise unlawfully interferes with the provision or use of public transportation services;

(g) Intentionally disturbs others by engaging in loud, raucous, unruly, harmful, or harassing behavior; or

(h) Destroys, defaces, or otherwise damages property of a municipality as defined in $\mathbf{R C W}$ 35.58.272 employed in the provision or use of public transportation services.

(2) For the purposes of this section, "municipal transit station" means all facilities, structures, lands, interest in lands, air rights over lands, and rights of way of all kinds that are owned, leased, held, or used by a municipality as defined in RCW 35.58.272 for the purpose of providing public transportation services, including, but not limited to, park and ride lots, transit centers and tunnels, and bus shelters.

(3) Unlawful bus conduct is a misdemeanor.

RCW 66.44.250

Drinking in public conveyance -- Penalty against individual -- Restricted application.

Every person who drinks any intoxicating liquor in any public conveyance, except in a compartment or place where sold or served under the authority of a license lawfully issued, is guilty of a misdemeanor. With respect to a public conveyance that is commercially chartered for group use and with respect to a for-hire vehicle licensed under city, county, or state law, this section applies only to the driver of the vehicle. 